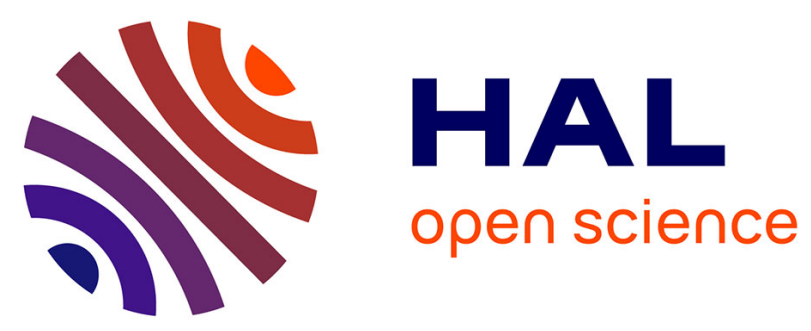

\title{
Les amphores du dépotoir flavien du Bas-de-Loyasse à Lyon
}

Bernard Dangréaux, Armand Desbat

\section{To cite this version:}

Bernard Dangréaux, Armand Desbat. Les amphores du dépotoir flavien du Bas-de-Loyasse à Lyon. Gallia - Fouilles et monuments archéologiques en France métropolitaine, 1988, 45, pp.115-153. 10.3406/galia.1987.2883 . hal-01939596

\section{HAL Id: hal-01939596 https://hal.science/hal-01939596}

Submitted on 14 Jan 2020

HAL is a multi-disciplinary open access archive for the deposit and dissemination of scientific research documents, whether they are published or not. The documents may come from teaching and research institutions in France or abroad, or from public or private research centers.
L'archive ouverte pluridisciplinaire HAL, est destinée au dépôt et à la diffusion de documents scientifiques de niveau recherche, publiés ou non, émanant des établissements d'enseignement et de recherche français ou étrangers, des laboratoires publics ou privés.

\section{(ㅇ)(1) $\$$}

Distributed under a Creative Commons Attribution - NonCommercial - NoDerivatives| 4.0 


\title{
LES AMPHORES DU DÉPOTOIR FLAVIEN DU BAS-DE-LOYASSE À LYON
}

\author{
par Bernard DANGREAUX et Armand DESBAT
}

Notre étude porte sur un matériel provenant d'un important dépotoir ménager découvert en 1970 sur le flanc s. du plateau de La Sarra, en bordure de la Montée du Bas-de-Loyasse, à proximité de la rue Pierre-Audry (fig. 1). Ce dépotoir constituait le prolongement des dépotoirs repérés ou fouillés plus à l'e., notamment lors des fouilles de Trion à la fin du siècle dernier (cf. Allmer, Dissard, 1887) et qui recouvraient partiellement les mausolées de Trion. En 1970, les travaux d'extension du cimetière de Loyasse, entre le chemin de Loyasse et la Montée du Bas-de-Loyasse mirent au jour une partie de ce dépotoir. Durant l'été 1970 fut donc réalisée, sous la direction de J. Lasfargues, une fouille de sauvetage ${ }^{1}$ qui permit de dégager une petite partie de ce dépotoir ( $25 \mathrm{~m}^{2}$ environ) et de récolter un très abondant matériel.

Située en bas de pente, la partie fouillée du dépotoir a livré une grande quantité de céramiques communes et d'amphores associées à des ossements d'animaux et des débris de construction. En revanche, les céramiques fines, en particulier les lampes et parois fines sont rares. Il est possible qu'un classement par gravité ait entraîné les éléments pondéreux au bas du dépotoir.

\section{CHRONOLOGIE}

Les céramiques fines ainsi que quelques monnaies recueillies dans ce dépotoir permettent de situer son installation vers 70 ap. J.-C.

1 Ont participé à cette fouille: $\mathbf{M}^{\mathrm{me}}$ Lasfargues, MM. A. Desbat, C. Lutrin, B. Mandy, F. Meyronein, J.-P. Pelatan, J. Raymond ainsi que des élèves du Groupe Pierre Termier.
Les monnaies au nombre de cinq se répartissent ainsi : trois as d'Auguste à la légende DIVVS AVGVSTVS PATER (14-15 ap. J.-C.); un as à l'autel de Lyon? très usé et enfin un as de Néron (5468) à fleur de coin.

La céramique fine est représentée par quelques tessons de parois fines sablées de Lyon, quelques fragments de lampe à huile ainsi que deux "firmalampen" signées ATIMETI et FORTIS.

Parmi la centaine de formes et céramique sigillée, les types suivants sont reconnaissables; Drag. 29 (en majorité), Drag. 30 et Drag. 37 précoces pour la sigillée décorée et Drag. 16, Drag. 15/17, Drag. 18, Ritt. 8, Ritt. 9, Ritt. 12, Drag. 24/25, Drag. 27, Drag. 35 et Drag. 36 pour la sigillée lisse.

L'atelier de la Gaufesenque semble majoritaire. Le reste appartient aux productions de Lezoux à vernis non grésé. La présence dans ce même dépotoir de Drag. 24/25 (dont on situe la fin de la production vers 60-65 ap. J.-C.) et de Drag. 35, 36, permet de placer ce dépotoir postérieurement aux années $60-65$ date d'apparition des formes Drag. 35, 36 et 37.

\section{LE MATERIEL AMPHORIQUE}

Le comptage du matériel amphorique a permis de dénombrer 437 individus, nombre minimum évalué après remontage de plus de 3000 fragments. Pour l'essentiel, ces amphores contenaient du vin, de l'huile ou de la saumure (ou conserve de poisson). Elles sont donc réparties à l'intérieur des trois grands groupes habituellement rencontrés.

Le tableau I ci-dessous, présente le détail des données quantitatives nous ayant amenés à proposer un nombre minimal d'individus pour chaque type d'amphore. Pour la plupart, le chiffre proposé résulte 


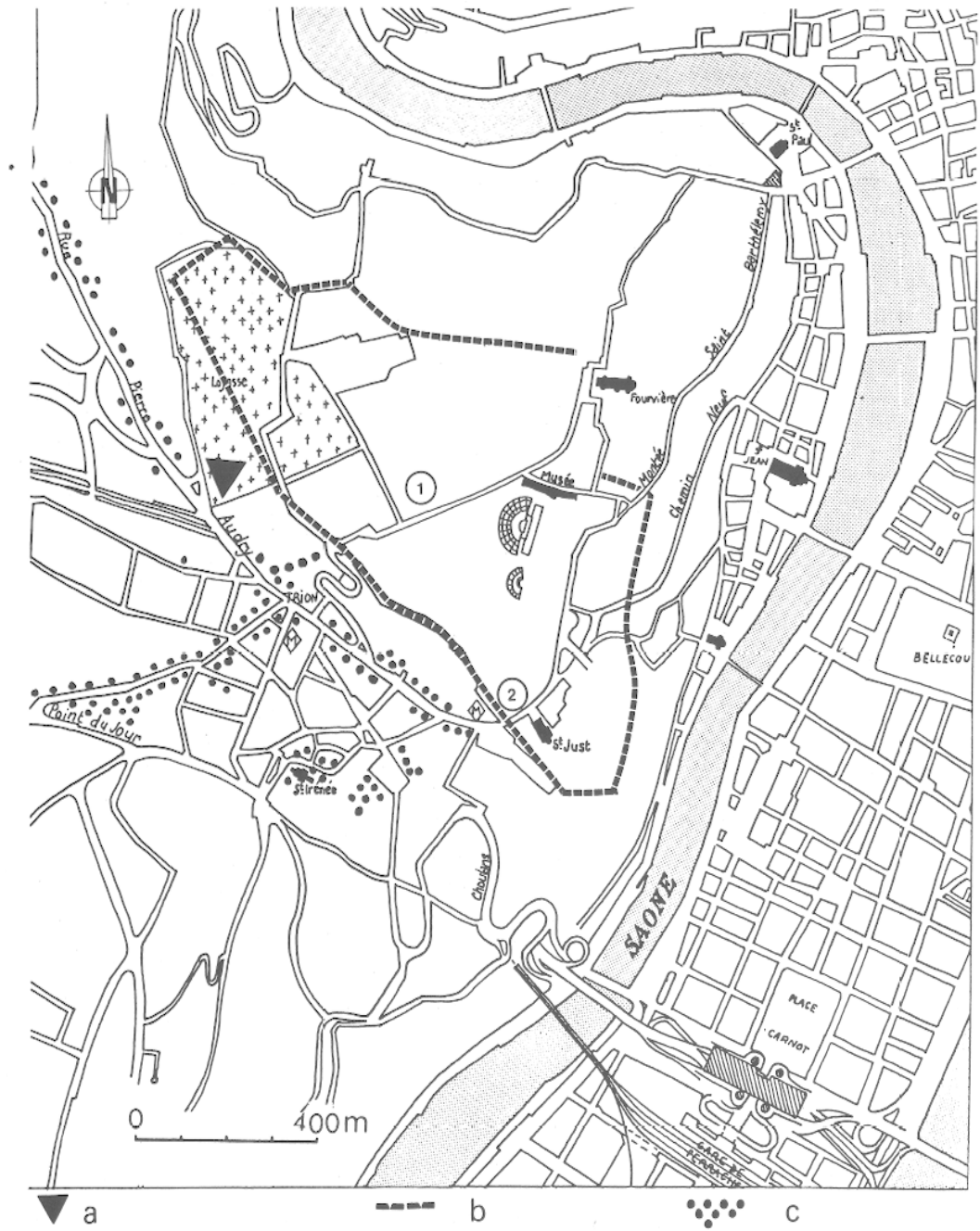

Fig. 1 - Situation de la fouille du Bas-deLoyasse.

1. Verbe Incarné

2. Rue des Farges

a, Bas-de-Loyasse

b, Tracé supposé du rempart antique

c, Nécropole du simple comptage des cols (complets ou fragmentaires) et des lèvres; c'est le cas des amphores pour lesquelles le nombre de tessons de ces éléments dépasse le nombre des autres fragments (panse, anse, fond) quand ils existent ${ }^{2}$. Dès lors que le rapport s'inverse, ce type de comptage n'est plus pertinent. Dans ce cas, c'est par comparaison des pâtes, en s'appuyant au besoin sur les résultats des analyses effectuées, que nous nous sommes efforcés de cerner le nombre d'exemplaires présents ${ }^{3}$.

Le regroupement par type de contenu a offert d'autres difficultés. En effet si, pour la grande majorité des amphores, le contenu est attesté par les

2 Il en va ainsi notamment des amphores Pascual I, Haltern 70, Haltern 70 similis, Gauloise I ...

3 C'est le cas, par exemple, des Dressel 2/4 pour lesquelles trente et un fragments d'anses venaient s'ajouter aux huit cols et fragments de lèvres. Un examen visuel laissait penser qu'à chaque fragment correspondait une amphore : cela a été confirmé par les analyses. Le nombre minimal d'individus tient donc compte de cet ensemble d'éléments. études antérieures (voir infra), il n'en est pas de même des amphores Haltern 70 (standard et simili), Dressel 28 et Dressel 9 «simili». Pour chacune d'entre elles, le problème de leur contenu est posé de manière différente : pour les Haltern 70 , il s'agit de savoir si le defrutum qu'elles contenaient est assimilable à un sirop non alcoolique plutôt qu'à du vin; pour les Dressel 28, il convient de trancher entre les différents produits compatibles avec le poissage dont leur surface interne fut enduite; quant aux amphores dites "similis", la question est de savoir si une ressemblance typologique induit un contenu similaire. Plusieurs raisons nous ont conduits à classer les amphores Haltern 70 parmi les amphores vinaires, laisser indéterminé le contenu des Dressel 28 et inscrire les deux dérivés de modèles standards dans le même groupe que ces derniers.

Enfin, le faible nombre de fonds inventoriés est explicable par leur réutilisation à d'autres fins. En effet, des traces de découpage sont observables sur plusieurs Dressel 20 et Beltran Ila. 
Tableau I

Le matériel amphorique, données quantitatives.

\begin{tabular}{|c|c|c|c|c|c|c|}
\hline & Type & $\begin{array}{l}\text { Cols } \\
\text { et/ou lèvres }\end{array}$ & $\begin{array}{l}\text { Fragments } \\
\text { d'anses }\end{array}$ & Fonds & $\begin{array}{c}\text { Nombre minimal } \\
\text { d'individu }\end{array}$ & $\begin{array}{l}\text { Nombre } \\
\text { d'analyses }\end{array}$ \\
\hline Vin & 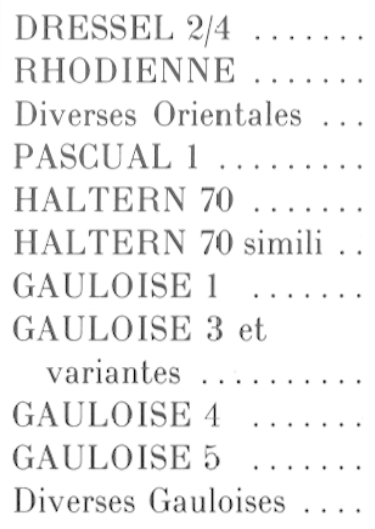 & $\begin{array}{r}8 \\
4 \\
4 \\
3 \\
7 \\
5 \\
6 \\
\\
9 \\
133 \\
36 \\
9\end{array}$ & $\begin{array}{r}31 \\
31 \\
1 \\
- \\
5 \\
4 \\
3 \\
\\
\\
149\end{array}$ & $\begin{array}{l}1 \\
2 \\
- \\
2 \\
2 \\
-1 \\
1 \\
59 \\
1\end{array}$ & $\begin{array}{r}35 \\
33 \\
5 \\
3 \\
7 \\
5 \\
6 \\
\\
9 \\
133 \\
36 \\
9\end{array}$ & $\begin{array}{r}30 \\
13 \\
3 \\
- \\
- \\
3 \\
- \\
\\
5 \\
8 \\
6 \\
1\end{array}$ \\
\hline Total .... & - & 224 & 224 & 68 & 281 & 69 \\
\hline Huile & DRESSEL $20 \ldots \ldots \ldots$ & 69 & 73 & 1 & 69 & - \\
\hline Total .... & - & 69 & 73 & 1 & 69 & - \\
\hline Saumures & $\begin{array}{l}\text { BELTRAN IIa } \ldots \ldots \\
\text { DRESSEL } 7 / 11 \ldots \ldots \\
\text { DRESSEL } 9 \text { simili } \ldots\end{array}$ & $\begin{array}{r}27 \\
9 \\
34\end{array}$ & $\begin{array}{r}25 \\
2 \\
13\end{array}$ & $\begin{array}{l}6 \\
7 \\
1\end{array}$ & $\begin{array}{r}27 \\
9 \\
34\end{array}$ & $\frac{-}{12}$ \\
\hline Total .... & - & 70 & 40 & 14 & 70 & 12 \\
\hline Indéterminées & $\begin{array}{l}\text { DRESSEL } 28 \ldots \ldots \ldots \\
\text { Divers } \ldots \ldots \ldots \ldots \ldots\end{array}$ & $\begin{array}{l}6 \\
5\end{array}$ & $\begin{array}{r}9 \\
13\end{array}$ & $\overline{11}$ & $\begin{array}{r}6 \\
11\end{array}$ & $\begin{array}{l}- \\
-\end{array}$ \\
\hline Total .... & - & 11 & 22 & 11 & 17 & - \\
\hline \multicolumn{2}{|c|}{ Total GÉNÉral } & 374 & 359 & 94 & 437 & 81 \\
\hline
\end{tabular}

\section{LES AMPHORES VINAIRES}

\section{Les amphores Dressel 2/4 (fig. 2)}

Avec trente-cinq exemplaires, les amphores Dressel $2 / 4$ représentent $12,5 \%$ des amphores à vin et $8 \%$ du total (voir tableau I). Les fragments les plus fréquents sont des anses ainsi que des cols ou lèvres (fig. $2, \mathrm{n}^{\text {os }} 1$ à 7 ). Un col et une panse non jointifs ont été attribués à ce type, bien que les proportions de la panse soient assez inhabituelles (fig. 2, $\mathrm{n}^{0} 7$ ).

Les cols et les lèvres montrent des différences très nettes dans les profils comme dans les pâtes: cela n'est pas surprenant compte tenu de la multipli- cité des ateliers ayant produit ce type d'amphore, sans aucun doute le plus répandu du monde romain 4 .

Un seul col (fig. $2, \mathrm{n}^{\circ}$ l) comporte une estampille, $A T T I$, pour laquelle nous n'avons trouvé aucun parallèle.

Les anses du type Dressel 2/4 sont formées le plus souvent de deux boudins accolés. Cette caractéristique existe sur les exemplaires orientaux et

4 Ce type qui dérive des amphores de Cos a été produit, en Méditerranée orientale, dans de nombreux ateliers en dehors de Cos même, de l'Égée à l'Égypte, et en Occident, en Italie, en Espagne, en Gaule et même cn Grande-Bretagne (Castle, 1978). Seule l'Afrique du Nord semble ne pas avoir produit ce conteneur. 


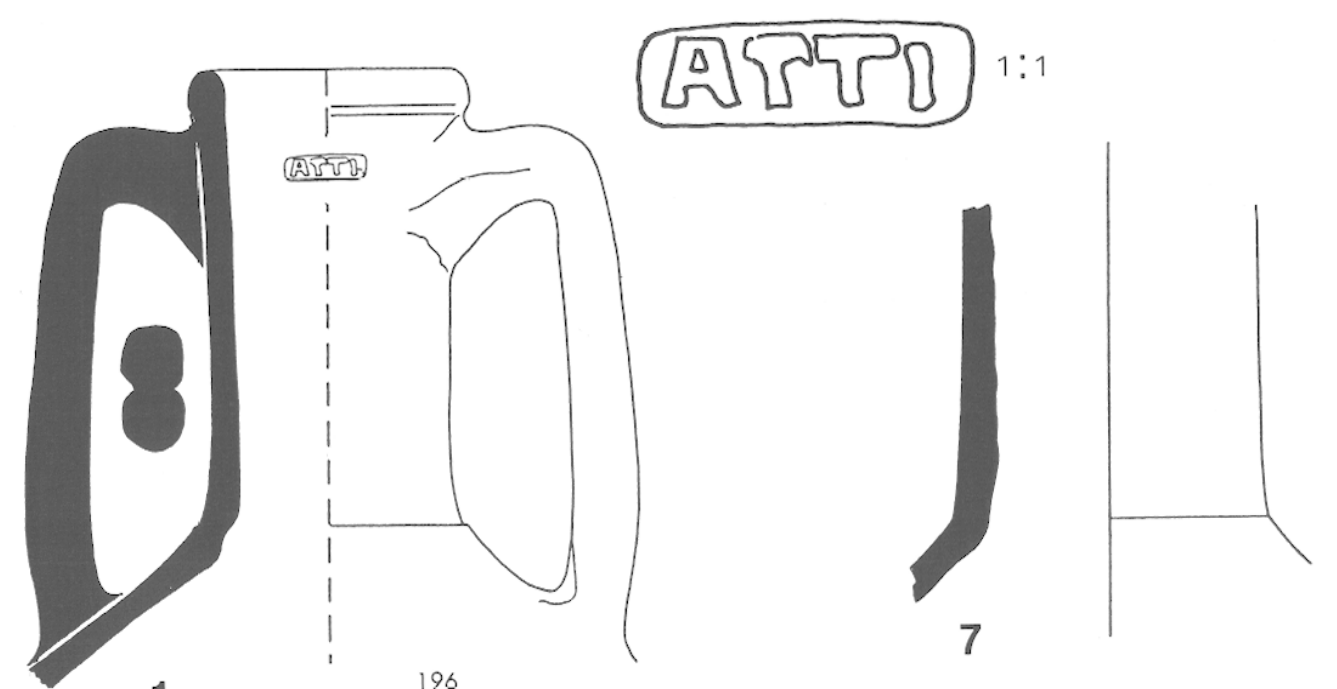

1

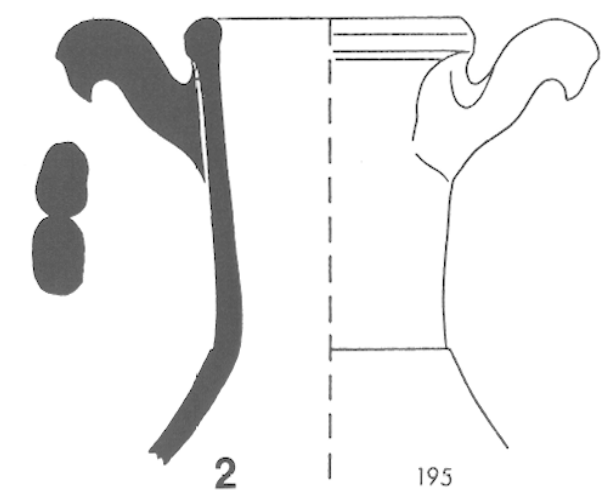

479
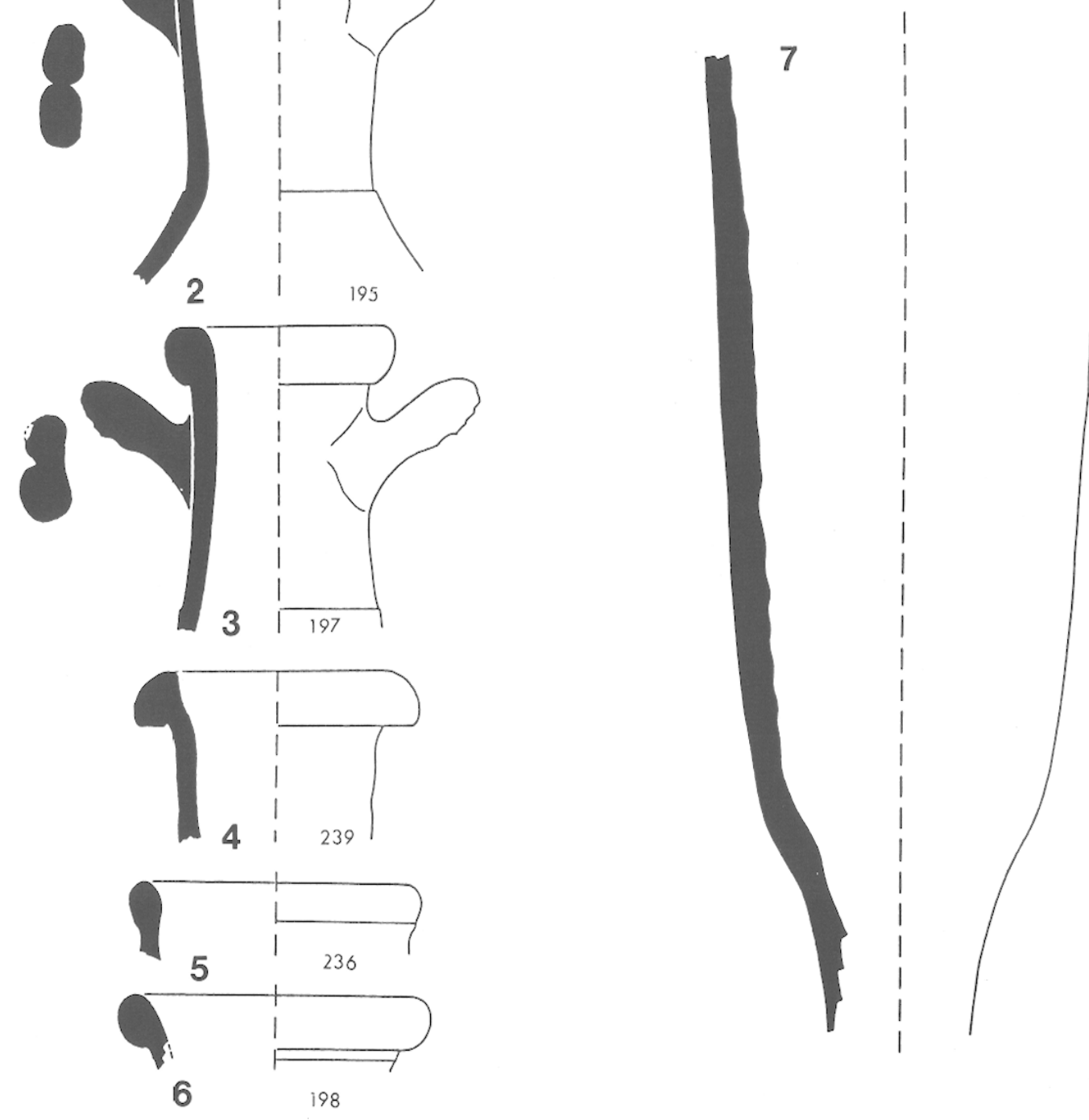

Fig. 2 - Amphores Dressel 2/4.

Toutes les amphores sont représentées à l'échelle $1 / 4$. 
italiques. Certaines anses pseudo-bifides sont réalisées avec un seul boudin marqué d'un sillon sur les deux faces de manière à donner l'illusion de deux boudins accolés. Onze anses du Bas-de-Loyasse appartiennent à cette catégorie fréquente sur les amphores gauloises.

La multiplicité des ateliers de Dressel 2/4, déjà évoquée, interdit une attribution d'origine sur les seuls critères typologiques, particulièrement dans le cas d'un matériel aussi fragmentaire. C'est pourquoi la quasi-totalité des amphores Dressel 2/4 a fait l'objet d'une analyse physico-chimique (en fluorescence $\mathrm{X}$ ) destinée à déterminer leur provenance, sauf dans le cas où un examen visuel s'avérait suffisant (pour les Dressel 2/4 de Tarraconaise, notamment).

Le résultat de ces examens a permis le classement suivant :

$\begin{array}{lr}\text { Italie } \ldots \ldots \ldots \ldots \ldots & 6 \\ \text { Orient } \ldots \ldots \ldots \ldots & 10 \\ \text { Tarraconaise } \ldots \ldots \ldots & 3 \\ \text { Gaule } \ldots \ldots \ldots \ldots & 12 \\ \text { Inclassable } \ldots \ldots \ldots & 4\end{array}$

L'Italie, peu représentée ne compte que quatre anses, une épaule et une lèvre (fig. $2, \mathrm{n}^{0} 5$ ). L'Orient comprend dix exemplaires dont le col (fig. 2, $\mathbf{n}^{\circ} 2$ ) ainsi que huit anses toutes bifides. La Tarraconaise n'est évoquée que par une lèvre (fig. $2, n^{0} 6$ ) et par deux anses bifides, reconnaissables à leur pâte caractéristique rouge à points blancs (Tchernia, Zevi, 1972). La Gaule, enfin, majoritaire, est représentée par le col estampillé $A T T I$ (fig. $2, \mathrm{n}^{\circ} 1$ ) ainsi que par les cols (fig. $2, \mathrm{n}^{\text {os }} 3$ et 4 ) dont la pâte présente une grande similitude avec celle des Dressel 9 similis auxquelles une origine Lyonnaise est attribuée (voir infra). Au groupe gaulois appartiennent en outre dix anses toutes pseudo-bifides et un col non figuré.

La composition du lot de Dressel $2 / 4$ confirme la faiblesse des importations de Dressel 2/4 italiques à partir du règne d'Auguste (Desbat, 1985 et Desbat, Martin-Kilcher, 1986) ainsi que la rareté des Dressel 2/4 de Tarraconaise à Lyon comme à Vienne. Le résultat marquant est l'importance des Dressel 2/4 gauloises dont l'origine est rhodanienne.

La production d'amphores de ce type en Gaule a déjà été démontrée par les découvertes des ateliers de Velaux (Tchernia, Villa, 1977), de Corneilhan (Laubenheimer, Widemann, 1977), de Marseille (Bertucchi, 1983) de Mougon (Schweitz et alii, 1986), ou encore de Puyloubier, Cannes et Ponteilla (Laubenheimer, 1985 , p. 354 , fig. 182). Aucune des am- phores du Bas-de-Loyasse ne semble se rattacher aux ateliers déjà connus mais plutôt au groupe rhodanien mis en évidence dans l'étude du dépôt de la Favorite (Becker et alii, 1986) qui conclut à la production régionale de Dressel $2 / 4$ dès l'époque augustéenne précoce.

\section{Les amphores rhodiennes (fig. 3)}

Les trente-trois exemplaires d'amphores de type rhodien (Haltern 67, Camulodunum 184) montrent que les amphores rhodiennes sont encore bien présentes au $\mathrm{I}^{\mathrm{er}} \mathrm{s}$. (12\% des amphores vinaires et $7,6 \%$ du total).

Trois lèvres (fig. $3, \mathrm{n}^{\text {os }} 1$ à 3 ) et deux pilons seulement (fig. $3, n^{\circ} 9$ et 10 ) se rattachent à cette forme surtout représentée, comme les Dressel 2/4, par des anses, avec la "corne» caractéristique des amphores rhodiennes d'époque impériale. Deux types de pâte sont identifiables dans les amphores du Bas-de-Loyasse, l'une fine, rose orangé, avec de fines inclusions blanches et un pseudo-engobe crème, l'autre plus grossière de couleur jaune.

Si le contenu de ces amphores n'a jamais donné lieu à discussion, la question de leur origine a été débattue par Peacock (1977), qui a montré l'existence de plusieurs "fabrics» et conclu à la possibilité, à côté des productions orientales, d'imitations occidentales de ce conteneur.

L'étude réalisée par le laboratoire de céramologie de Lyon sur trente-cinq échantillons issus des fouilles lyonnaises (dont treize exemplaires du Basde-Loyasse) a conclu à l'origine orientale de tous les exemplaires analysés (Desbat, Picon, 1986). La même étude a cependant montré que les exemplaires ne provenaient pas tous de Rhodes même, mais qu'un tiers au moins venait de la Pérée rhodienne, où des ateliers ont été récemment découverts par des prospections (Empereur, Picon, 1986). Il apparaît donc que ce conteneur correspond à un produit mais surtout au territoire de Rhodes.

\section{Les amphores orientales diverses (fig. 3)}

En dehors des amphores rhodiennes, les amphores orientales comptent encore cinq exemplaires. Quatre correspondent à des amphores de petite taille et la cinquième est représentée par une anse isolée (non reproduite).

Trois cols (fig. $3, \mathrm{n}^{\text {os }} 11,12,14$ ) appartiennent à des exemplaires à pâte fine avec un col cylindrique rétréci sous la lèvre. Cette caractéristique permet de les identifier au type Dressel 43 / Knossos 4-5, présent à Pompéi et pour lequel une origine crétoise est supposée (Panella, 1986, p. 620, fig. 17). 

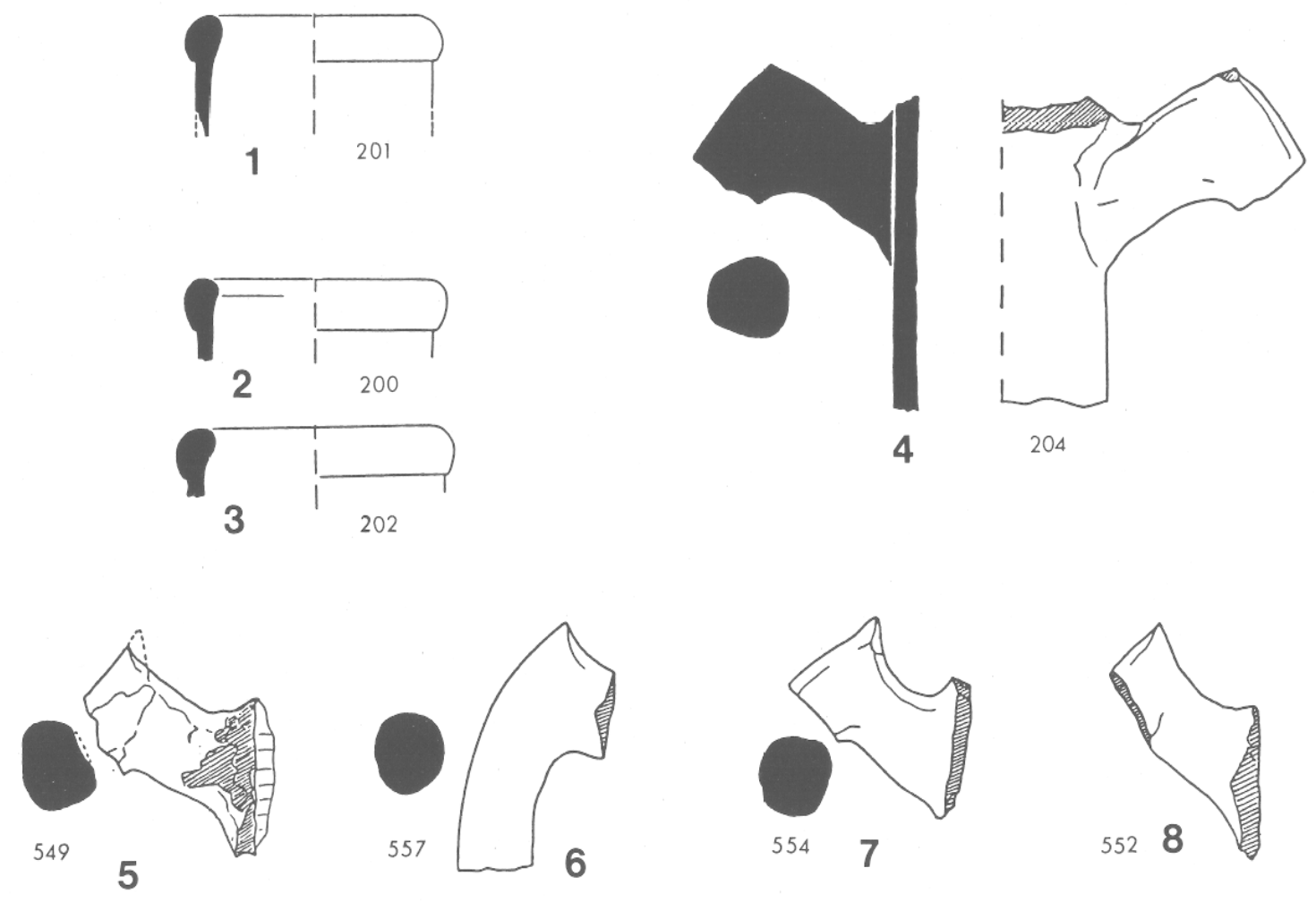

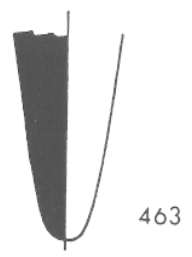

9

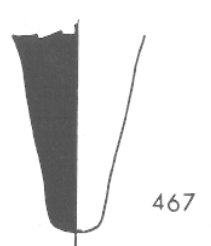

10

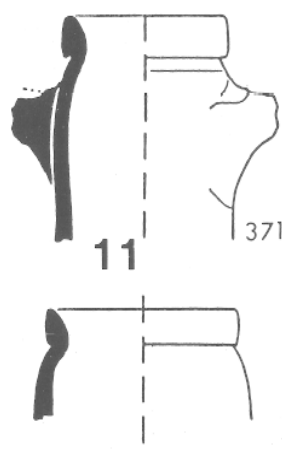

12

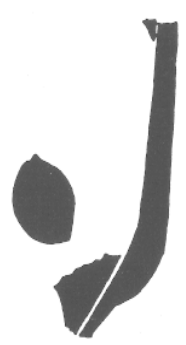

13

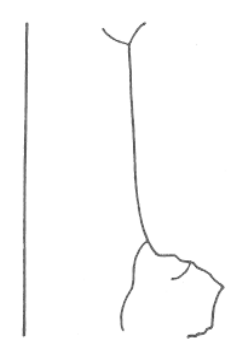

372

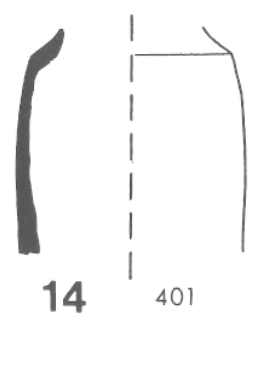

Fig. 3 - Amphores rhodiennes : nos 1 à 10 . Diverses orientales : nos 11 à 14 . 
Le quatrième col appartient à une amphore à pâte jaunâtre à anse de section ovale (fig. $3, \mathrm{n}^{\circ} 13$ ). Sur le col figure un titulus EPITV? (Desbat, Lequément, Liou, 1987). Ce dernier col ne se rattache pas à un type précis, mais la section de l'anse suggère un type oriental, ce que l'analyse a confirmé.

L'anse isolée, fine et de section ovalisée, évoque également des types orientaux qui présentent fréquemment des anses de section rondes ou ovales (amphores de Chios, de Cnide, Dressel 43 par exemple).

Les analyses réalisées sur trois de ces amphores (l'anse, le col avec tilulus et une des lèvres de Dressel 43 (fig. $3, \mathrm{n}^{0} 11$ ), ont confirmé leur origine orientale mais sans qu'il soit possible de les attribuer précisément à une région.

\section{Les amphores Pascual 1 (fig. 4)}

Trois lèvres seulement appartiennent au type Pascual 1 qui ne représente que $1 \%$ des amphores vinaires et $0,7 \%$ du total.

Une seule lèvre possède la pâte rouge à points blancs typique de cette production (Tchernia, Zevi, 1972). Les deux autres ont une pâte jaune qui correspond à la deuxième variété de pâte de Tarraconaise moins répandue que la pâte rouge.

Une lèvre à pâte jaune (fig. $4, \mathrm{n}^{\circ} 1$ ) porte une estampille fragmentaire $/ \ldots J C I$, identifiable à la marque $M . P O R C I$ très fréquente sur ce type d'amphore (Comas, 1985, fig. 59 et 60).

Apparaissant à la fin du $\mathrm{I}^{\text {or }} \mathrm{s}$. av. J.-C., les Pascual 1 semblent disparaitre assez rapidement au début du $\mathrm{I}^{\mathrm{er}}$ s. ap. J.-C. : elles sont alors relayées par les Dressel 2/4. Leur faible représentation dans le dépotoir du Bas-de-Loyasse confirme cette chronologie et permet de penser qu'il s'agit de matériel résiduel, comme la lèvre de Léetanienne 1 (voir infra p. 145).

\section{Les amphores Haltern 70 (fig. $4, \mathrm{n}^{\text {os }} 4$ à 10)}

L'amphore Haltern 70 ne compte que sept exemplaires $(2,5 \%$ du lot des amphores vinaires et $1,6 \%$ du total).

D'une manière générale, l'amphore Haltern 70 est caractérisée par une lèvre haute et évasée mais les différents fragments de lèvres recueillis montrent de grandes variations de détail : deux exemplaires (fig. $4, n^{0 s} 7$ et 9 ) ont ainsi une lèvre arrondie assez irrégulière.

La forme Haltern 70 qui apparaît vers le milieu du $\mathrm{I}^{\text {rr }}$ s. av. J.-C. - le plus ancien fragment connu provient de l'épave de la Madrague de Giens
(Tchernia, 1980) - est supposée disparaître au milieu du I ${ }^{\text {er }} \mathrm{s}$. de notre ère (Colls et alii, 1977, p. 35). Il n'est cependant pas impossible que la production se soit poursuivie un peu plus avant dans le $\mathrm{I}^{\mathrm{er}} \mathrm{s}$. : c'est ce que semble proposer la chronolugie des Haltern 70 à Sheepen (Sealey, 1985, p. 64). Les lèvres (fig. $4, n^{\text {os }} 8$ et 9 ) pourraient être des variantes tardives de cette forme. De même, la relative abondance de Haltern 70 dans les niveaux flaviens de Nimègue conduit Van der Werff (1984) à supposer que la production de ce type s'est prolongée au-delà des années 50.

Si une origine de Bétique recueille l'accord de tous, la polémique reste ouverte quant au contenu. Les amphores Haltern 70 ont longtemps été considérées comme des amphores recevant une sauce de poissons, le liquamen, jusqu'à ce que la découverte de l'épave de Port-Vendres II permette d'en préciser le contenu (Colls el alii, 1977, p. 86-91) : l'inscription defr(utum) excel(lens) sur plusieurs Haltern 70 de cette épave conduisait B. Liou à ne plus douter qu'il s'agissait là d'amphores vinaires. De fait, le defrulum est rangé avec la sapa et le caroenum parmi les vins cuits, utilisés aussi comme substituts du miel pour leur extrême concentration en sucre (André, 1981, p. 164). Mais d'autres inscriptions sur Haltern 70 mentionnent des olives, conservées dans ce defrulum (Colls et alii, 1977, p. 86-91 ; Lequément, Massy, 1980 ; Liou, 1982, p. 444). Pour sa part, Sealey refuse d'assimiler vin et defrutum, lequel reste selon lui un sirop non alcoolique, incluant la sapa, seulement utilisé pour la conservation d'autres fruits, les besoins en cuisine ou le traitement des vins (Sealey, 1985$, p. 62 et $s q$.$) .$

La discussion reste ouverte dans la mesure où B. Liou (1982, p. 444, n. 18) avait écarté ces arguments déjà proposés dans une étude précédente (Parker, Price, 1981). Dans l'état actuel des connaissances, nous avons donc pris le parti d'en rester à ce qui est communćment admis et rangé l'amphore Haltern 70 parmi les amphores vinaires, malgré les réserves émises par les auteurs anglais.

\section{Les amphores Hallern 70 similis (fig. $4, \mathrm{n}^{\mathrm{os}} 11$ à 15)}

Un col complet et quatre lèvres appartiennent à un type d'amphore que l'on peut définir comme Haltern 70 similis.

Des exemplaires complets trouvés à Augst (Callender, 1965, pl. III, B) à Nyon ou à Vienne (Desbat, 1985, fig. 10 et 11), permettent en effet de constater que cette amphore dérive de la forme Haltern 70. Elle en présente les caractéristiques: panse fuselée terminée par un pilon pointu, anse 

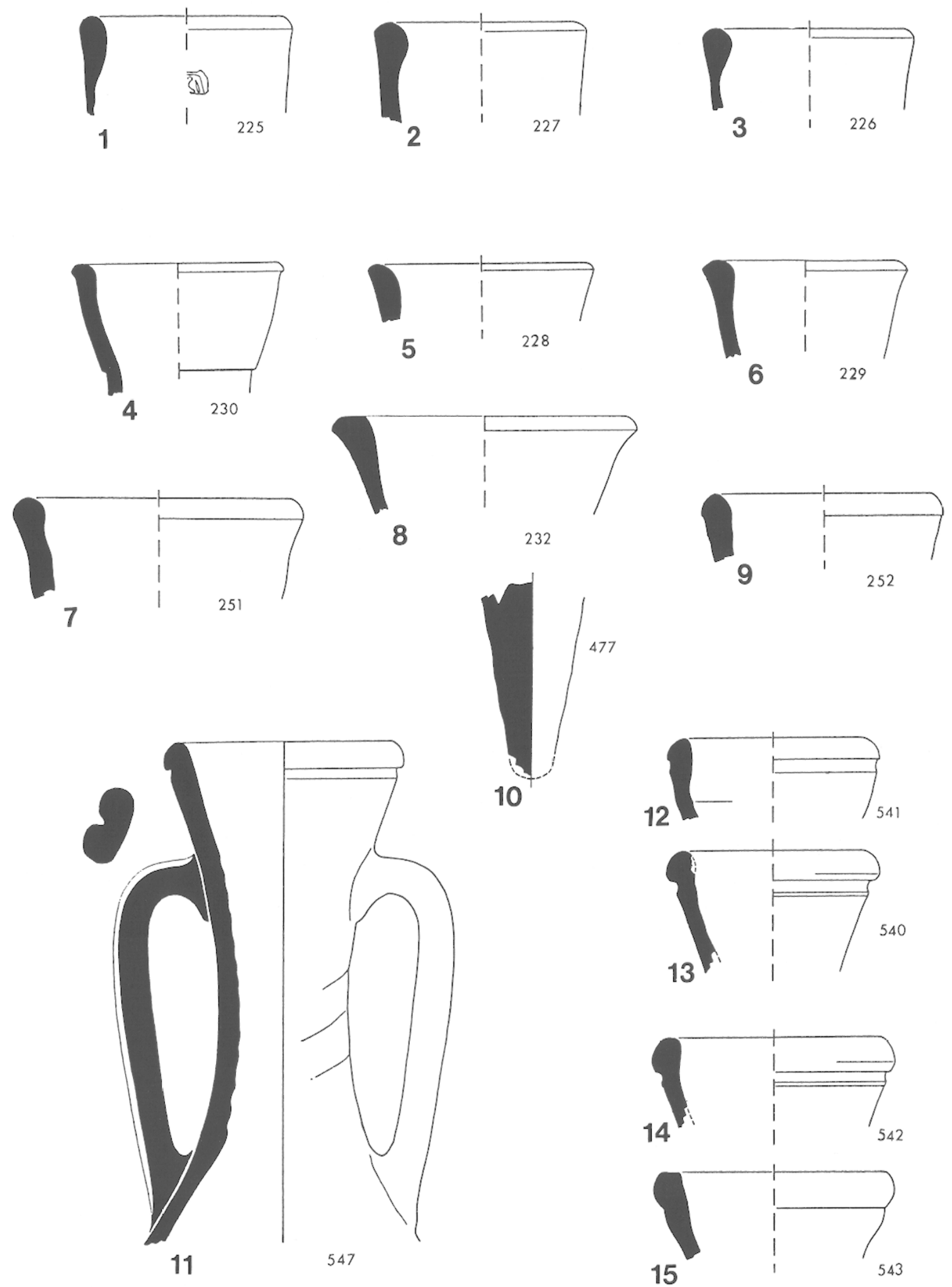

Fig. 4 - Amphores Pascual $1:$ nos $^{\text {à }} 3$. Haltern $70:$ nos $^{\circ}$ à 10 . Haltern 70 similis : nos 11 à 15 . 
avec un sillon très marqué, col long s'évasant vers le haut. La différence essentielle avec les "vraies" Haltern 70 est l'absence du ressaut séparant le col de la lèvre et la présence d'un sillon sous le rebord de celle-ci.

La référence au type Haltern 70 est confirmée par la découverte à Vienne ou à Nyon en particulier, d'amphores qui constituent des intermédiaires entre les Haltern 70 standard et les exemplaires du Basde-Loyasse : lèvre avec un ressaut et avec sillon par exemple (Desbat, Picon, 1987).

Deux types de pâte se rencontrent dans les exemplaires du Bas-de-Loyasse : le premier à pâte granuleuse avec dégraissant de quartz (fig. 4, $\mathrm{n}^{\text {os }} 11$ et 15), proche des pâtes de G3 ou G4 (fig. $4, \mathrm{n}^{\text {os }} 12$ à 14).

Ce type d'amphore est présent sur de nombreux sites autres que ceux déjà mentionnés, en particulier à Neuss (Filtzinger, 1972, Pl. 24,8), à LondresBillingsgate (Jones, 1980, fig. 20, 29), à Fishbourne (Cunliffe, 1971, II, fig. 100, no 184-4) et à Vérulamium (Frère, 1972, fig. $99, \mathrm{n}^{\circ} 9$ i. Il est également signalé par Peacock et Williams (1986, no 59, p. 215) et correspond à un exemplaire complet publié par Wheeler (1930, Groupe E). Sans en donner le dessin, Sealey (1985, p. 64 et 167) évoque également ce type qu'il désigne par l'appellation London 555.

Les diverses trouvailles datées, en Gaule, permettent de proposer une chronologie qui couvre toute la seconde moitié du $\mathrm{I}^{\text {er }} \mathrm{s}$., les exemplaires les plus anciens se situant vers 50 ap. J.-C., à Lyon en particulier. Sealey (1985, p. 167) étend cette date jusqu'en 125 d'après les découvertes anglaises.

La filiation évidente avec les Haltern 70 suggère naturellement une même origine pour ces amphores, comme nous l'avons nous-même proposé ultérieurement (Desbat, 1985). Une origine de Bétique est également proposée par Sealey (1985, p. 167) qui remarque : "some have a fabric that is indistinguishable by touch and eye from that familiar to us from Haltern 70 and Dressel 20». Cependant, les deux types de pâtes des exemplaires du Bas-de-Loyasse sont retrouvés dans les productions rhodaniennes. Les analyses ont confirmé l'origine régionale des Haltern 70 similis du Bas-de-Loyasse ${ }^{5}$.

5 La production gauloise d'amphores de ce type avait déjà été suggérée par Paunier (1981, p. 236) à cause de la découverte d'une Haltern 70 simili avec la marque SOLIT, connue également sur Dressel 9 similis. Paunier signale également la même marque sur G4. Cette dernière identification a été cependant remise en cause. L'exemplaire identifié par K. Roth-Rubi (1975) serait en fait une Dressel 9 simili (communication de S. Martin-Kilcher).
Le contenu de ces amphores était vraisemblablement le même que celui des Haltern 70 standard. L'exemplaire de Nyon avec la marque SOLIT (Paunier, 1981, p. 236) comporte en effet un titulus mentionnant du vin doux DUL(ce) (Pélichet, 1946, $\left.\mathrm{n}^{0} 17\right)^{6}$. Une autre amphore inédite d'Augst comporte également la mention DUL.?. Sealey (1985, p. 167) signale par ailleurs, la découverte dans la Tamise d'une amphore London 555 contenant 6000 noyaux d'olives dans du defrutum et identifie l'amphore de Soisson avec l'inscription "Olivia nigra ex defruto" (Lequément, Massy, 1980) comme une amphore du même type ${ }^{8}$.

La question essentielle reste de savoir si toutes ces amphores Haltern 70 similis ont la même origine ou s'il faut envisager la possibilité d'une production en Bétique et en Gaule. Pour les exemplaires du Basde-Loyasse une chose est certaine : il s'agit d'une production gauloise.

\section{Les amphores Gauloise 1 (fig. $5, \mathrm{n}^{\text {os }} 1$ à 6)}

Avec six exemplaires, les amphores Gauloise 1 (G1), constituent le groupe le moins important des amphores à fond plat dites "gauloises» (Laubenheimer, 1985) puisqu'elles ne représentent que $2,1 \%$ des amphores à vin et $1,4 \%$ du total.

Ce groupe est caractérisé par une lèvre épaisse de profil triangulaire. Quatre exemplaires présentent la pâte sableuse, beige ou rose, caractéristique de la plus grande partie de la production et attribuable à la région de Nîmes (Laubenheimer, 1977 et 1985, p. 243 à 257).

Le seul col complet (fig. $5, \mathrm{n}^{\circ} 1$ ) et la lèvre (fig. 5, $\mathrm{n}^{\circ} 5$ ) présentent des pâtes différentes :

- le col montre une pâte fine rouge orangé, à très fin dégraissant micacé, qui s'apparente à celle de l'atelier de Velaux, où une forme proche est signalée (Tchernia, Villa, 1977, p. 239, fig. 8, nº 1). L'absence d'analyse ne permet pas cependant de confirmer celle altribution;

6 E. Pélichet (1946, p. 198) propose la lecture VI(num) $\mathrm{Dul}(\mathrm{ce})$ mais cette lecture n'est pas certaine, la première ligne pouvant être lue "Oli(va) ex Dul(ci)", équivalent de Oliva ex defruto.

7 Nous devons cette communication à S. MartinKilcher à qui nous adressons nos plus chaleureux remerciements, pour les nombreuses informations dont elle a eu la gentillesse de nous faire part.

8 La publication de R. Lequément et J.-L. Massy (1980) ne montre qu'un col dépourvu de lèvre. Dès lors, nous pouvons nous interroger sur les critères qui ont permis à P. Sealey d'identifier cette amphore comme London 555 plutôt que comme Haltern 70 . 

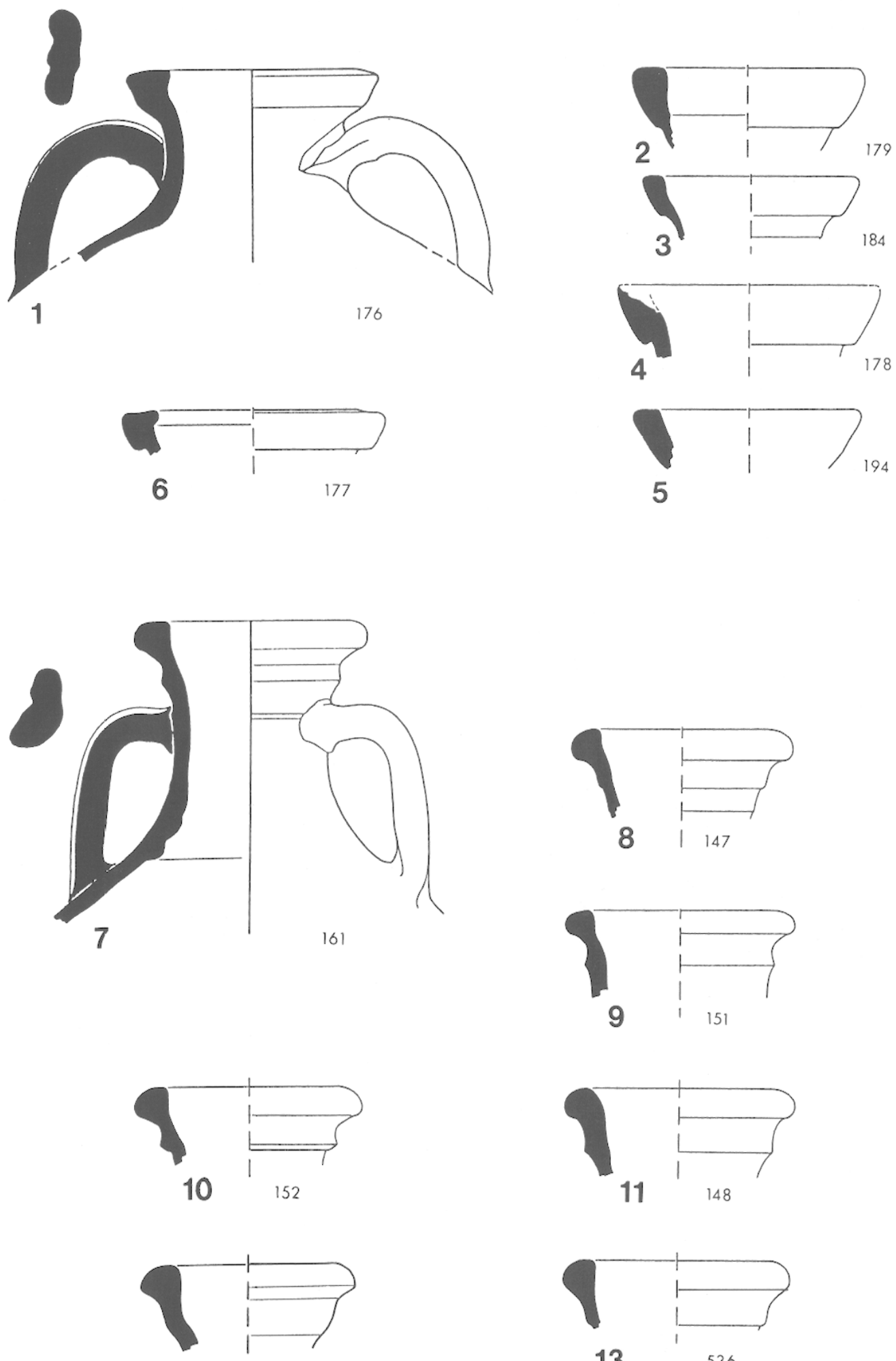

$12 \quad 185$

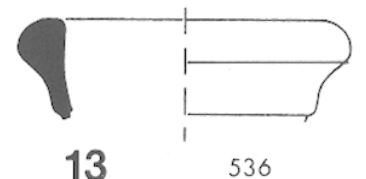

Fig. 5 - Amphores Gauloise $1: n^{\circ s} 1$ à 6 . Gauloise $3: n^{\circ s} 7$ à 13 . 
- la lèvre présente une pâte beige non sableuse qui correspond au deuxième type de pâte rencontrée dans les G1 (Laubenheimer, 1985. p. 245). Un autre exemplaire à pâte sableuse (fig. $5, \mathrm{n}^{\circ} 6$ ), possède une lèvre légèrement différente, moins haute, avec un profil moins anguleux et un bourrelet interne, qui pourrait constituer une variante précoce des Gl. Une lèvre semblable, avec la pâte sableuse typique des G1, provient en effet d'un niveau augustéen de Saint-Romain-en-Gal. Un seul fond (fig. $12, n^{\circ} 6$ ) appartient à ce type.

La présence d'amphore du type Gl dans le dépotoir coïncide avec la chronologie généralement admise pour ce type (Paunier, 1981, p. 241, no 440 et Laubenheimer, 1985, p. 389). La production de ce type d'amphore a dû cependant se prolonger aux I $^{\mathrm{e}}$ et III $^{\mathrm{e}} \mathrm{s}$. comme le montre son existence dans des contextes de cette époque à Lunel-Viel et Ambrussum (Raynaud, 1984 et 1986), ainsi qu'à Vienne. Produite durant la même période que les G4, cette forme n'a eu qu'une diffusion restreinte en dehors de la région productrice où elle est très abondante comme en témoignent les tableaux d'Ambrussum et de Vié-Cioutat (Laubenheimer, 1985, fig. 189 et 190).

\section{Les amphores Gauloise 3 (fig. 5 , n ${ }^{\text {os }} 7$ à 13 )}

Avec seulement neuf exemplaires, les amphores Gauloise 3 ne représentent qu'une petite partie des amphores "gauloises": $3,2 \%$ des amphores vinaires et $2 \%$ du total.

Ce type défini par F. Laubenheimer (1985, p. 257) est caractérisé par un ressaut sous la lèvre arrondie, qui le distingue du type G4. Le dépotoir du Bas-de-Loyasse n'a livré qu'un seul col complet (fig. 5, $\mathrm{n}^{0} 7$ ); plusieurs fragments de cols permettent cependant de reconnaître des variantes dans la lèvre, plus ou moins arrondie, le ressaut sous la lèvre plus ou moins marqué. Aucun des exemplaires du Bas-deLoyasse ne présente le mème profil que les G3 de l'atelier de Corneilhan, seul atelier avec Marseille où la production est attestée. Les profils s'apparentent au contraire aux différents exemples de G3 présents dans la vallée du Rhône en particulier à Lyon et à Vienne (Laubenheimer, 1985, fig. 116).

Les pâtes des exemplaires du Bas-de-Loyasse sont fines, avec un fin dégraissant. Leur couleur varie de l'orange au beige avec une surface généralement beige allant au crème pour les exemplaires bien cuits, caractéristique retrouvée sur les $\mathrm{G} 4$, dont les pâtes ne se distinguent pratiquement pas des G3 et sur certaines Haltern 70 similis. La documentation rend actuellement difficile la distinction entre les fonds de
G3 et ceux des G4 (fig. 12, nos 1 à 5), de même que les anses.

L'existence de types intermédiaires entre l'amphore à bandeau concave de Marseille (Bertucchi, 1983) et la Gauloisc 3, caractérisés par un bandeau concave mais une lèvre arrondie et un bourrelet au niveau de l'attache des anses, suggère la possibilité d'une filiation entre l'amphore de Marseille et la Gauloise 3 dont la production est maintenant attestée à Marseille (Bertucchi, 1983).

La date d'apparition de la G3 semble pouvoir être située durant la première moitié du $\mathrm{I}^{\mathrm{er}} \mathrm{s}$., mais les exemples bien datés sont peu nombreux. A Corneilhan, ce type est daté de la première moitié du ${ }^{\text {Ir }}$ s. (Laubenheimer, 1985, p. 385). En dehors des découvertes terrestres, nous pouvons signaler l'épave du Petit-Congloué qui associe Dressel 2/4 de Tarraconaise et G3 dans une épave à dolia (Corsi, Liou, 1985 , p. 26 à 43 i.

La faible représentation de ce type nous parait un argument pour supposer que le type G3 constitue une forme de transition entre l'amphore de Marseille à fond plat et la G4. La G3 dont la production est limitée, serait relayée par la G4 qui connaît un très grand développement. Bien qu'aucun titulus sur G3 ne soit connu, elles sont considérées comme des amphores vinaires, ce qui paraît logique si, comme il est permis de le penser, il ne s'agit que de la forme précoce des G4.

\section{Les amphores Gauloise 4 (fig. 6 et 7)}

Avec 133 exemplaires, les amphores à fond plat dites Gauloise 4 (Laubenheimer, 1985) ou Pélichet 47 (Pélichet, 1946) constituent le groupe le plus important du dépotoir. Elles représentent 47,33\% des amphores vinaires et $30,4 \%$ du total.

Les cols, beaucoup plus nombreux que les fonds, montrent une assez grande variété dans les profils de lèvres. Rien ne permet cependant d'affecter les différentes variantes de lèvre d'une incidence chronologique ou géographique. Tous les exemplaires recueillis présentent une grande similitude de pâte : il s'agit de pâtes fines, calcaires, dont la teinte varie de l'orangé au beige clair, la surface extérieure étant généralement plus claire que le cœur de la pâte.

Malgré des différences dans les profils, nous remarquons des constantes : les cols sont hauts (le rapport hauteur de col/diamètre de la lèvre étant sensiblement égal à 1) et le sommet des anses nettement inférieur à la lèvre. Toutes les anses, de section lenticulaire, sont creusées d'un sillon médian; aucune ne présente de marque. Les fonds à 

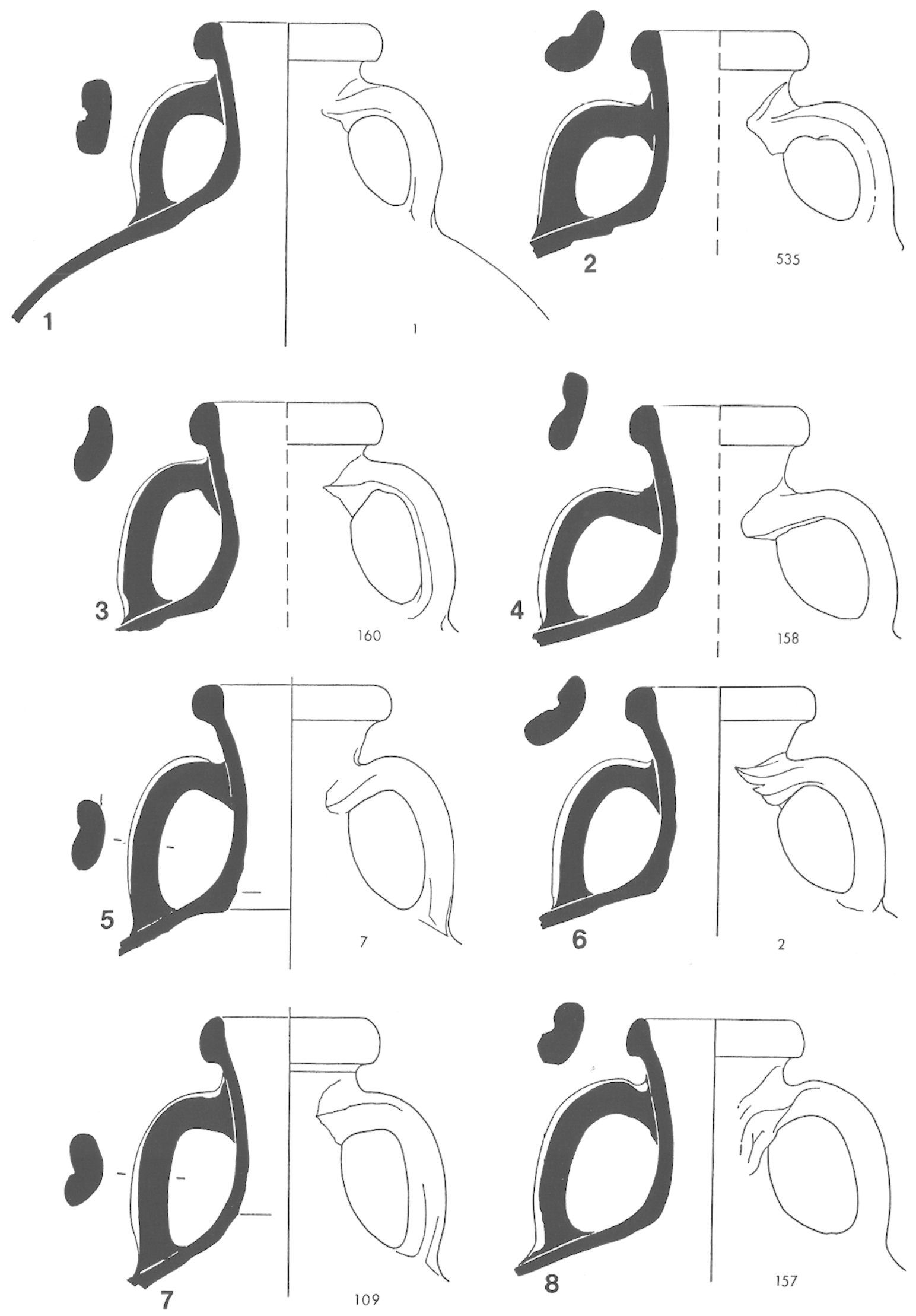

Fig. 6 - Amphores Gauloise 4. 

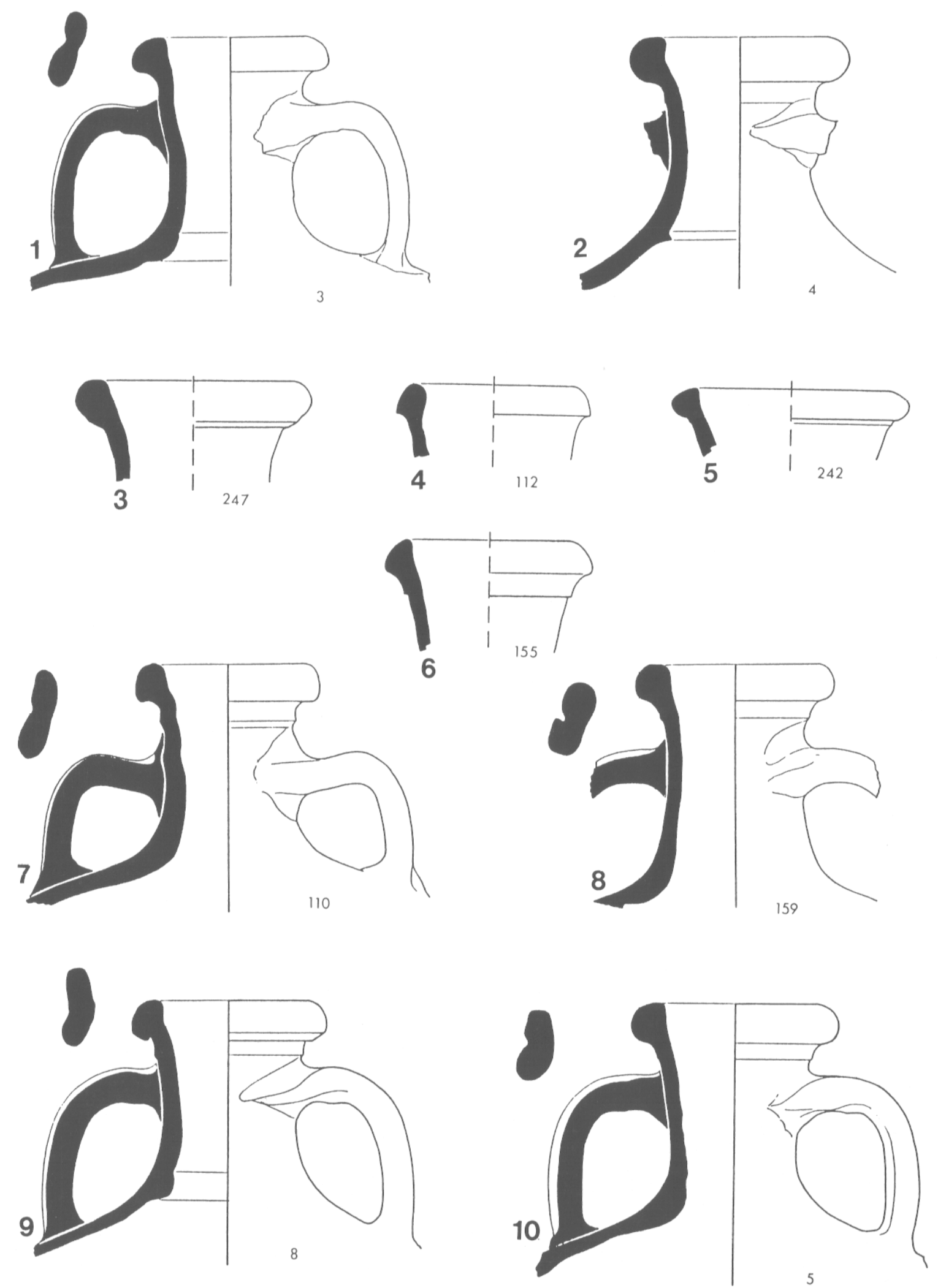

Fig. 7 - Amphores Gauloise 4. 

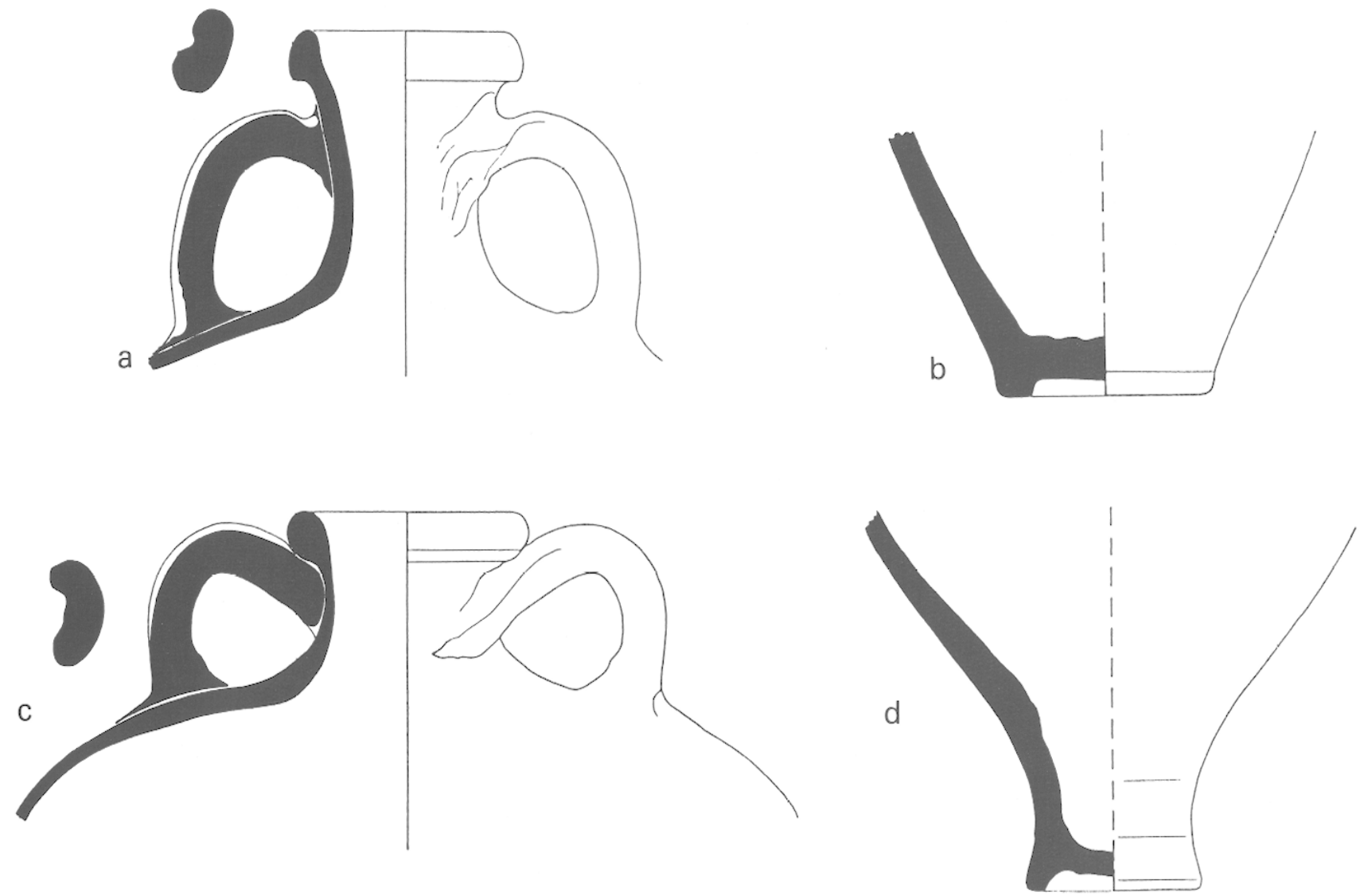

Fig. 8 - a et b : exemples de col et de fond de G4 du $\mathrm{I}^{\text {er }}$ s. (Bas-de-Loyasse); $\mathrm{c}$ et $\mathrm{d}$ : exemples de col et de fond de G4, fin II $^{\mathrm{e}}-$ début III $^{\mathrm{e}}$ s. (Rue des Farges, E4).

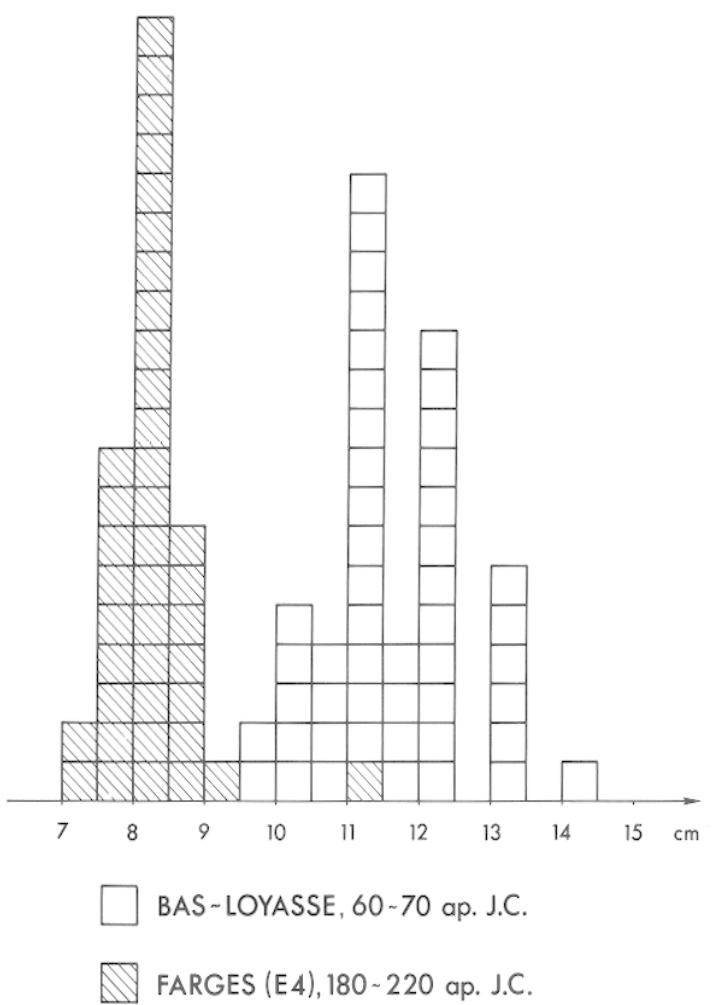

Fig. 9 - Diagramme des diamètres comparés de fonds de G4 du Bas-de-Loyasse et d'un dépotoir de la Rue des Farges.

pieds annulaires, ont des diamètres qui varient entre 9 et $14 \mathrm{~cm}$ avec une moyenne de $11 \mathrm{~cm}$.

Toutes ces caractéristiques sont typiques des G4 $\mathrm{du} \mathrm{I}^{\mathrm{er}} \mathrm{s}$. Contrairement à ce qui ressort de l'étude récente de $\mathrm{F}$. Laubenheimer (1985), les G4 montrent une évolution typologique très nette : si le diamètre des lèvres change peu, il apparaît en revanche une évolution de la forme avec le temps, caractérisée par une diminution du diamètre du fond et un raccourcissement du col. En conséquence, l'espace entre le sommet de l'anse et la lèvre diminuant, celle-ci parvient à être tangente sur les exemplaires du III $\mathrm{s}$. (fig. 8) ${ }^{9}$. Cette évolution morphologique, qu'illustre

9 Malgré de très nombreuses mensurations effectuées sur les G4, F. Laubenheimer n'a mis en évidence aucune évolution typologique. Il nous semble que pour ce type d'étude, il eût mieux fallu soit choisir (ou pour le moins tester) plusieurs critères plutôt que de mesurer uniquement les diamètres des fonds et des lèvres, soit partir de matériels datés. Au demeurant, ce dernier choix permet, dans la mesure où 
le diagramme des diamètres des fonds du Bas-deLoyasse et d'un dépotoir du début du $11 I^{\circ}$ s., rue des Farges (fig. 9), conduit à donner aux G4 des II $^{e}$ et III $\mathrm{s}$. une forme en toupie qui les distingue nettement des exemplaires du $\mathbf{I}^{\mathrm{er}} \mathrm{s}$.

L'ignorance de cette évolution morphologique peut être cause d'erreur dans la détermination des types. Ainsi, Sealey (1985, p. 96, fig. 17) attribue au type Dressel 28 des fonds que ni leur forme ni leur pâte ne permettent de rapprocher des types connus de Dressel 28 alors qu'ils sont en tout point comparables aux fonds de G3 ou G4 du Bas-de-Loyasse. Il justifie cette attribution par le fait que les Pélichet 47 typiques ont des fonds étroits et qu'elles n'apparaissent qu'après 50 ap. J.-C.

Aucune des G4 du Bas-de-Loyasse ne présente d'estampille. Cela rejoint les observations réalisées sur l'ensemble du matériel lyonnais, où les estampilles sur G4 n'apparaissent pas avant le début du II $^{*} \mathrm{~s}$.

Dans son ouvrage sur les ateliers de Narbonnaise F. Laubenheimer (1985, p. 350, fig. 179) recense vingt-deux ateliers producteurs de G4. Rien ne permet cependant de rattacher les G4 du Bas-deLoyasse aux ateliers connus. Comme pour les G3, l'examen des pâtes et les analyses réalisées sur huit échantillons montrent un matériel très homogène dont l'origine serait à chercher dans la vallée du Rhône.

Plusieurs des G4 du Bas-de-Loyasse présentent des inscriptions peintes (Laubenheimer, 1985, p. 447, $\mathrm{n}^{\circ} 11$, p. 448, $\mathrm{n}^{\mathrm{os}}$ 20-27-28; Desbat, Lequément, Liou, 1987, nos L2, L4, L7, L8, L9). Deux désignent le vin: $A M I N($ neum) VET(us) (Laubenheimer, 1985, p. 447, no 11 ; Desbat, Lequément, Liou, 1987, $\mathrm{n}^{\circ} \mathrm{L} 2$ ) et MAS(sicum) VET(us) (Laubenheimer, 1985 , p. 448, nº 20 ; Desbat, Lequément, Liou, 1987, $\mathrm{n}^{\circ}$ L4). Ces inscriptions qui s'ajoutent à une liste déjà longue (Liou, Marichal, 1978) apportent une nouvelle preuve du contenu de ces amphores qui ne fait maintenant plus de doute.

Les amphores Gauloise 5 (fig. 10 et $11, \mathrm{n}^{\text {os }} 1$ à 3 )

Beaucoup moins nombreuses que les G4, les G5 ne comptent que trente-six exemplaires soit $13,9 \%$ des amphores vinaires et $8,2 \%$ du lot.

Ces amphores caractérisées par une lèvre plate ont comme les $\mathrm{G} 4$, diverses variantes dans le profil

l'évolution morphologique des G4 est perceptible pour qui travaille sur des contextes datés, de proposer une fourchette chronologique pour la plupart des ateliers de G4 découverts par prospections et présentés par F. Laubenheimer sans datation. des lèvres plus ou moins épaisses et plus ou moins plates. Quelques exemplaires (fig. $10, \mathrm{n}^{\text {os }} 6,9,10$ ) présentent un léger bourrelet sous la lèvre. Deux autres (fig. $11, \mathrm{n}^{\mathrm{os}} 1$ et 2 ) ont un ressaut très net qui les rapproche des G3. La lèvre plate et la similitude de pâte avec les autres G5 permettent cependant de les classer comme des variantes de G5.

Comme pour les G4, rien ne permet de voir dans ces nombreuses variantes de détail, l'indice d'une chronologie et d'une origine différentes. Les anses de section lenticulaire, plus ou moins plates, ne comportent, comme celles des G3 et G4, qu'un seul sillon, médian. L'attache de celle-ci sur le col est cependant plus basse que sur les Gauloise 4.

La similitude de pâte permet d'attribuer à la forme G5 plusieurs fonds (fig. $12, \mathrm{n}^{\mathrm{os}} 7$ à 9 ). Ceux-ci présentent des diamètres comparables aux $\mathrm{G} 4$ avec toutefois un pied annulaire plus fin que sur les G4 et un profil externe oblique, caractéristique retrouvée sur l'exemplaire complet du musée de Lyon (Laubenheimer, 1985, fig. 158).

Aucun des fonds du Bas-de-Loyasse ne présente d'ombilic comme les G5 produites dans l'atelier de Fréjus-Pauvadou (Laubenheimer, 1985, p. 239-99, fig. 154). Les pâtes différentes de celles des G4 et G3, ont une texture plus fine et une plus grande dureté. Plus riches en calcaire (les exemples analysés montrent des pourcentages qui dépassent $30 \%$ ), elles ont une surface beige clair et une pâte rosée avec de fins points blancs, voire beige clair pour les amphores très cuites. Les cinq exemplaires analysés montrent une composition très proche qui diffère nettement de celles des G4 et autres productions gauloises.

Leur origine reste indéterminée mais ne peut se rattacher à aucun des ateliers de $\mathrm{G5}$ actuellement connus : Marseille, Fréjus, Istres ou Viens (Laubenheimer, 1985, p. 293). La production de l'atelier du Pauvadou a été datée du dernier tiers du $\mathrm{I}^{\mathrm{er}} \mathrm{s}$. (Brentchaloff, 1980). Les découvertes sur les sites de consommation indiquent une production à partir des années 50 et jusqu'au début du ${ }_{1}{ }^{\mathrm{e}} \mathrm{s}$. (Laubenheimer, 1985, p. 390). L'étude des amphores de Nimègue (Van der Werff, 1984) illustre cette chronologie : les G5 ne sont présentes que dans la phase Id-II, entre 71 et 104. Aucune des G5 du Bas-de-Loyasse ne présente d'estampille ni de tituli picti, toutefois à Fos-sur-Mer deux G5 mentionnent l'une le picatum (Laubenheimer, 1985, tabl. 29, n $^{\text {os }} 3$ et 6) l'autre le Massicum (Liou, Marichal, 1978, n 39, fig. 19, p. 148).

Les autres amphores gauloises (fig. 11, $\mathrm{n}^{\text {os }} 4$ à 12)

Parmi les amphores gauloises, neuf exemplaires, soit environ $3 \%$ du lot des amphores vinaires $(2 \%$ 

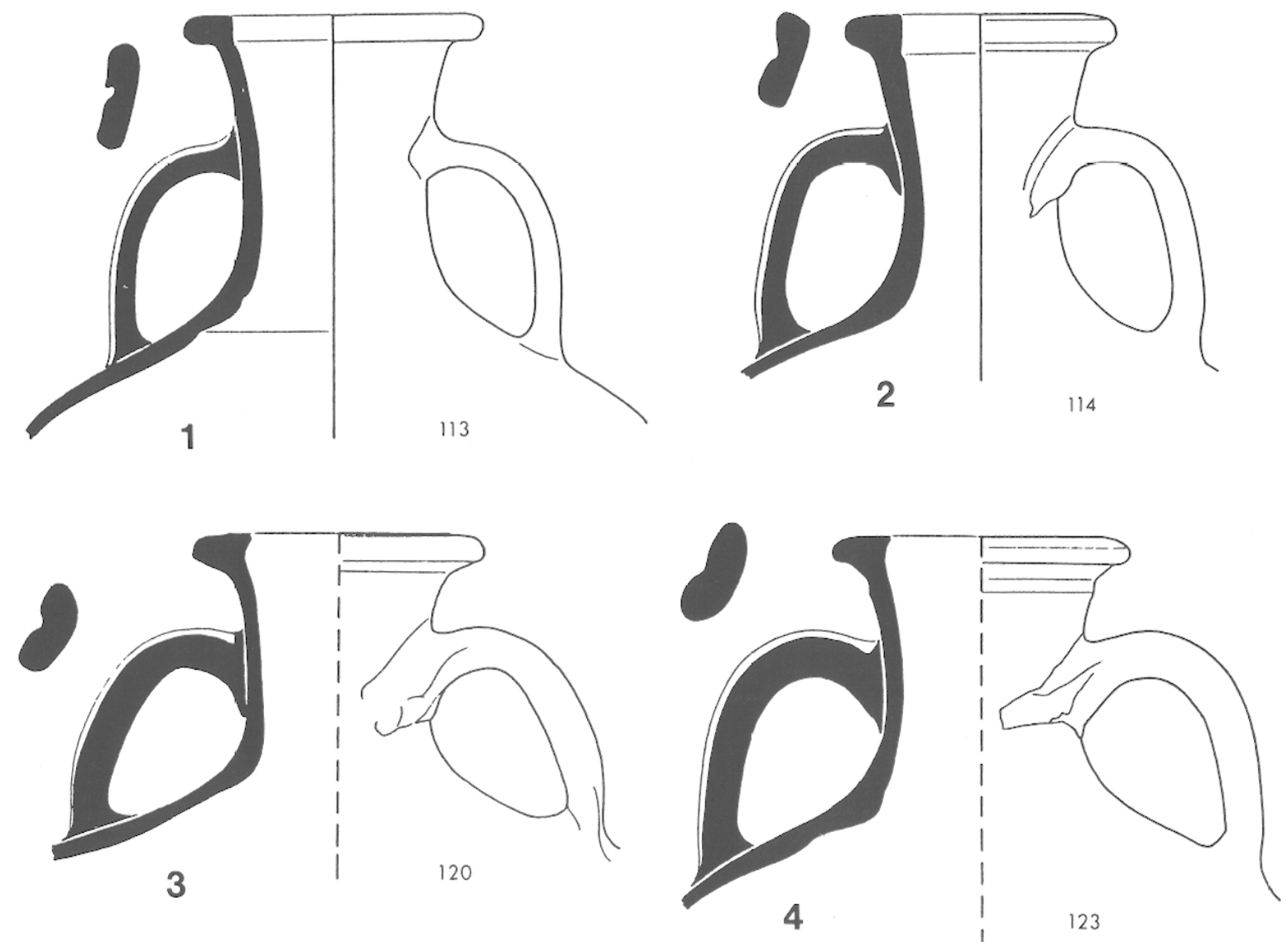

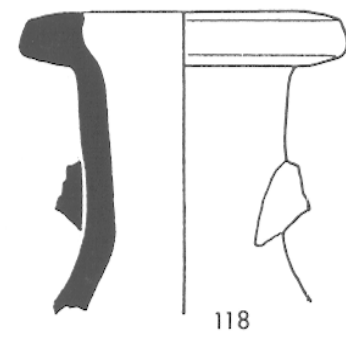

5

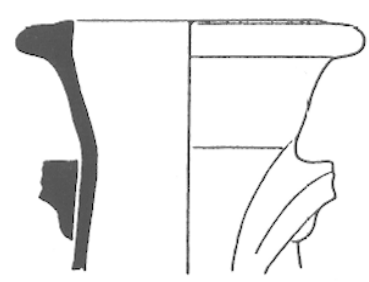

8

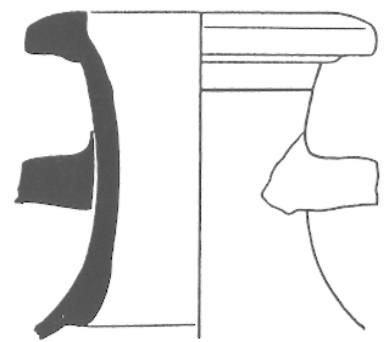

6

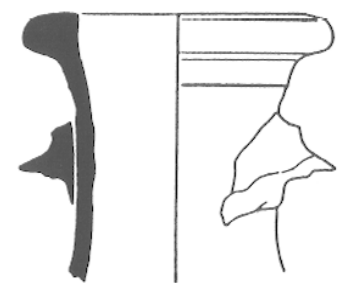

9

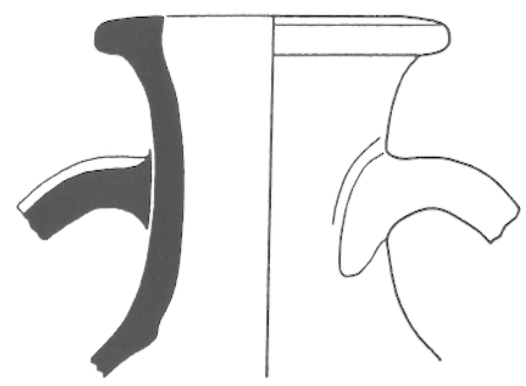

7

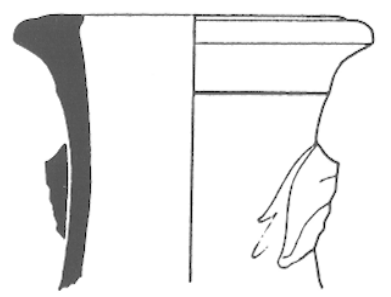

$10 \quad 115$
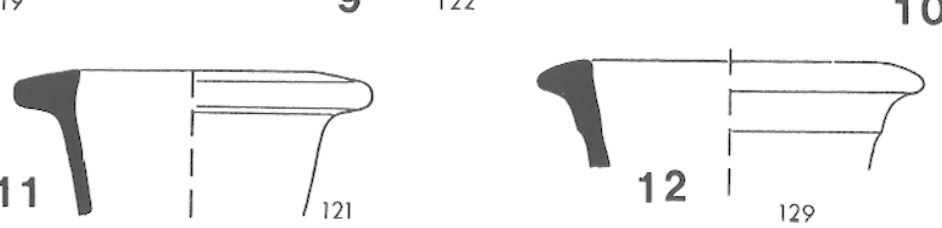

Fig. 10 - Amphores Gauloise 5. 

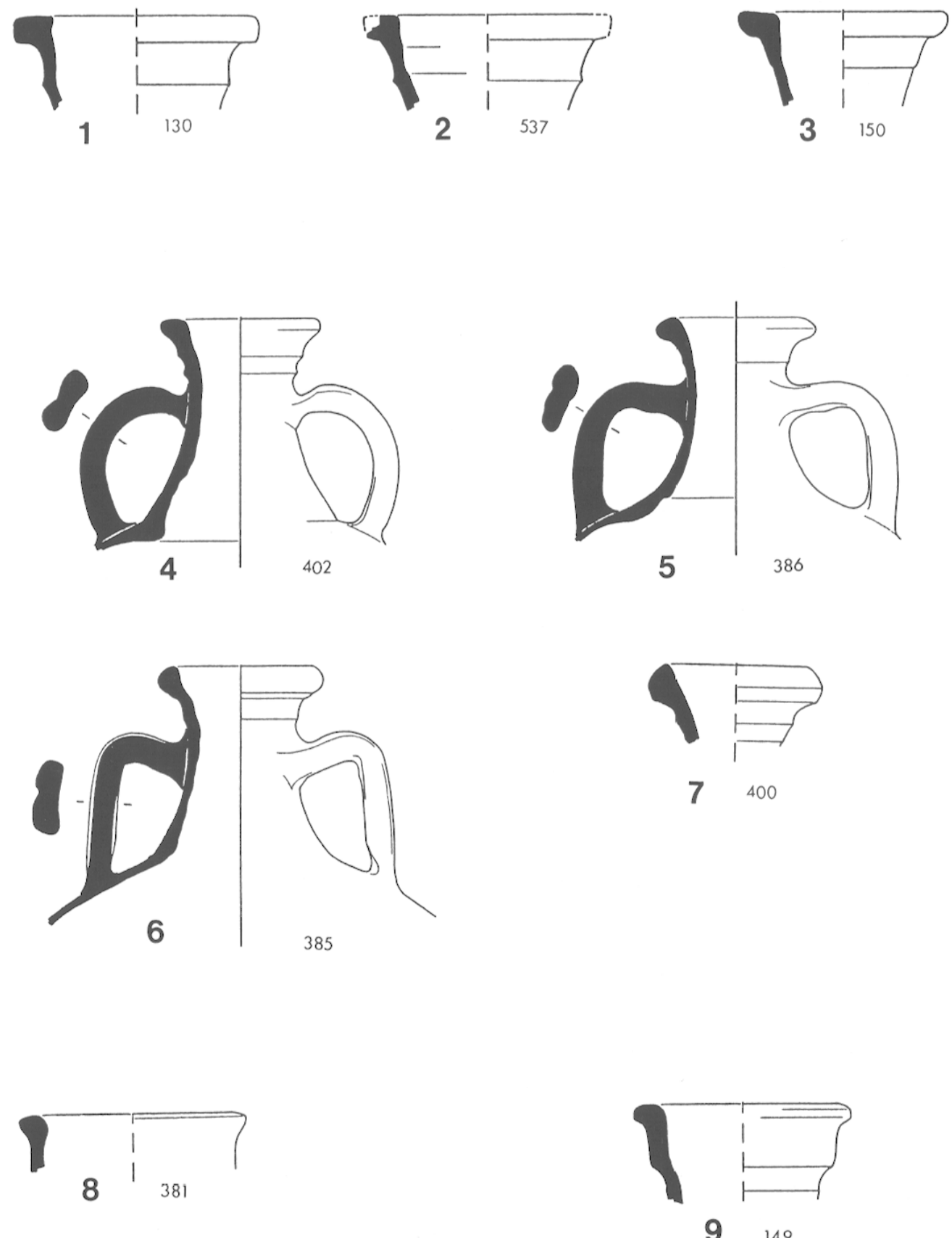

9
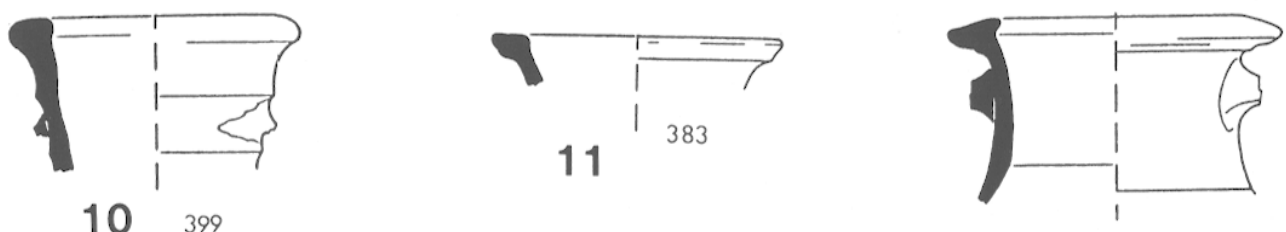

12403

Fig. 11 - Amphores Gauloise 5 et variantes : nos 1 à 3 . Divers gauloises : nos 4 à 12 . 

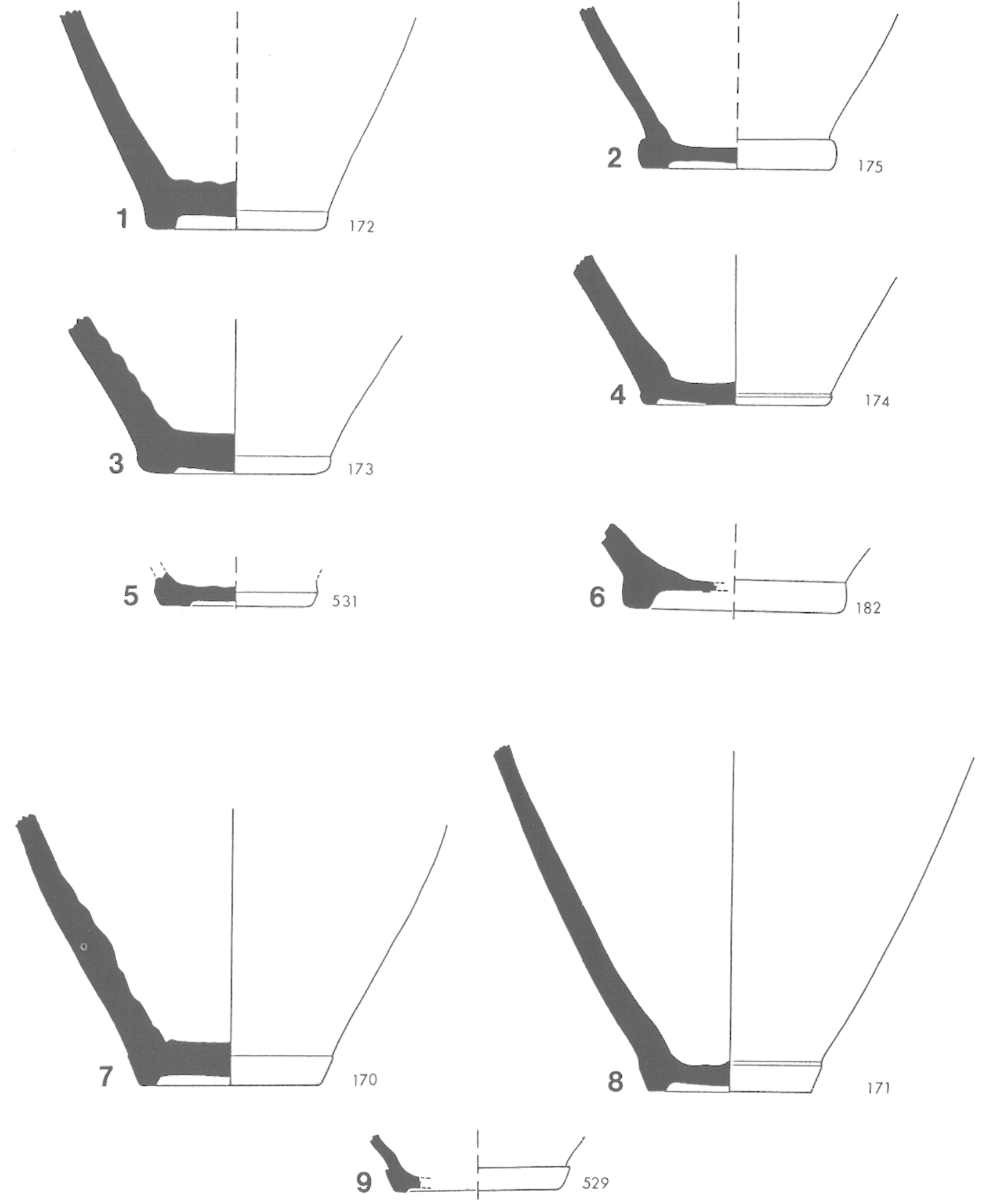

Fig. 12 - Amphores gauloises. Fonds G4 et G3 : nos 1 à 5, G1 : $n^{\circ} 6$, G5 $: n^{\text {os }} 7$ à 9 .

du total) ne peuvent se ranger dans l'une ou l'autre des formes énoncées précédemment. Certaines s'en approchent cependant sensiblement. C'est notamment le cas d'un exemplaire (fig. 11, no 9 ) qui se distingue des G3 par une lèvre aplatie surmontant un bandeau vertical. Un autre exemplaire (fig. 11, $\left.\mathrm{n}^{\circ} 10\right)$ pourrait constituer une variante isolée des G5 dont il se rapproche par une pâte identique mais
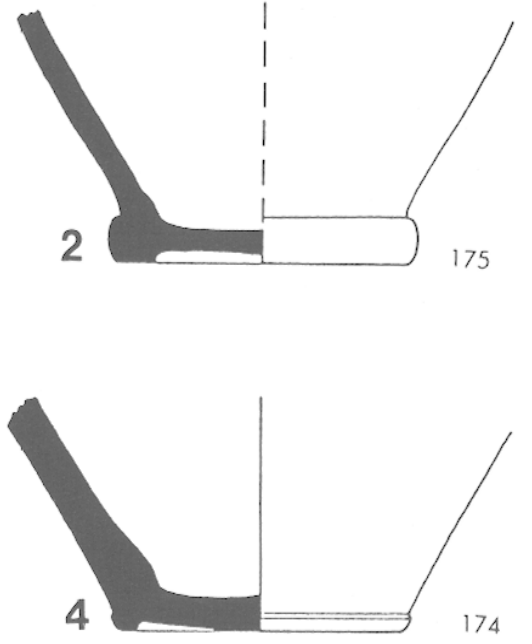

6

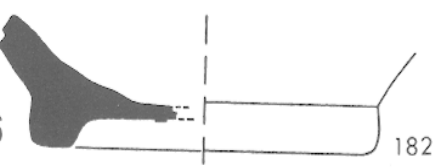

s'écarte par un double ressaut et un diamètre inférieur au modèle courant.

Il faut enfin noter la présence, mais sous la forme d'un seul fragment de lèvre (fig. 11, $\mathrm{n}^{0} 8$ ), d'une amphore à bandeau provenant de Marseille comme l'atteste le mica visible dans son argile. Trois cols et une lèvre (fig. $11, \mathrm{n}^{\text {os }} 4$ à 7 ) appartiennent à des amphorettes dont le diamètre des lèvres est 
voisin de $9 \mathrm{~cm}$, et qui s'apparentent aux G3 et G4. Un exemplaire complet trouvé rue des Farges, dans un dépotoir légèrement postérieur à celui du Bas-deLoyasse, confirme qu'il s'agit de récipients à fond plat. Seule la lèvre (fig. 11, $\mathrm{n}^{0}$ 7) présente un engobe crème. Un col et une lèvre, enfin (fig. 11, nos 11 et 12), appartiennent à des amphorettes de type indéterminé.

\section{LES AMPHORES À HUILE}

Les amphores à huile ne sont représentées que par la seule Dressel 20 originaire de Bétique. Soixante-neuf exemplaires de celle-ci ont été inventoriés : cela représente $16 \%$ de l'ensemble du dépôt.

\section{Les amphores Dressel 20 (fig. 13 à 15)}

En dépit des nombreuses variantes que fournissent leurs lèvres, elles forment un ensemble assez homogène dans la chronologie. Seuls en effet, un fragment de lèvre (fig. $13, \mathrm{n}^{\circ} 1$ ) et deux fragments d'anses appartiennent par leur typologie à des formes précoces: lèvre sans rebord, offrant un diamètre étroit $(13,6 \mathrm{~cm})$ tout comme à Augst (Martin, 1983), anses présentant une section relativement faible ainsi qu'à La Favorite (Becker et alii, 1986).

Pour le reste, nous retrouvons les caractéristiques connues dès le règne de Claude et qui domineront sous les Flaviens (Tchernia, 1967; Colls et alii, 1977, p. 23 et $s q . ;$ Martin, 1983) : anses allongées (hauteur $20 \mathrm{~cm}$ pour l'exemplaire $\mathrm{n}^{\circ} 7$, fig. 13), lèvre marquée d'une gorge à l'intérieur, au bourrelet aplati à son sommet et aux rebords étirés portant le diamètre toujours au-delà de $15 \mathrm{~cm}$, quelquefois jusqu'à $20 \mathrm{~cm}$. Quant à la chronologie, les caractéristiques d'ensemble permettent de négliger les variantes de détails rencontrées de même à Augst, dans les contextes stratigraphiques datés de la seconde moitié du Ir $^{\text {s }}$ s. ap. J.-C. (Martin, 1983). Notons encore la présence de deux opercules (fig. $13, n^{\text {os }} 9$ et 10 ), identiques à ceux découverts à Port-Vendres. L'un d'eux encore en place, sa partie conique orientée vers l'intérieur, confirme l'observation des auteurs de cette publication (Colls et alii, 1977, p. 40).

Aucun des fragments d'amphores Dressel 20 n'a livré d'inscriptions peintes. En revanche, vingt-deux anses portent des estampilles. Si l'on tient compte du fait qu'une seule des deux anses était estampillée ${ }^{10}$,

10 Les amphores Dressel 20 estampillées sur leurs deux anses paraissent en effet fort rares. Ainsi, a Port-Vendres, aucune amphore ayant conservé les deux anses ne porte deux marques (Colls et alii, 1977, p. 26). Il en existe cependant: le pourcentage des Dressel 20 ainsi marquées s'élève à $32 \%$ : nous sommes alors très proche du chiffre annoncé par S. Schupbach qui, pour Avenches, évalue à $35 \%$ le nombre d'amphores Dressel 20 estampillées (Schupbach, 1983). Ce recoupement ne doit cependant pas faire illusion : c'est certainement très au-delà de ce chiffre que doit se situer, pour la période qui nous concerne, le pourcentage d'amphores estampillées en référence aux résultats de sondages récents effectués à Saint-Romain-en-Gal ${ }^{11}$.

Ces vingt-deux marques proviennent toutes d'un poinçon différent ${ }^{12}$. Certaines d'entre elles peuvent cependant ètre rassemblées, ramenant ainsi l'inventaire à dix-sept officines (cf. tableau II p. 138).

Ce tableau permet de revenir sur un fait souligné lors de l'étude des estampilles sur Dressel 20 de l'épave de Port-Vendres II. En effet, contrairement au matériel de cette épave (Colls et alii, 1977, p. 27), la lecture des marques ne se fait pas uniquement dans le sens col-panse même si ce sens de lecture est, ici également, le plus courant.

A l'exception de l'estampille SEX. $\overparen{V A} L . \widehat{R V S}$, toutes les marques lisibles sont déjà connues. La plupart sont publiées par H. Callender (1965) et nombre d'entre elles trouvent régionalement, voire localement, leur correspondant. La numérotation des estampilles renvoie à la figure 15 .

\section{$1-B \widehat{A R N} \overparen{A E I}$}

Mentionnée par H. Callender (1965, p. 81, $\mathrm{n}^{\mathrm{o}}$ 181). Deux exemplaires sont connus à Lyon : l'un provient de la fouille de Trion en 1885 (Allmer, Dissard, 1892, IV, p. 236, no 494-32), l'autre figure au Musée de la Civilisation Gallo-romaine sans indication de provenance.

\section{$2 \mathrm{a}$ et $2 \mathrm{~b}-B R \widehat{O C O D V}, B R \overparen{O C} O D V$}

Il existe de nombreux poinçons pour cette marque très fortement représentée et citée par H. Callender (p. 84-85, n²05 a). Le Musée de la

citons notamment les estampilles $L . V \widehat{A L}, T R O P H I M$ associee à $S A B I N I$ (Saint-Romain-en-Gal, découverte de 1845, Allmer, Dissard, 1892, p. 257, $\left.\mathrm{n}^{\circ} 484-182\right)$, PORODOV associée à $A E L F O$ (Musee du Vieil Istres, Amar, Liou, 1984, n"* 104 et 180), C. SER. SEL associèe à $Q$. SER. IIYL (Saint-Romainen-Gal, fouilles 1986, inédit).

11 Les sondages effectués en différents points du site dans les vides sanitaires composés de Dressel 20 portent à $65 \%$ (75 inscriptions pour 116 amphores) le nombre d'amphores estampillées à l'époque flavienne.

12 La lecture de ces estampilles doit beaucoup à F. Mayet à qui nous les avions confiées pour les intégrer dans un inventaire général. Nous la remercions de nous avoir autorisés à faire état de ses observations. 

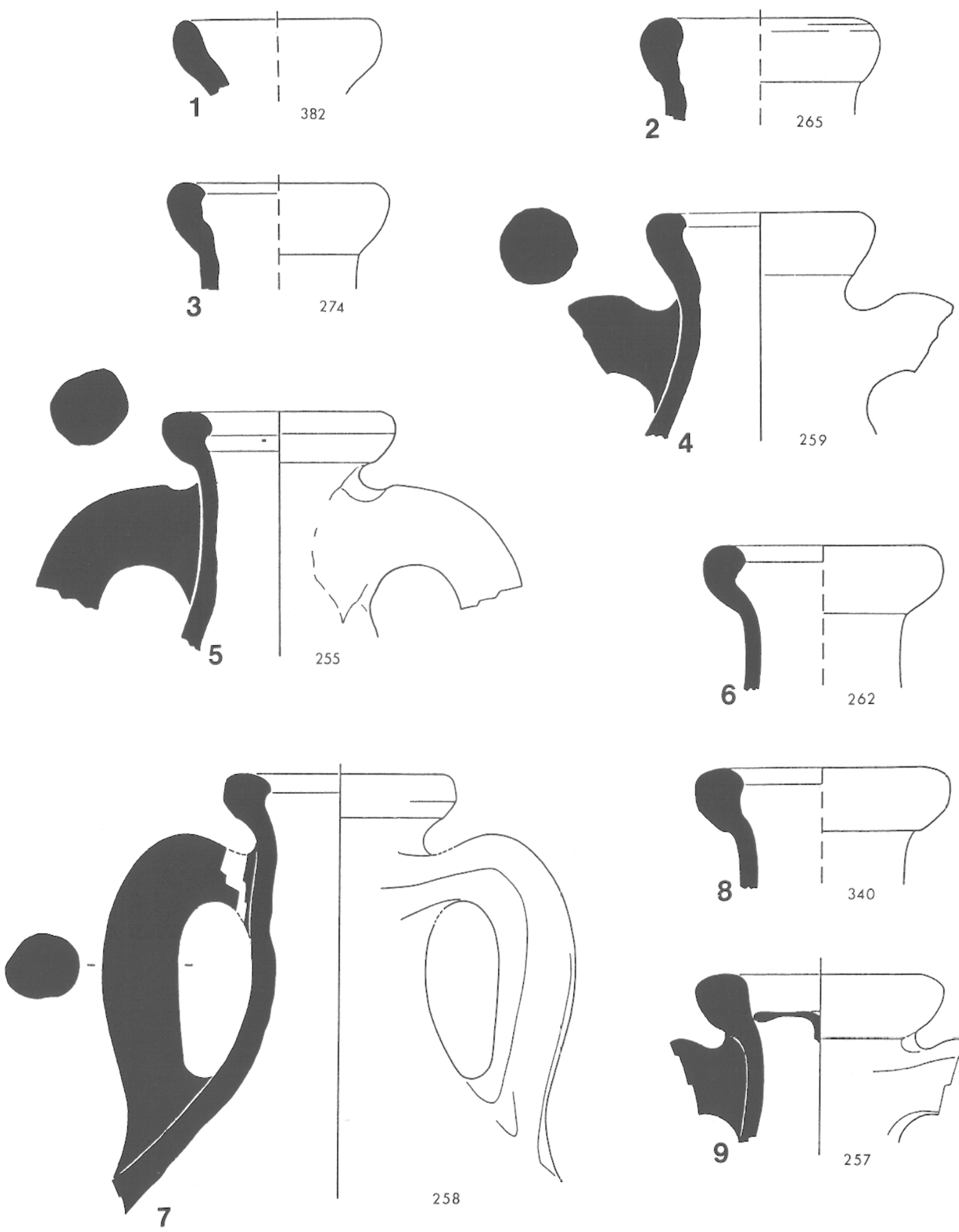

Fig. 13 - Amphores Dressel 20.
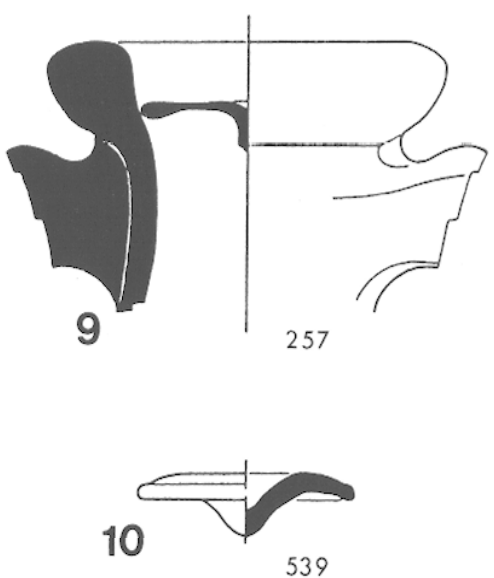

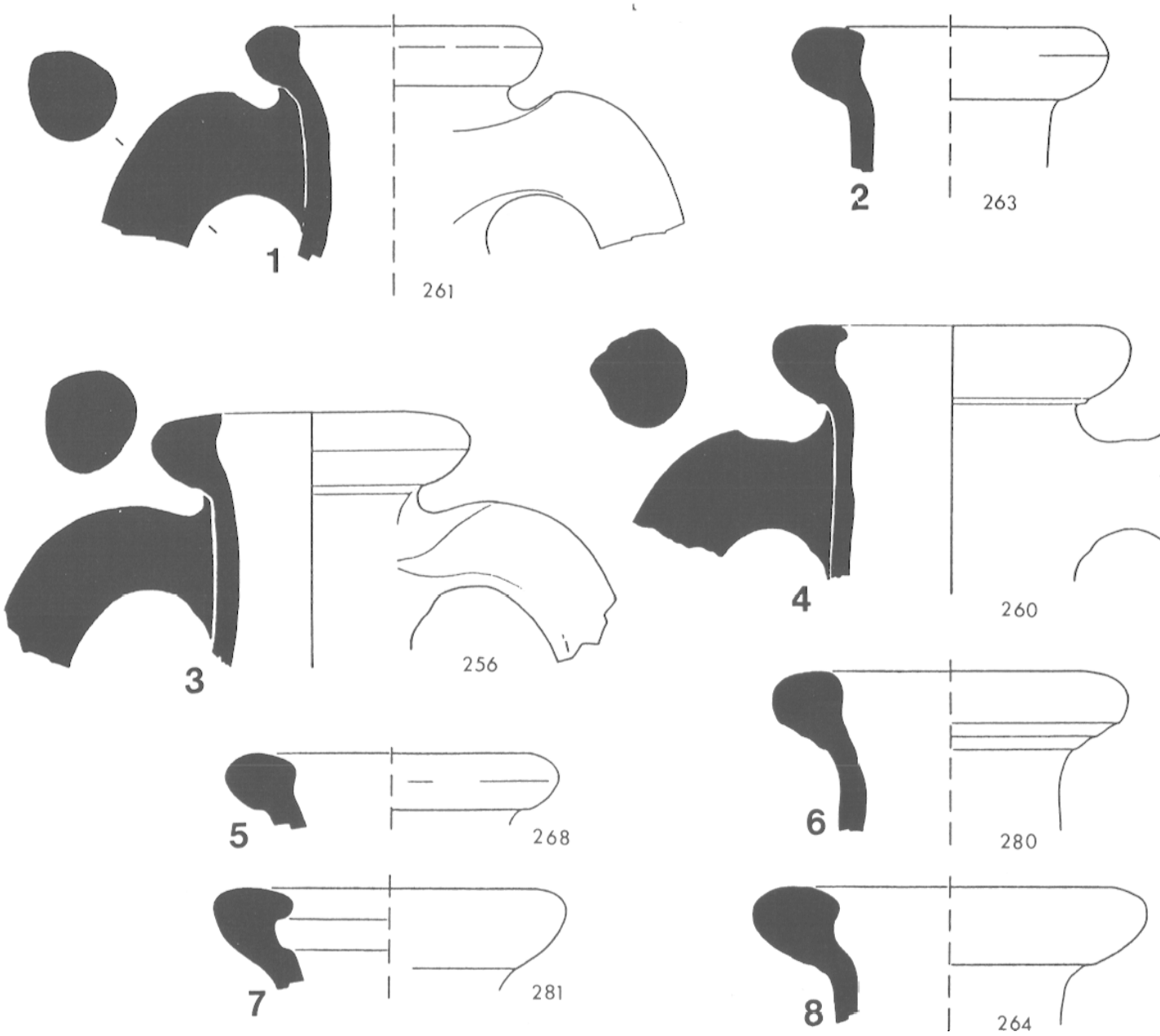

Fig. 14 - Amphores Dressel 20.

Civilisation Gallo-romaine en possède cinq exemplaires. Nous la retrouvons en Gaule à Alba (Ardèche), Aoste (Isère), Avignon, Béziers, Fos, Roanne (?), Sens, Toulouse, Vienne, dans l'Hèrault, ainsi que dans divers sites d'Allemagne, d'Espagne, de Grande-Bretagne et de Suisse (Rouquette, 1970 ; Rougier, 1976; Aulas, 1981; Amar, Liou, 1984, nos 111-112). A Augst, elle se trouve à l'intérieur d'horizons stratigraphiques datés de 25 à 100 ap. J.-C. (Martin, 1983).

La diversité des poinçons laisse la place à plusieurs lectures : $B R Q O D V, B R O . O D V$, voire $P O R$ $O C O D V$ à en croire Remesal (1978). La comparaison avec l'ensemble des estampilles publiées nous a cependant fait opter pour la lecture sous laquelle nous présentons cette marque.

$3-C \ldots$

Cette marque est presque totalement illisible. Seul le $\mathrm{C}$ initial est certain ; il pourrait être suivi d'un $R$ et d'un $E$ ou d'un $F$, mais la lecture est trop douteuse pour être sujette à comparaison.
$4-C \widehat{A N} / \ldots$

Cette estampille peut être rapprochée avec certitude de celle publiée par $\mathrm{H}$. Callender et rattachée à G. ANTONI QVIETI (Callender, 1965, p. 90$91, \mathrm{n}^{\circ} 243$ et fig. $\left.4, \mathrm{n}^{\circ} 48\right)$. Cette marque bien connue par ailleurs (Amar, Liou, 1984, $\mathrm{n}^{\circ} 117$ ) est souvent mentionnée dans la région : Allmer en signale six exemplaires issus de Sainte-Colombe et deux de Trion (Allmer, Dissard, 1892, p. 234, nos 494-17 et 18). Elle est retrouvée par trois fois à Genève (Paunier, 1981, tabl. p. 244, $\mathrm{n}^{\text {os }} 7,8$ et 9 ) et elle est également connue à Avenches (Schupbach, 1983, p. 358) où sa datation est comprise entre 40 et 110 .

\section{$5-C \widehat{M A} R S \overparen{L L}$}

Quatre exemplaires identiques, dont deux provenant de Sainte-Colombe (Allmer, Dissard, p. 246, $n^{\circ}$ 494-102) sont présents au Musée de la Civilisation Gallo-romaine. Ce poinçon semble cependant inédit pour une estampille connue sous diverses écritures (Callender, p. 106, $\mathrm{n}^{0} 387$; Rouquette, 1980, $\mathrm{n}^{0} 37$; Amar, Liou, 1984, $\mathrm{n}^{\circ}$ 128). Lue C. MARI SILVANI, 
elle était datée jusqu'à présent, avec réserves, des années 70-110.

$6 \mathrm{a}$ à $6 \mathrm{~d}-C V \widehat{V A}, C . V . \overparen{V A}, C . V . \widehat{V A}, C V . V I \ldots$

L'intégration de la dernière estampille à ce même groupe est quelque peu incertaine dans la mesure où malgré la cassure, il semble possible de juger de l'absence de la ligature $V A$. Nous pouvons être cependant en présence d'un poinçon inédit et c'est pourquoi nous avons préféré cette lecture à une autre bien qu'elle puisse être appelée dans l'avenir à correction $^{\mathbf{1 3}}$.

Cette marque est déjà connue dans la région où elle a été découverte à Trion et à Sainte-Colombe (Allmer, Dissard, 1892, p. 260, n 202, p. 261, $\mathrm{n}^{\circ} 261$ ). H. Callender (p. 118, $\mathrm{n}^{\circ} 506 \mathrm{~b}$ ) la situe au milieu du $\mathrm{I}^{\mathrm{e}}$ s. ce qui est beaucoup trop has, compte tenu des éléments de datation offerts par d'autres découvertes (Amar, Liou, 1984, $\mathrm{n}^{\circ} 131$ ) auxquelles s'ajoute maintenant celle du Bas-de-Loyasse.

\section{$7-L \widehat{A T} R V S$}

Cette estampille est à rapprocher des exemplaires $\mathrm{L} . \widehat{\mathrm{AT}}$ et $\mathrm{L} . \widehat{\mathrm{AT}}$. RV découverts dans l'épave de Port-Vendres (Colls et alii, 1977, p. 31). Nous ferons nôtres les remarques des auteurs relatives à l'interprétation de H. Callender (p. 148, no 803) quant à une marque rencontrée à Fos (Amar, Liou, 1984, $\left.n^{0} 245\right)$, dans la vallée du Rhône, et notamment. à Lyon (Allmer, Dissard, p. 236, n 494-27), en Suisse et en Grande-Bretagne. Le milieu du $\mathrm{I}^{\mathrm{er}} \mathrm{s}$. proposé par Callender est une nouvelle fois, après l'épave de Port-Vendres, confirmée ici.

$8-L . M[\ldots(?)$

L'aspect fragmentaire de l'estampille et une lecture difficile rendent mème la simple reproduction très douteuse. L'absence d'éléments de comparaison ne permet aucun rapprochement.

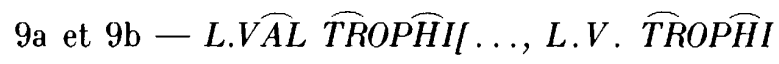

Cette estampille est bien connue à Lyon et dans la région. Il en existe six exemplaires au Musée de la Civilisation Gallo-romaine, dont un exemplaire identique au poinçon de la deuxième inscription (fig. 15, $9 \mathrm{~b} ; \mathrm{BLO} 70 / 330)$, et elle est également connue à Genève (Paunier, 1981, tabl. p. 245, nº 32). L'inscription peut se lire $L$ (ucii) Valer(ii) TROPHIMI à partir d'exemplaires complets ou plus développés

13 Pour sa part, F. Mayet propose de lire celle-ci $C A M$ avec une écriture rétrograde. Cette marque serait alors à rapprocher du no 235 de $H$. Callender, $C A M$ ou $C A \widehat{M A}$, dont ce serait le premier exemplaire découvert en Gaule.
(Amar, Liou, 1984, $\mathrm{n}^{\circ} 160$ ) retrouvés également à Trion (Allmer, Dissard, p. 257, no 494-182). Notons qu'une même estampille est associée à SABINI sur une amphore Dressel 20 portant une inscription sur chacune de ses anses (voir supra, note 10). La datation proposée par $H$. Callender pour cette marque - début II $^{e} \mathrm{~s}$. - doit être, à partir des éléments du Bas-de-Loyasse quelque peu remontée.

\section{$10-\widehat{M A} S \overparen{S A E} \widehat{N I A T I S T A}$}

Cette marque est bien connue à Sainte-Colombe où A. Allmer a enregistré quatre exemplaires issus de poinçons différents dont un en écriture rétrograde (Allmer, Dissard, p. 251, n ${ }^{\text {os }} 494-141$ à 143). La dernière ligature est quequefois lue $\widehat{A T}$ ou $\widehat{T A}$. C'est cette dernière que retient $H$. Callender (p. 238-240, $n^{\circ} 1559$ i) mais il semble bien en comparaison des autres ligatures qu'il s'agisse d'un I plutôt que d'un T.

\section{$11-P O R C P R$}

C'est encore une marque bien attestée sous différents poinçons (Callender, p. 211 et 212, $n^{\circ} 1370$; Amar, Liou, 1984, $\left.n^{\circ} 179\right)$. L'un d'eux est mentionné à Augst (Martin, 1983) dans un horizon stratigraphique daté des années 50-60. Cette chronologie, déjà approchée par H. Callender, est ici pleinement confirmée.

$12-$ P.R. S...

Les trois premières lettres de cette inscription sont très lisibles mais la suite se révèle être d'une lecture hasardeuse. Il est peut être possible d'y voir entre deux espaces un $\mathrm{A}$ puis un $\mathrm{E}$ et un N. Cette lecture nous conduirait à restituer un P.R. S[AE$N I]$ à rapprocher des nombreuses marques relatives aux Saenianenses figlinae (Callender, p. 238-240, $\mathrm{n}^{\circ} 15591$; Amar, Liou, 1984, $\mathrm{n}^{\circ} 205$ ) et qui existent dans la région à Genève (Paunier, 1981, tableau p. 247, $\mathrm{n}^{0}$ 74), Lyon et Sainte-Colombe (Allmer, Dissard, p. 251-252, n ${ }^{\mathrm{ss}} 494142$ à 150). Bien quc plausible, cette proposition ne peut pourtant rester qu'à l'ẹtat d'hypothèse.

\section{$13-R O . S \overparen{A E N I}$}

Le commentaire précédent concernant les Saenianenses figlinae peut s'appliquer à cette estampille. Son poinçon, inédit, vient s'ajouter à la longue liste de ceux déjà connus.

\section{$14-S C \overparen{A L E S T A} . C \overparen{A L P}$}

La marque est mentionnée sous la forme SCALENSIA par H. Callender (p. 242 et 243, $\left.n^{0} 1576\right)$ mais ce poinçon n'est pas signalé parmi les 

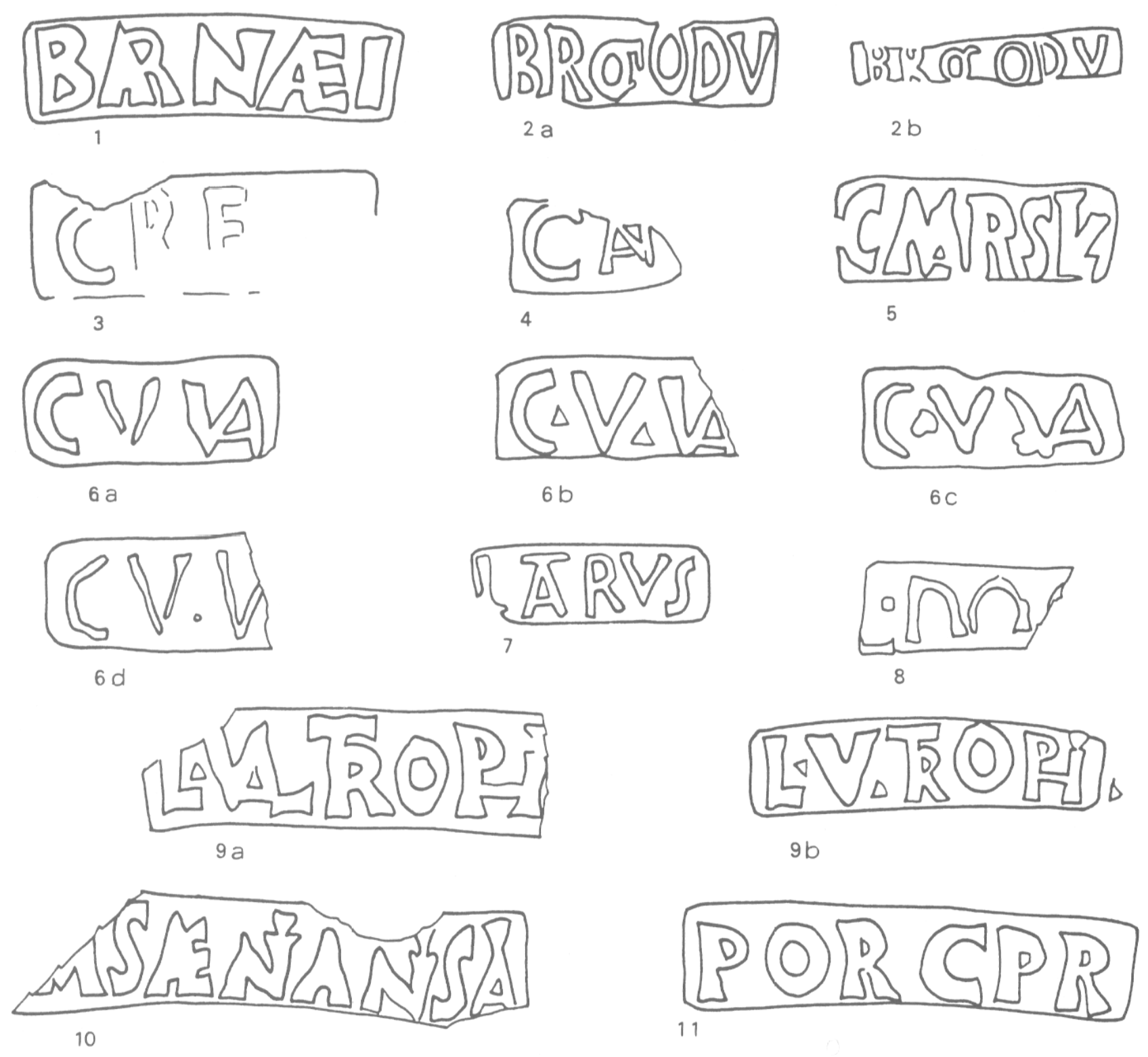

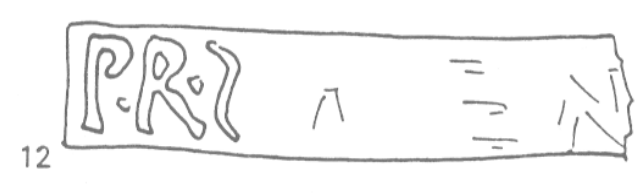

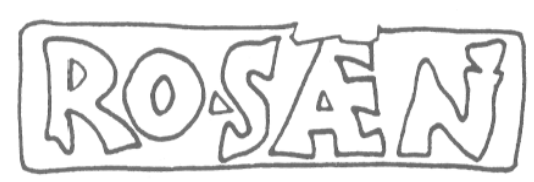

13

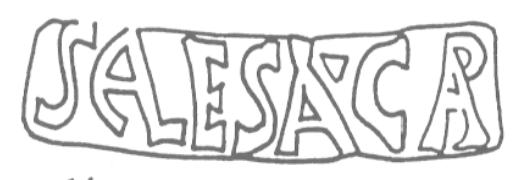

14

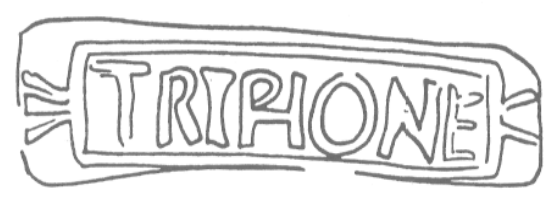

16

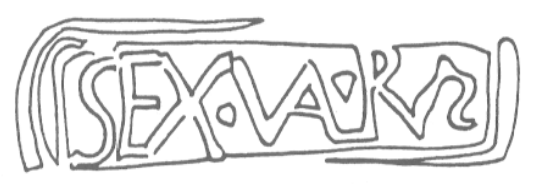

15

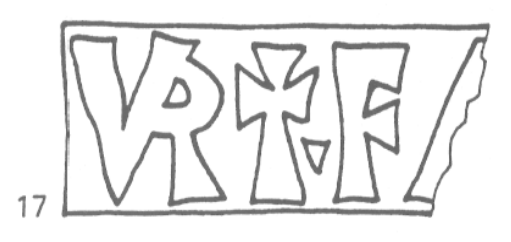

Fig. 15 - Estampilles sur amphores Dressel 20. 
nombreuses écritures différentes. Celui-ci semble de même inconnu dans la région: une épigraphie similaire existe sur une marque issue des fouilles de Trion (Allmer, Dissard, p. 253, $\mathrm{n}^{\circ}$ 494-153) mais $S C A L E S I A$ est dans ce cas suivi de $F O$. En revanche, des estampilles de Calpurnius provenant d'amphores découvertes à Sainte-Colombe et au Trion (Allmer, Dissard, p. 237, $\mathrm{n}^{\circ}$ 494-38 et p. 245, $\mathrm{n}^{\circ}$ 494-93) sont connues.

\section{$15-S E X . V \widehat{A L} . R \widehat{V} S$}

C'est la seule estampille du lot à notre connaissance inédite. Elle n'est pas répertoriée par H. Callender et nous n'avons trouvé aucun correspondant.

\section{$16-T R I \widehat{P H} O N E$}

Un autre exemplaire de cette estampille, provenant du même poinçon, a été découvert à Fos (Amar, Liou, 1984, no 215). Cette marque n'est connue, par ailleurs, que par la seule mention de $\mathrm{H}$. Callender (p. $260, \mathrm{n}^{\circ} 1738$ ) sous la forme TRIPHO sans ligature.

\section{$17-\widehat{V R I T T I}$. FAI. .}

La marque d'Vrittius se rencontre souvent, associée à différents noms : $E R(o s), E P A$ (phroditus), EV(tyches), FES(tus) (Callender, p. 261, no 1751) ou encore TER(tuis?) (Amar, Liou, 1984, no 220). Notre estampille existe sous les formes $\widehat{V R I T} . F A$ à Le Cayla (Lamour, Mayet, 1981, $\left.\mathrm{n}^{\circ} 109\right)$ et $\overparen{V R I T T I}$ $\dot{F} \widehat{A V}$ à Port-de-Bouc (deux exemplaires) et Fos (Amar, Liou, 1984, no 218 a, b, c). Pour ces dernières, Amar et Liou proposent de lire Vritti Fau(sti?) avec une datation de l'époque flavienne confirmée ici.

L'étude de cette collection d'estampilles donne en définitive des renseignements de trois ordres. Elle permet tout d'abord de nuancer l'appréciation issue de l'étude Port-Vendres II quant au sens de lecture des inscriptions. Elle confirme en outre l'importance du nombre d'amphores estampillées, d'autant que d'autres indices nous invitent à voir dans ces $32 \%$ un seuil minimal. Enfin et peut-être surtout, elle offre des éléments de datation à des estampilles qui, dans la région où ailleurs, ont été recueillies en dehors de tout contexte archéologique daté.

Les AMPHORES $\dot{A}$ SAUMuRES OU CONSERVES DE POISSON

Les amphores Bellran IIa (fig. 16 et $17, n^{\text {os }} 1$ à 7 )

Les amphores Beltran IIa sont majoritaires (vingt-cinq exemplaires) dans le groupe des am-
Tableau II

Estampilles sur Dressel 20 (fig. 15).

\begin{tabular}{|c|c|c|c|c|}
\hline \multirow[t]{2}{*}{$\mathrm{N}^{0}$} & \multirow[t]{2}{*}{ Estampilles* } & \multirow{2}{*}{$\begin{array}{c}\mathrm{N}^{\circ} \\
\text { Inventaire } \\
\text { Bas-de- } \\
\text { Loyasse }\end{array}$} & \multirow{2}{*}{\multicolumn{2}{|c|}{$\begin{array}{l}\text { Sens de la lecture } \\
\text { panse-col col-panse }\end{array}$}} \\
\hline & & & & \\
\hline 1 & $B \widehat{A R N \widehat{A E I}}$ & $70 / 324$ & & • \\
\hline $2 \mathrm{a}$ & $B R \overparen{O C O D V}$ & $70 / 336$ & & $\bullet$ \\
\hline $2 \mathrm{~b}$ & $B R O C O D V$ & $70 / 338$ & & - \\
\hline 3 & $C \ldots$ & $70 / 337$ & & - \\
\hline 4 & $C \widehat{A N}[\ldots$ & $70 / 327$ & & - \\
\hline 5 & $C \widehat{M A R S I L V}$ & $70 / 334$ & & - \\
\hline $6 \mathrm{a}$ & $C V \widehat{V A}$ & $70 / 320$ & & $\bullet$ \\
\hline $6 \mathrm{~b}$ & $C . V . \widehat{V A}$ & $70 / 326$ & & - \\
\hline $6 \mathrm{c}$ & $C . V . \widehat{V A}$ & $70 / 333$ & & \\
\hline $6 \mathrm{~d}$ & $C V . V[\ldots$ & $70 / 259$ & & $\bullet$ \\
\hline 7 & LAT RVS & $70 / 323$ & - & \\
\hline 8 & L. $M[\ldots$ & $70 / 335$ & - & \\
\hline $9 \mathrm{a}$ & L.VAL TROPHII & $70 / 260$ & & - \\
\hline $9 \mathrm{~b}$ & L.V. TROP $\overparen{T H}$ & $70 / 330$ & & $\bullet$ \\
\hline 10 & $\widehat{M A}$ SACENIATISIA & $70 / 329$ & - & \\
\hline 11 & POR CPR & $70 / 321$ & & - \\
\hline 12 & P.R. S... & $70 / 331$ & & - \\
\hline 13 & RO. SAENI & $70 / 325$ & - & \\
\hline 14 & SCALESTA. CAALP & $70 / 319$ & & $\bullet$ \\
\hline 15 & SEX. VALL. RVS & $70 / 322$ & - & \\
\hline 16 & TRIPHONE & $70 / 328$ & & $\bullet$ \\
\hline 17 & $\widehat{V R I T T I . F A[\ldots .}$ & $70 / 332$ & & - \\
\hline
\end{tabular}

* Nous avons adopté pour ce catalogue l'ordre alphabétique de la première lettre de l'estampille, nous rangeant en cela à l'avis exprimé par G. Amar et B. Liou (1984, p. 148).

phores à saumures ou conserves de poisson dans lequel elles représentent $36 \%$.

Chacun des exemplaires du lot a une pâte poreuse, jaune, souvent verdâtre caractéristique des amphores à garum de Bétique (Beltran, 1977). Typologiquement, cette série d'amphores est définie par son embouchure large et la variante IIa par une lèvre pendante. Le profil de cette dernière sc présente cependant sous des formes extrêmement 
diverses qui figurent dans notre lot. Remarquons notamment sur plusieurs exemplaires (fig. 16, $\mathrm{n}^{\text {os }} 4$ à 6 et fig. $17, \mathrm{n}^{\text {os }} 1$ et 2) la présence d'un ressaut à la liaison de la lèvre et du col, critère déjà noté sur des amphores découvertes à Nyon et datées de la première moitié du $\mathrm{r}^{\text {er }} \mathrm{s}$. (Beltran, 1970, p. 422, $\mathrm{n}^{\circ} 4$ ). De même, si l'on connaît par ailleurs des exemplaires possédant un pilon plein, ici, tous les pieds sont creux (fig. $17, \mathrm{n}^{\text {os }} 3$ à 7 ).

Les variantes IIa et IIb définies par M. BeltranLloris sont inégalement représentées dans la région où, selon Paunier $(1981$, p. 236) la forme IIa semblait prévaloir. Cette observation paraît confirmée ici, mais la chronologie généralement admise, seconde moitié du $\mathrm{I}^{\mathrm{er}} \mathrm{s}$., peut être légèrement remontée compte tenu de la présence dans notre lot d'exemplaires comparables à ceux rencontrés à Nyon dans la première moitié de ce même siècle.

Les amphores Dressel 7/11 (fig. 17, nos 8 à 19)

Elles sont faiblement représentées dans leur lot : neuf exemplaires soit moins de $13 \%$ des amphores à saumures ou conserves de poisson, et $2 \%$ du total.

Elles possèdent le même type de pâte jaune et poreuse commune à toutes les amphores à garum de Bétique et déjà remarquée au sujet des amphores Beltran IIa (voir supra). Leur usage est attesté depuis l'époque d'Auguste jusqu'à la fin du $\mathrm{I}^{\text {er }} \mathrm{s}$., voire jusqu'au II $^{e} \mathrm{~s}$. de notre ère (Beltran, 1970, p. 388-420; Colls et alii, 1977, p. 40).

L'amphore Dressel 7-11 regroupe en fait plusieurs amphores d'une même famille. La forme générale est caractérisée par une embouchure en entonnoir, un large col et une panse ovoïde mais il existe de nombreuses variantes de détail en particulier dans la lèvre. Le matériel du Bas-de-Loyasse en offrant huit profils de lèvre différents (fig. 17, $\mathrm{n}^{\text {os }} 8$ à 15) est en ce sens bien représentatif de ce type de production.

Ce matériel a néanmoins des correspondances typologiques, en Bétique même et notamment dans deux ateliers, Cerro de los Mártires et Punta Umbria, situés sur les rivages du golfe de Cadix (Beltran, 1977) où cinq de nos profils sont attestés :

\begin{tabular}{|c|c|c|c|}
\hline $\begin{array}{c}\text { Bas-de- } \\
\text { Loyasse } \\
\mathrm{N}^{0} \text { Inventaire }\end{array}$ & $\begin{array}{c}\text { Fig. } 17 \\
\mathrm{~N}^{0}\end{array}$ & $\begin{array}{c}\text { Beltran } 1977 \\
\text { Référence }\end{array}$ & Atelier \\
\hline $70 / 245$ & 9 & p. 121 , fig. 5 , no 28 & Cerro de los Mártires \\
\hline $70 / 246$ & 11 & p. 122, fig. 7, no $^{\circ} 4$ & Cerro de los Mártires \\
\hline $70 / 248$ & 10 & p. 122 , fig. 7, no $^{\circ}$ & Cerro de los Mártires \\
\hline $70 / 241$ & 12 & p. 121, fig. $5, n^{0} 31$ & Cerro de los Mártires \\
\hline $70 / 240$ & 15 & p. 123, fig. 12, no $35-3$ & Punta Umbria \\
\hline
\end{tabular}

Par ailleurs, les amphores Dressel 7-11 présentes au Bas-de-Loyasse peuvent constituer, pour une bonne part, un matériel résiduel.

Cinq de nos exemplaires (fig. $17, \mathrm{n}^{\text {os }} 8$ à 10,12 et 13) sont en effet déjà présents dans le dépôt augustéen de la Favorite (Becker et alii, 1986). Cette remarque est à rapprocher des données chiffrées concernant les amphores Dressel 7-11 et Beltran IIa ; elles convergent assez pour laisser supposer que, à l'époque flavienne, l'amphore Beltran IIa a constitué le type majoritaire pour l'exportation des saumures ou conserves de poisson.

\section{Les amphores Dressel 9 similis (fig. 18 et 19)}

Trente-quatre amphores appartiennent à ce type relativement abondant sur les sites suisses (Paunier, 1981, $\mathrm{n}^{\circ} 435$ ).

Il se distingue des Dressel 9 standard par un col plus étroit, évasé vers le haut et une pâte différente. Tous les exemplaires du Bas-de-Loyasse ont une pâte beige granuleuse, à dégraissant de quartz, proche par l'aspect de certaines pâtes de Tarraconaise, mais dure et bien cuite.

Le matériel du Bas-de-Loyasse montre plusieurs variantes dans les types de lèvre :

- La première présente une lèvre évasée avec un rebord débordant légèrement retombant. Ia liaison col-lèvre assez marquée, peut être soulignée par un léger ressaut (fig. 18, $\mathrm{n}^{\circ} 3$ ). C'est la variante la plus fréquente dans le dépotoir. Elle existe avec deux modules : grand module, diamètre de la lèvre : $16-17 \mathrm{~cm}$ et petit module, diamètre de la lèvre : $13 \mathrm{~cm}$ (fig. $18, \mathrm{n}^{\text {os }} 7$ à 10 ).

- Une deuxième variante est caractérisée par une lèvre arrondie; celle-ci n'est représentée que par trois exemplaires (fig. 19, $\mathrm{n}^{\text {os }} 1$ à 3 ), avec également deux modules différents : diamètres de 16 et de 12 à $11 \mathrm{~cm}$. Un exemplaire complet de petit module a été recueilli rue des Farges dans un contexte de la fin du $\mathrm{I}^{\mathrm{er}} \mathrm{s}$. ap. J.-C.

- Une troisième variante est représentée par des amphores à lèvre évasée mais à profil en amande (fig. $19, \mathrm{n}^{\text {os }} 4$ et 5 ); il s'agit de petit module (diamètre : $10 \mathrm{~cm}$ ).

Deux autres exemplaires (fig. $19, \mathrm{n}^{\text {os }} 6$ et 7 ) se rapportent encore à d'autres variantes, toujours de petit module.

Enfin, trois exemplaires (fig. 19, $\mathrm{n}^{\text {os }} 9$ à 11) paraissent devoir se rattacher au type de Lenzbourg (Ettlinger, 1977, fig. 3) caractérisé par une lèvre saillante arrondie, plus ou moins aplatie.

Une amphore (fig. $18, n^{\circ} 1$ ) porte une estampille 

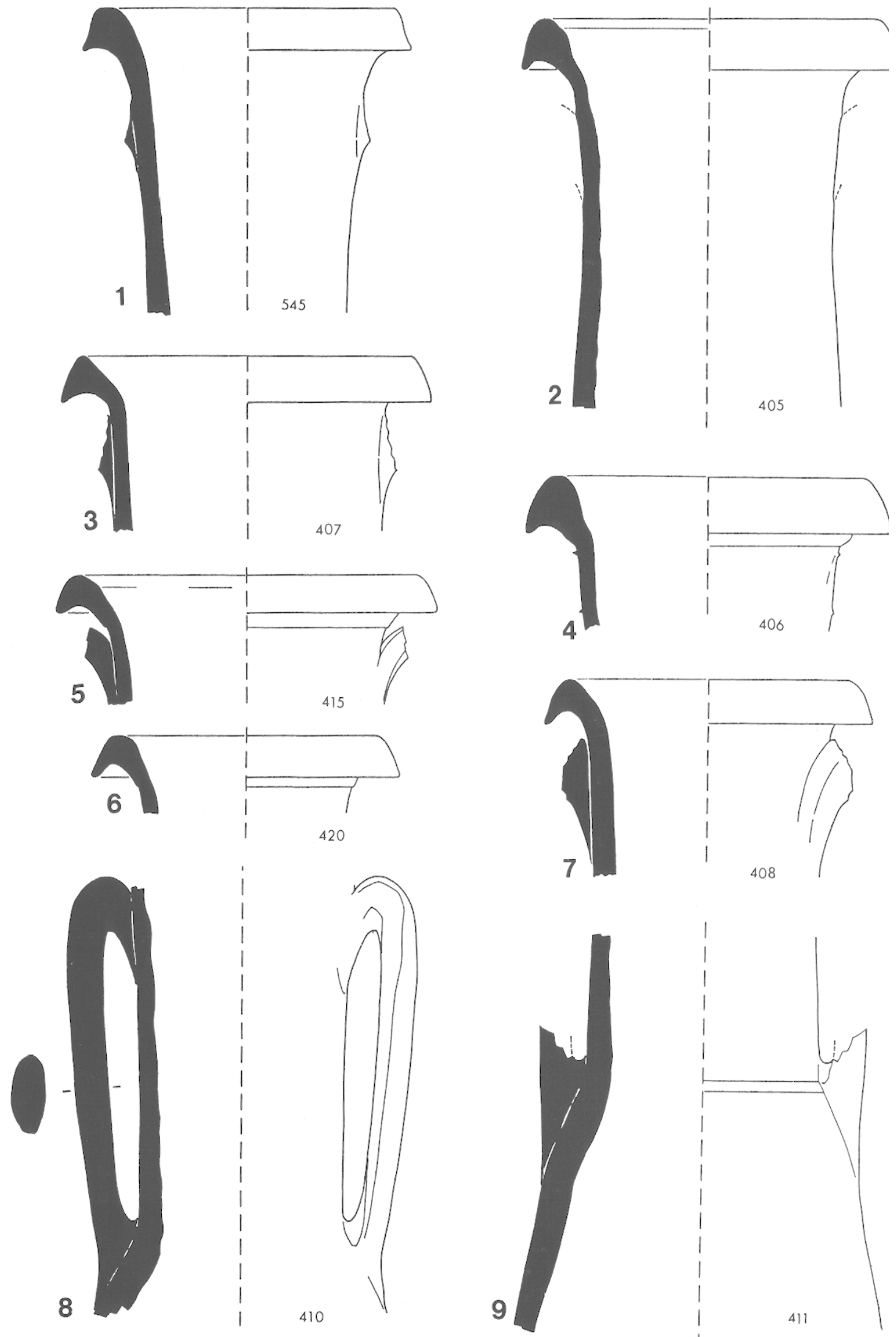

Fig. 16 - Amphores Beltran IIa. 

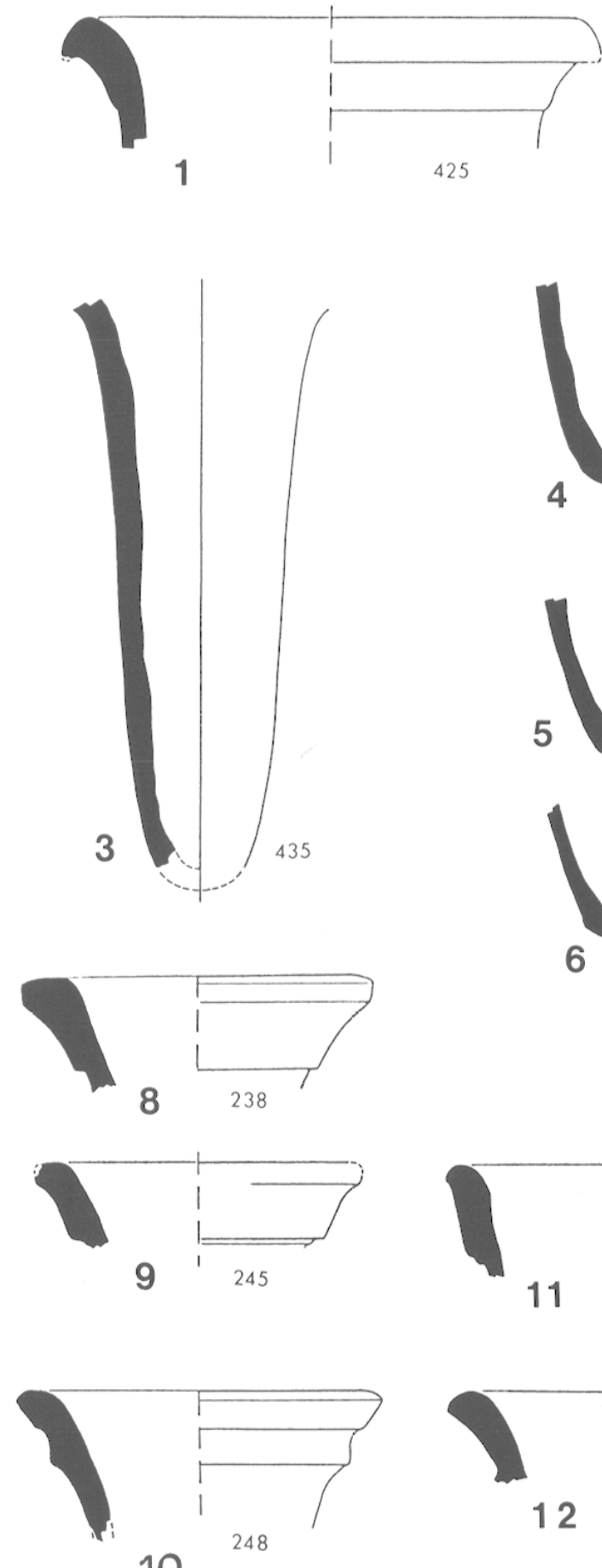

10

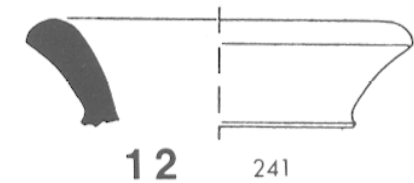

11
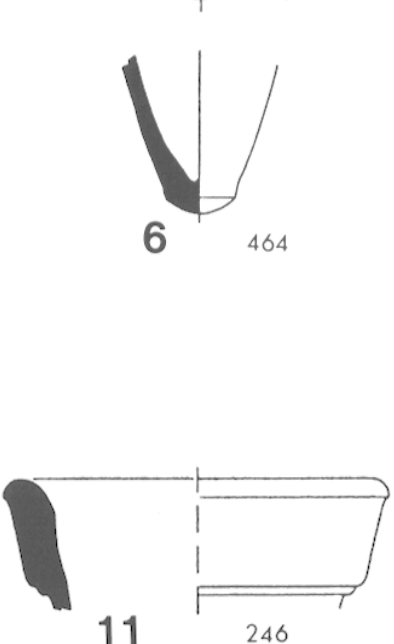

12

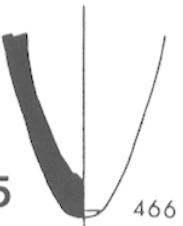

14

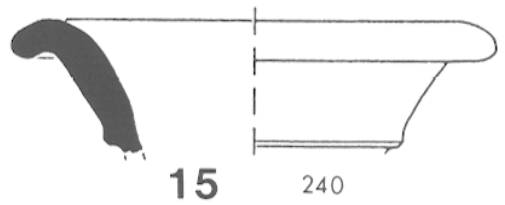

17

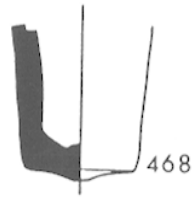

18

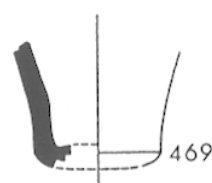

13

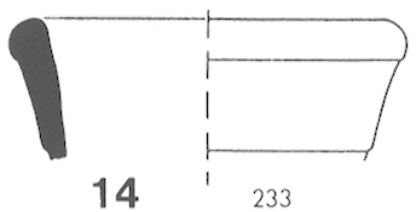

16

461

Fig. 17 - Amphores Beltran IIa : n*s 1 à 7 . Dressel $7 / 11: n^{\text {ox }} 8$ à 19 . 


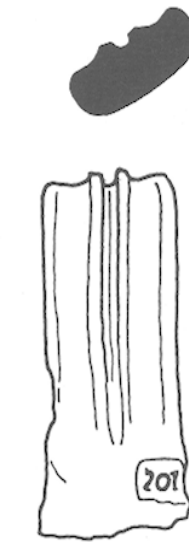

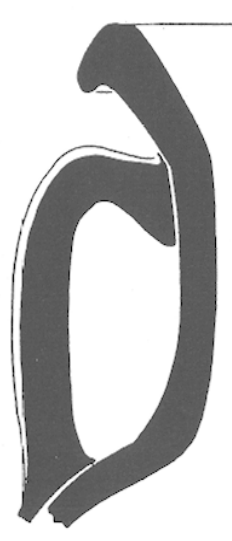

1

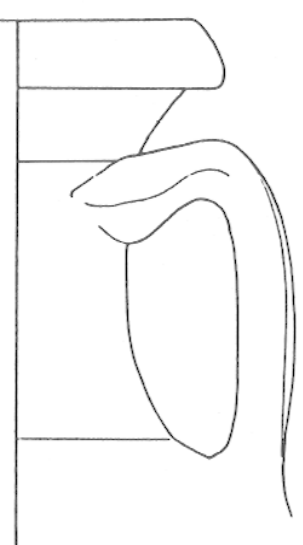

205

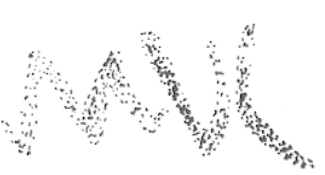

$20 r$
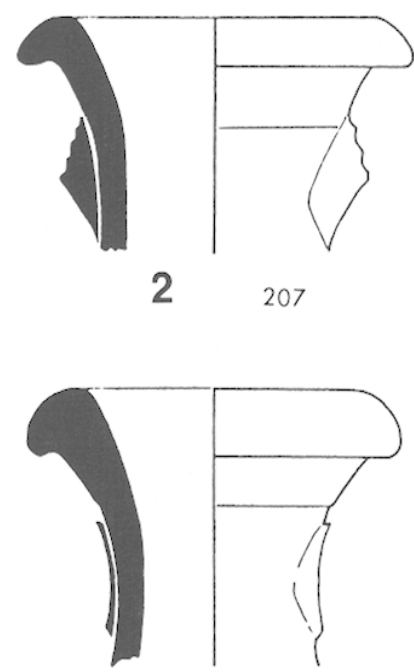

3

206
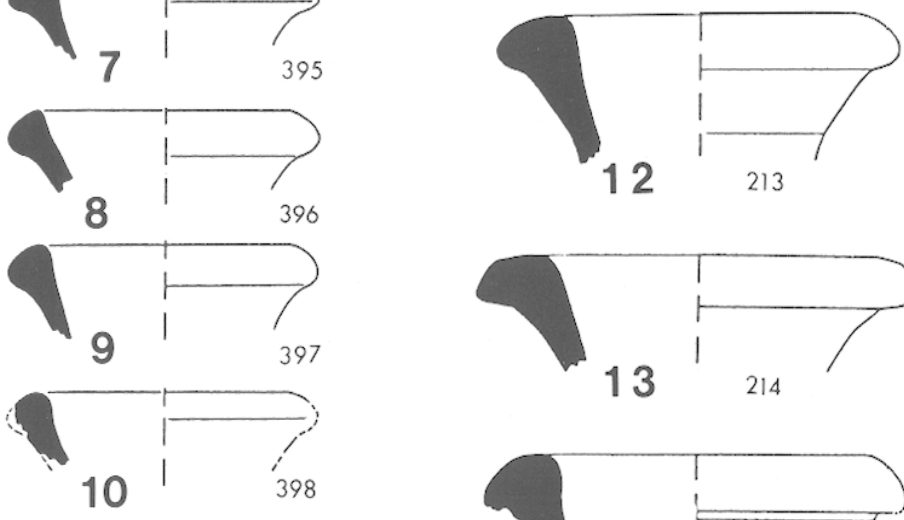

61215
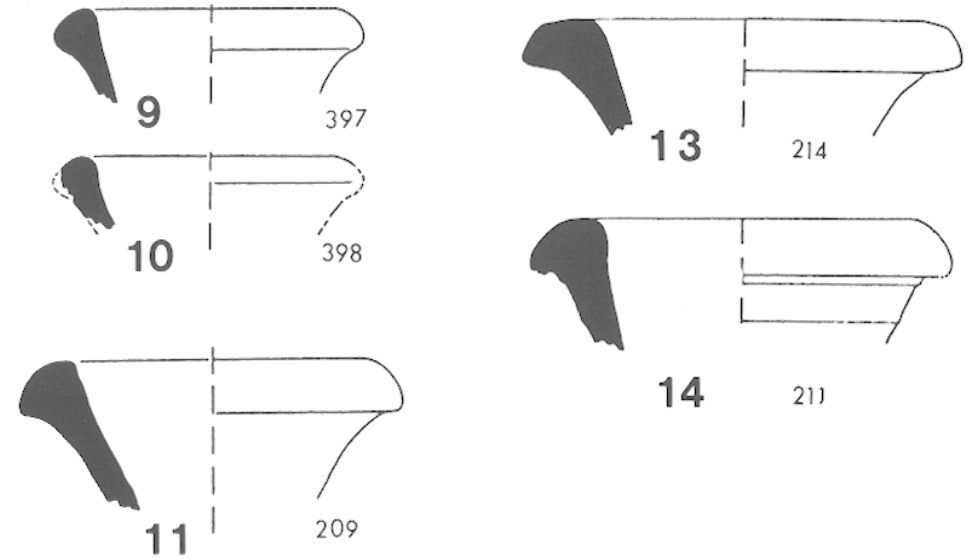

14211

Fig. 18 - Amphores Dressel 9 similis. 

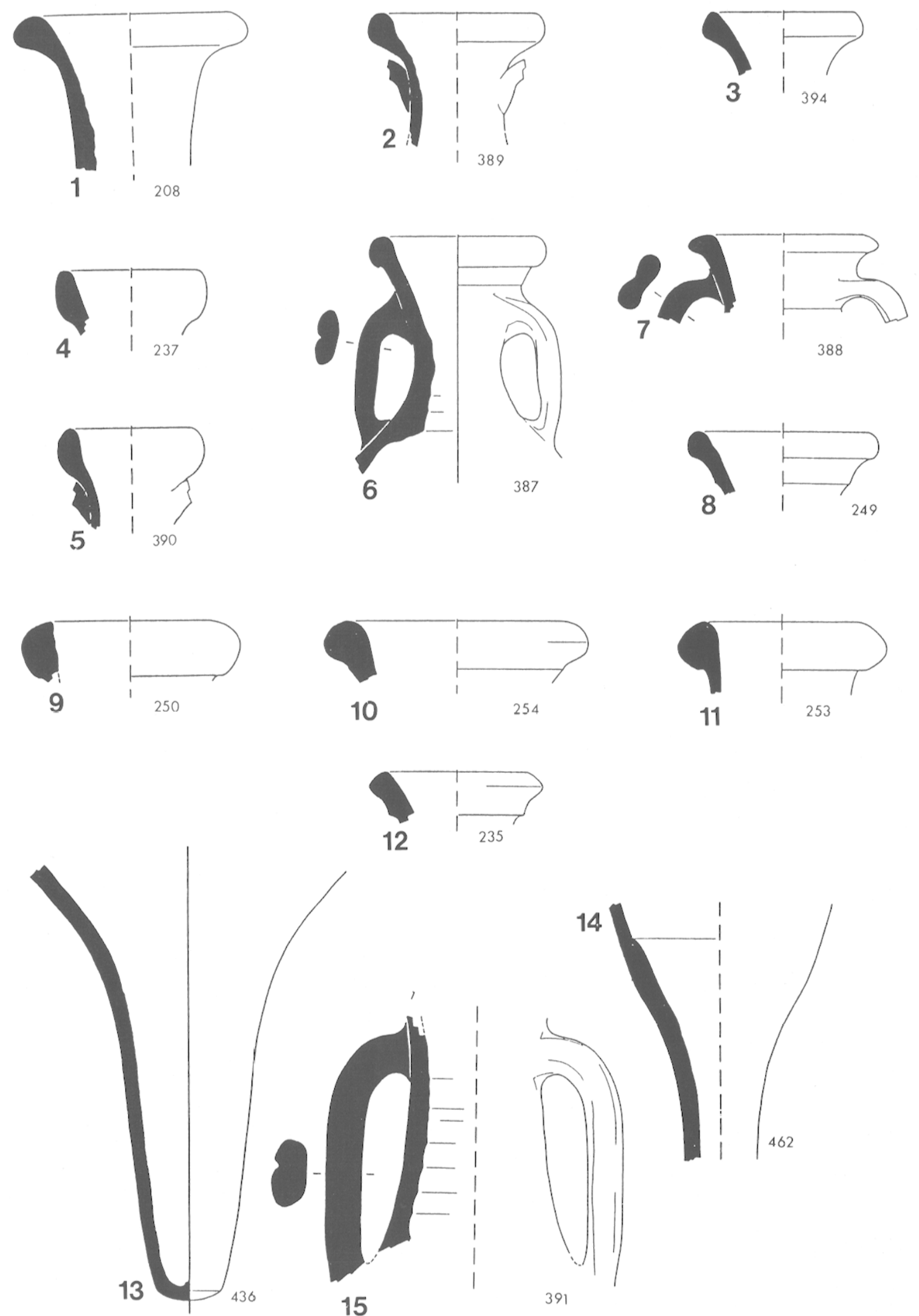

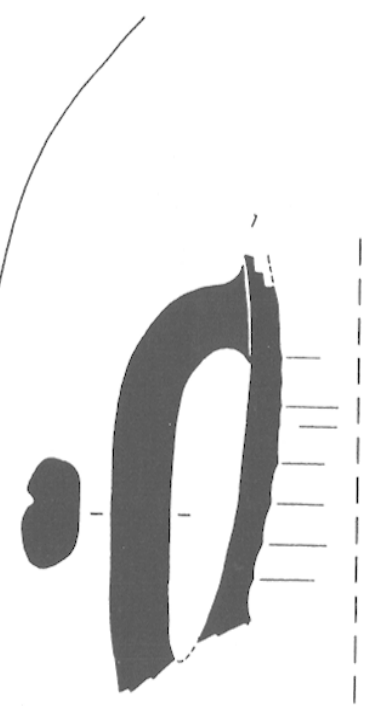

15

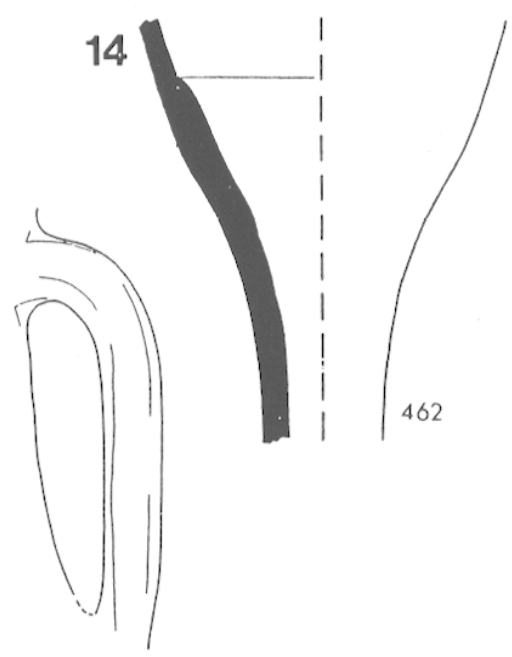

391

Fig. 19 - Amphores Dressel 9 similis. 
à la base de l'anse (ZOT(ilus)? et un titulus (Desbat, Lequément, Liou, 1987, p. 150-L11).

Les exemplaires complets de $\operatorname{Dr} 9$ similis trouvés à Nyon ou à Vidy possèdent des fonds pointus ou plats. I'état de fragmentation du matériel du Bas-de-Loyasse ne permet pas de vérifier la présence de ces deux types de fond. Les deux seuls fonds attribuables par leur pâte à cette catégorie d'amphores appartiennent à des amphores à pilon creux (fig. $19, \mathrm{n}^{\text {os }} 13$ et 15 ).

Signalons toutefois que l'amphore de petit module de la rue des Farges qui fournit un parallèle aux lèvres (fig. 19, $n^{\text {os }} 2$ et 3 ), est à fond plat. Quant au type de Lenzbourg, il semble n'exister qu'avec un fond plat.

Paunier (1981) à la suite de Roth-Rubi (1975) et d'Ettlinger (1977), propose une origine gauloise pour ces amphores dont il souligne l'absence en Italie et en Espagne (voir en particulier Panella, 1970 et 1973). Cette hypothèse a été récemment contredite par Peacock et Williams (1986, p. 117-119), dont la classe 16 regroupe les Dressel 9 et leurs variantes, le type $\mathrm{C}$ correspond à la Dressel 9 simili et le type D au type Lenzbourg. Ils signalent une forme équivalente à celle de Genève (Paunier, 1981, $\mathrm{n}^{\circ}$ 435) à Badalona et concluent à une origine hispanique probable pour les amphores de ce type.

La production d'amphores à saumures en Tarraconaise avait déjà été évoquée par A. Tchernia qui signale la marque TIBISI sur I)r 10 (Tchernia, 1976, fig. 3) ainsi que sur une amphore du golfe de Fos (Tchernia, 1971, p. 67, fig. 19) proche des Dr 9 similis.

A. Hesnard $(1980, \mathrm{pl} . \mathrm{V}, \mathrm{l})$ identifie également trois amphores de la Longarina comme des Dr 9 de Tarraconaise, reconnaissables à leur pâte comparable à celles des Dr 2/4 et des Pascual 1. M. Corsi et B. Liou proposent également une origine Tarraconaise pour trois amphores Dr 9-10 de l'épave chrétienne H (Corsi, Liou, 1985, fig. 73) qui ont toutefois des pâtes différentes des exemplaires d'Ostie, mais proches des Dr 2/4 de la cargaison.

Les amphores proches du type défini comme Dr 9 simili restent rares en Tarraconaise (Pascual, 1977). M. Comas (1986), dans son étude récente sur les amphores de Badalona n'attribue d'ailleurs aucune Dr 7-11 à la Tarraconaise. Les Dressel 9 similis sont au contraire très fréquentes en Suisse : elles sont en effet connues à Genève (Paunier, 1981, $\mathrm{n}^{\circ} 435$ ) à Nyon, à Vidy, à Avenches ${ }^{14}$, ainsi qu'à

14 Communication de S. Schupbach, que nous remercions vivement.
Vindonissa (Ettlinger, Simonett, 1952, $\mathrm{n}^{\mathrm{os}} 579$ et 588; Ettlinger, 1977, fig. 4 et 8), Soleure (RothRubi, 1975, n 256), Berne, Yverdon (Paunier, 1981) et bien sûr, à Augst (Callender, 1965), pl. III, b).

En dehors de Suisse, ces amphores sont ègalement bien représentées puisqu'elles apparaissent à Annecy (Paunier, 1981) à Neuss (Filtzinger, 1972, pl. 24, nos 4 à 7), Aislingen (Panella, 1973, fig. 68), Kempten (Panella, 1973, fig. 77), Arentsburg (Panella, 1973, fig. 78), Nimègue (Van der Werff, 1984, fig. 10,3), mais également en Grande-Bretagne, en particulier à Fishbourne (Cunliffe, 1971, fig. 99, 146).

Les différents contextes de découvertes à Lyon ou sur les autres sites, concourent à situer la production des Dr 9 similis durant la seconde moitié $\mathrm{du} \mathrm{I}^{\mathrm{er}} \mathrm{s}$.

L'origine gauloise, et même Lyonnaise, des amphores de ce type trouvées au Bas-de-Loyasse a été confirmée par les analyses réalisées au laboratoire de céramologie de Lyon (Desbat, Picon, 1987). La composition des exemples du Bas-de-Loyasse est en tout point semblable à celle de cols de même type découverts en 1966, dans un contexte d'atelier céramique, sur le site de la Manutention militaire à une cinquantaine de mètres des fouilles de la Muette. Elle est également similaire à celle des mortiers trouvés dans les mêmes fouilles et présente une grande ressemblance avec celle des productions grossières de la Muette.

La découverte d'inscriptions peintes, $g$ (arum) hispa(num) et Mur(ia) hisp (ania), sur Dr 9 similis à Augst (Bohn, 1926, p. 202, no 2 et p. 203, no 4; Grenier, 1934, p. 615, 617, fig. 210, 211, 213) et $G$ (ari) $F(l o s)$ à Lyon, rue des Farges (Desbat, Lequément, Liou, 1987), Muria à Vindonissa (Ettlinger, 1977, fig. 2, p. 13) semblait indiquer sans ambiguité le contenu et l'origine de ces amphores. Un col du Bas-de-Loyasse (fig. 18, $\mathrm{n}^{\circ}$ 1) présente cependant une inscription peinte d'abord interprétée comme $M \widehat{U R}(i a)$ mais qui pourrait être lue $M U L($ sum) : vin miellé (Desbat, Lequément, Liou, $1: 0,1$. La question du contenu de ces amphores est de nouveau posée : l'amphore du Bas-de-Loyasse correspond-elle à une réutilisation ou faut-il concevoir deux contenus possibles pour ces amphores? Les deux groupes à fond pointu et à fond plat pourraient dans ce cas correspondre à deux contenus différents : vin pour la première et garum pour la seconde ${ }^{15}$.

Il reste cependant à justifier la présence de

15 La série abondante des inscriptions MUR(ia) sur Dr 9 similis (dont plusieurs encore inédites) rend beaucoup plus probable la lecture Muria que Mulsum. 
muria ou de garum dans des amphores fabriquées en Gaule notamment à Lyon.

\section{LES AMPHORES À CONTENU NON DÉTERMINÉ}

\section{Les amphores Dressel 28 (fig. 20, $\mathrm{n}^{\mathrm{os}} 1$ à 6)}

Les amphores à fond plat Dressel 28 , caractérisées par une lèvre à double moulure dite "en poulie», sont représentées par six exemplaires, soit 1,4\% de la totalité du lot.

Cette série n'offre toutefois pas un aspect homogène. Un col (fig. 20, n' 1 ) à pâte orangée et à lèvres aux moulures épaisses est à rapprocher du type Oberaden 74 (Loeschke, 1942, p. 78-80 et pl. 34) alors que trois lèvres (fig. $20, \mathrm{n}^{\mathrm{os}} 3,4$ et 6 ) rappellent les exemplaires de l'épave de PortVendres II tant par leur profil (Colls et alii, p. 45, fig. 17) que par leur pâte jaunâtre. Un quatrième exemplaire (fig. $20, n^{\circ} 2$ ) a, en revanche, une pâte rouge proche de celle de Tarraconaise alors que la pâte granuleuse d'un cinquième (fig. $20, \mathrm{n}^{\circ} 5$ ) présente une grande similitude avec les pâtes des Dressel 9 similis (voir supra, p. 000).

Ces différentes pâtes renvoient aux difficultés déjà évoquées dans la publication de Port-Vendres pour la chronologie et l'origine de ce type d'amphore. La forme Oberaden 74 , très analogue au type Dressel 28, datée de l'époque augustéenne, aurait une origine tarraconaise où des ateliers sont connus (Tchernia, 1976). En revanche la Bétique est proposée pour origine des exemplaires de Port-Vendres II, plus récents d'un demi-siècle (Colls et alii, 1977, p. 47).

A ces deux productions, attestée pour la première, supposée pour la seconde, il convient désormais d'ajouter une production lyonnaise: les analyses effectuées à partir d'une Dressel 28 issue des niveaux augustéens de l'atelier de la Muette (Desbat, Picon, 1987) ${ }^{16}$ montrent clairement son appartenance à cette officine. Des origines diverses, ainsi que l'avait. suggéré D. Paunier, au terme de l'étude des deux exemplaires présents à Genève (Paunier, 1981, p. 236), et notamment lyonnaise sont donc aujourd'hui certaines pour ce type d'amphore.

Le contenu de ces amphores Dressel 28 reste lui aussi sujet à questions. Il reste inconnu, mais si F. Zevi a pu suggérer des produits tels que le miel, les olives ou les mollusques (Zevi, 1966), il faut envisager une denrée compatible avec la poix dont

16 Ce matériel est entreposé dans les réserves du Musée de la Civilisation gallo-romaine à Lyon; il est actuellement inédit. les Dressel 28 furent enduites ainsi que l'attestent les exemplaires de Port-Vendres (Colls el alii, p. 47, n. 126).

La tentation de la ranger parmi les amphores vinaires grâce à une morphologie proche des amphores gauloises ne tiendrait pas compte d'un diamètre d'embouchure nettement plus large et négligerait de plus, les indices en faveur des sauces ou conserves de poisson.

En Bétique se trouvaient de nombreux ateliers d'amphores à salaison (Beltran, 1977), amphores dont les pâtes à l'aspect peu homogène, presque spongieux, rappellent celles de certaines Dressel 28. La lecture, sur une Dressel 28 provenant d'une fouille londonienne (Jones, $1980, \mathrm{n}^{\circ} 37$, p. 45 et fig. 21, p. 46) du titulus G(ari) IIII C(ongii) quatre congés de garum, soit 13,13 litres, irait dans le même sens.

La contenance serait alors celle d'une demiamphore: c'est une capacité qui se rapproche beaucoup de la quantité contenue par la Dressel 28 provenant de la Muette : 14 litres ${ }^{17}$. Les arguments permettant de trancher de manière définitive restent cependant aujourd'hui trop fragiles et penser, comme Sealey (1985, p. 97), qu'il serait surprenant que la Dressel 28 soit autre chose qu'une amphore à vin, ne justifie pas à lui seul un classement dans cette catégorie. Nous avons donc en définitive préféré en laisser le contenu indéterminé.

Les amphores diverses (fig. 20, $\mathrm{n}^{0 \leqslant} 7$ à 15 )

Plusieurs fragments, pilons, cols ou lèvre appartiennent à des amphores difficilement identifiables à partir de ces seuls éléments.

Il s'agit notamment de six pilons de formes diverses (fig. 20, nos 7 à 12) et d'un col (fig. 20, no 14) qu'il est impossible de rattacher avec certitude à une forme précise.

En revanche une lèvre (fig. 20, no 13 ) semble attribuable à la forme Léetanienne 1 (Comas, 1985), et constituerait un élément résiduel, ce type ayant précédé l'amphore Pascual 1.

Quant à l'anse (fig. 20, $n^{\circ} 15$ ), il pourrait s'agir d'une anse d'amphore tripolitaine, mais cette attribution reste peu assurée.

\section{LES DONNEES ÉCONOMIQUES}

Avec 437 amphores inventorièes, le dépôt du Bas-de-Loyasse présente l'avantage d'offrir un

17 Vous avons nous-mèmes mesuré cette capacité après remplissage jusqu'à $12 \mathrm{~cm}$ du niveau d'embouchure. 

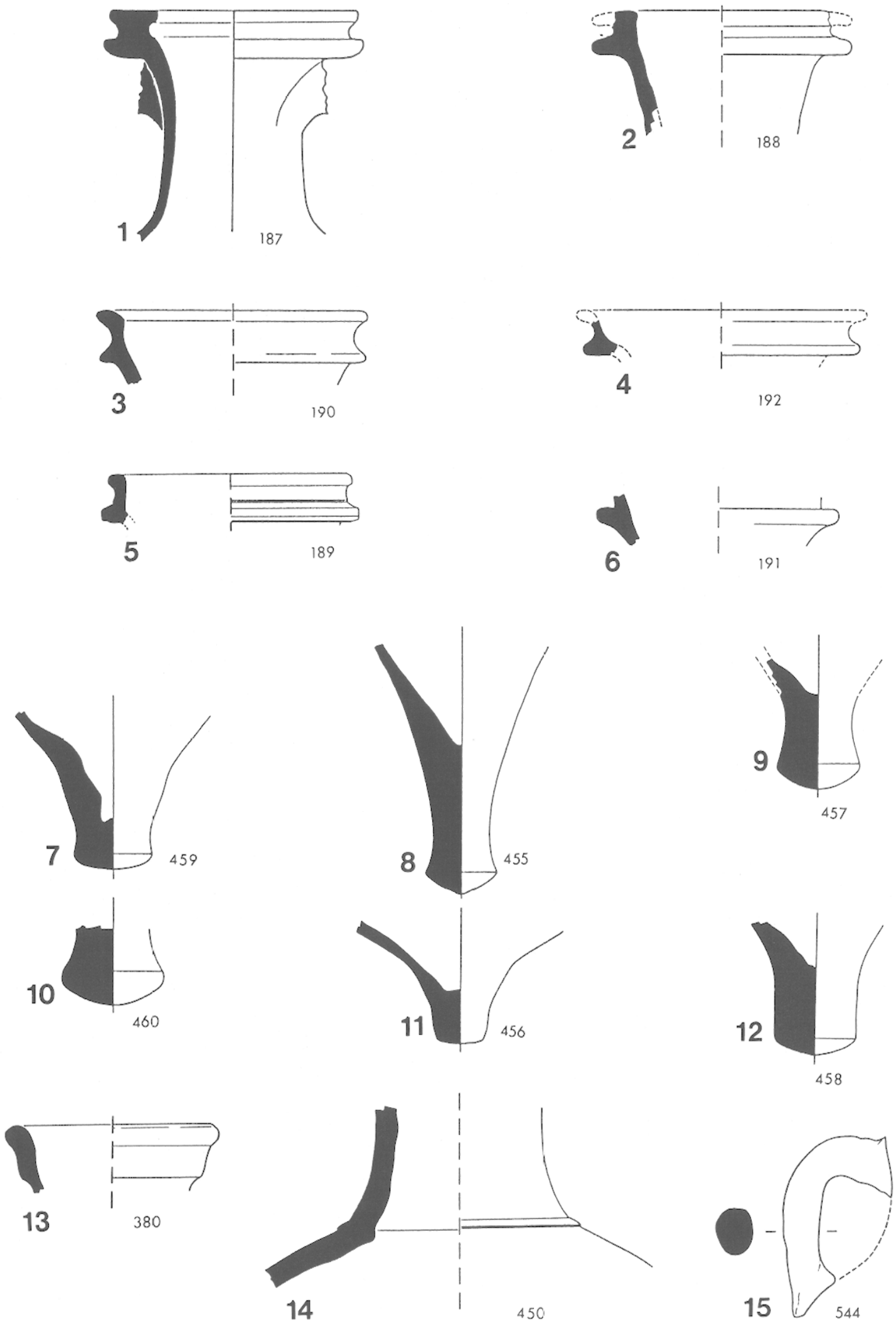

Fig. 20 - Amphores Dressel $28: n^{0 s} 1$ à 6 . Divers : $n^{\circ \times} 7$ à 15 . Léetanienne $1(?): n^{\circ} 13$. 
échantillon quantitativement important. De plus, la classification n'a laissé qu'une faible part $(4 \%)$ aux indéterminations. La grande majorité des amphores a pu être répartie dans les trois grandes catégories de produits dont elles furent les conteneurs : vin, huile, saumures ou conserves de poisson (fig. 21 et 22). Enfin, replacées dans la perspective des données offertes par le matériel amphorique de Lyon et de Vienne à l'époque augustéenne (fig. 23 à 26), les informations apportées par le dépôt du Bas-deLoyasse confirment, malgré la différence de nature des vestiges recueillis (niveaux de remblaiement, vide sanitaire, dépotoir), certains constats : diminution irréversible des productions italiques, situation étale des importations orientales, présence de plus en plus sensible, malgré le palier que marquent les dix années autour du changement d'ère, des amphores de fabrication gauloise (fig. 24).

Ce faisceau d'informations invite à voir dans le matériel du Bas-de-Loyasse un échantillon à partir duquel nous pouvons esquisser certaines évolutions intéressant les principaux produits du commerce.

\section{LE VIN}

Dans le dépôt du Bas-de-Loyasse, c'est le premier produit en importance : 281 amphores soit $64 \%$ de la totalité du lot (fig. 21 et 22). La prédominance des amphores gauloises est marquée $(75 \%)$, elles devancent celles en provenance de l'Orient (17\%), d'Espagne $(4,6 \%)$ et surtout d'Italie (2\%) (fig. 24)

La faible part des importations italiques s'inscrit dans la suite logique d'un phénomène amorcé dès l'époque augustéenne (Desbat, 1985 et Desbat, Martin-Kilcher, 1986). En revanche, le petit nombre d'amphores hispaniques peut surprendre en comparaison des données précédentes. En effet, le matériel amphorique découvert dans les contextes augustéens de Saint-Romain-en-Gal, du Verbe Incarné et de la Favorite à Lyon, montre (fig. 26) qu'à l'époque augustéenne la baisse de l'exportation des amphores italiques semble s'être réalisée au profit des productions hispaniques, les premières étant en constante diminution quand les secondes apparaissent en nombre toujours croissant.

Or, nous constatons au Bas-de-Loyasse une chute brutale des importations de vin hispanique $(5 \%)$ matérialisée par la présence de trois Dressel $2 / 4$ de Tarraconaise seulement. Un tel résultat rejoint le constat déjà dressé à partir de l'étude des épaves de Tarraconaise (Corsi, Liou, 1985, p. 171-172). Les auteurs concluaient que les témoins des exportations des Dressel 2/4 cessaient dès le règne de Néron. Toutefois, notre résultat paraît en contradiction avec ceux des fouilles des thermes du Nageur à Ostie où, dans les niveaux flaviens, les Dressel $2 / 4$ de Tarraconaise représentent encore $13,7 \%$ des amphores vinaires et $8,7 \%$ du total (Tchernia, 1986, p. 238).

Il convient cependant de rappeler que l'étude des épaves de Tarraconaise souligne que les trois épaves à dolia, datée dans un horizon chronologique proche du milieu du $\mathrm{I}^{\mathrm{er}} \mathrm{s}$., "témoignent évidemment d'une évolution dans le transport du vin de Tarraconaise" (p. 168). Dès lors; les chiffres fournis par le dépôt du Bas-de-Loyasse peuvent s'interpréter de différentes façons. Nous pouvons considérer, en effet, que le développement rapide de la vigne en Gaule a concurrencé les importations hispaniques de manière telle que la diffusion du vin de Tarraconaise s'est surtout faite en Italie. Mais, une partie des amphores gauloises a pu servir de conteneur pour la redistribution de vin arrivé en vrac dans les bateaux à dolia. Bien qu'aucune inscription sur amphore vinaire ne permette pour l'instant de confirmer un tel transvasement, il parait néanmoins important de ne pas écarter trop vite cette possibilité ${ }^{18}$.

Les comptages font également ressortir la part relativement stable réservée aux importations orientales qui représentent toujours près de $20 \%$ des amphores vinaires depuis les premiers contextes de Saint-Romain-en-Gal. Le dépotoir du Bas-de-Loyasse montre cependant l'apparition des Dressel 43 (d'origine crétoise?) jusque-là absentes des contextes lyonnais et viennois. Le vin oriental reste cependant surtout représenté par les amphores rhodiennes qui comptent à elles seules pour $12 \%$ des amphores vinaires. En revanche, les Dressel $2 / 4$ orientales, encore présentes à concurrence de $10 \%$ dans le dépôt de la Favorite (Becker et alii, 1986) ne correspondent plus au Bas-de-Loyasse qu'à $3,6 \%$ des amphores vinaires.

Il faut enfin remarquer la grande diversité typologique des amphores vinaires gauloises: amphores à fond plat, dites Gauloises 1, 3 ou 4, pour l'essentiel, mais aussi imitations de Dressel 2/4, de Haltern 70 auxquelles on pourrait ajouter les Dressel 28 , si le problème de son contenu ne restait posé (voir supra).

18 Sur cette question ainsi que sur l'éventualité d'un transport du vin en tonneaux dès l'époque augustéenne, voir Desbat, Martin-Kilcher, 1986. 


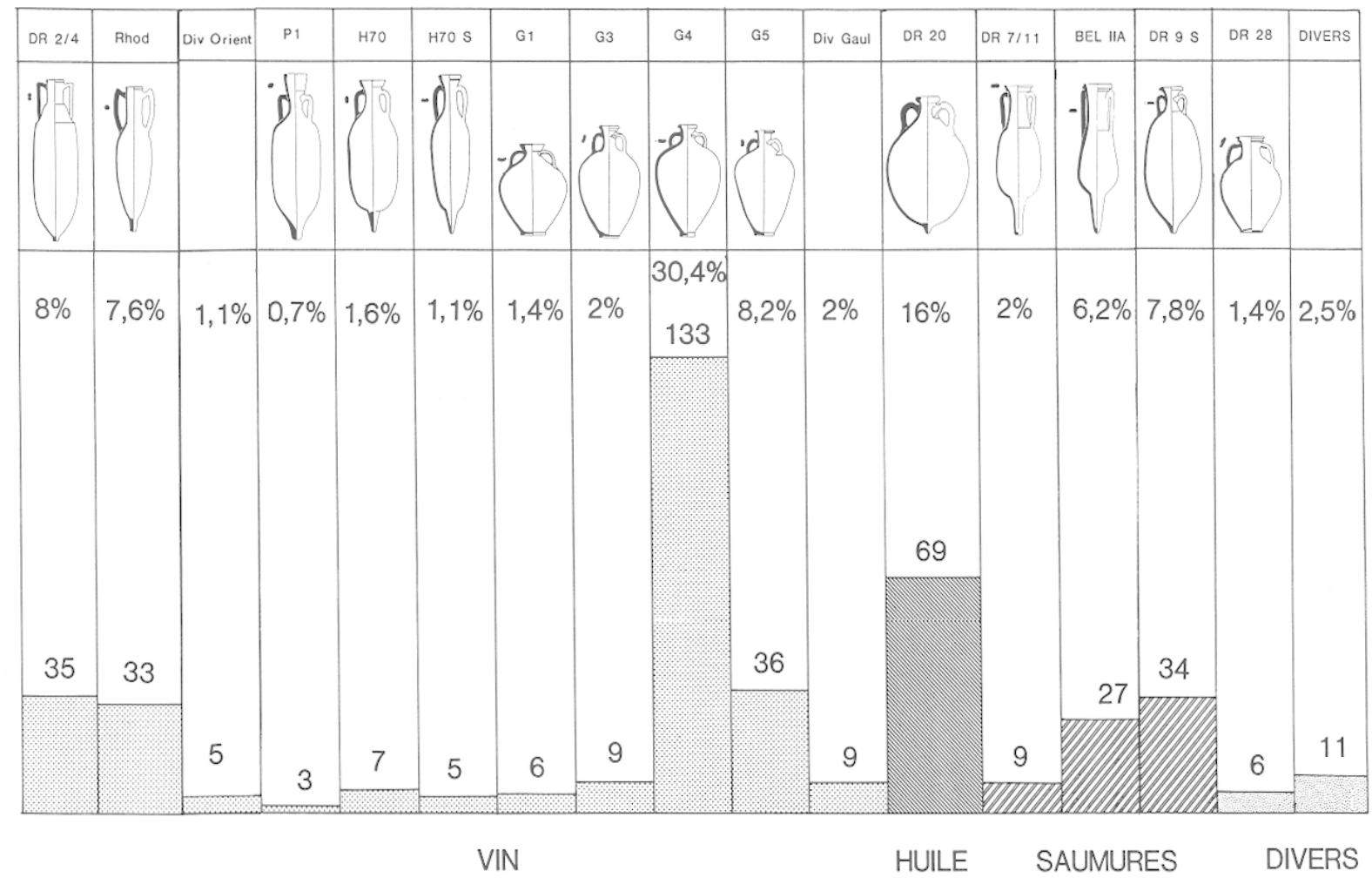

Fig. 21 - Tableau de répartition des amphores par types.

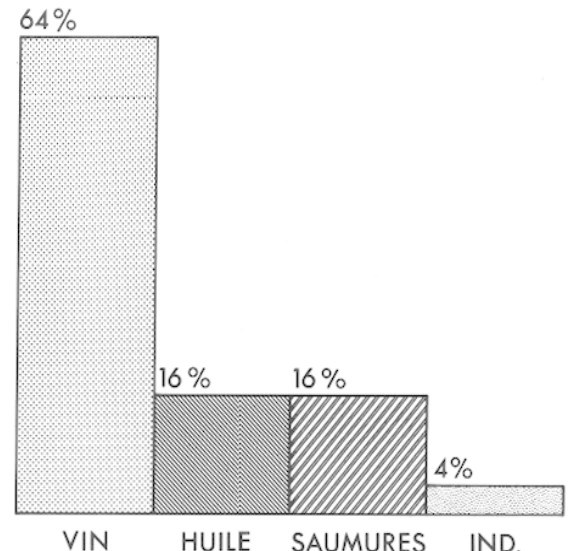

Fig. 22 - Répartition des amphores du Bas-de-Loyasse par produit.

\section{L'HUILE}

L'huile n'occupe qu'une place moyenne ( $16 \%$ ) dans les amphores du Bas-de-Loyasse. Cette denrée est exclusivement représentée par les amphores de Bétique, Dressel 20. L'amphore de Brindes, présente dans les niveaux datés de 30-20 av. J.-C. à SaintRomain-en-Gal et à Lyon (Favorite), dans les dix années entourant le changement d'ère (Desbat, Martin-Kilcher, 1986), a désormais totalement disparu. Cela traduit bien le développement, et un quasi- monopole de fait, des exportations d'huile de Bétique à partir de Claude.

\section{Les saumures et CONSERVES DE POISSON}

Les amphores à saumures, garum, hallex, liquamen, muria, et conserves de poisson, occupent une place égale $(16 \%)$ à celle de l'huile (fig. 22). Leur baisse relative est sensible comparée aux résultats tirés des niveaux augustéens (fig. 23) d'autant que ces denrées sont les seules à connaître ce tassement au contraire du vin et de l'huile.

L'élément le plus marquant est cependant la présence, à côlé des amphores à saumures de Bétique, Beltran Ila et Dressel 7/11, d'amphores à saumures gauloises Dressel 9 "similis" produites vraisemblablement à Lyon même (voir supra), et cela à parts presque égales : $49 \%$ pour ces dernières et $51 \%$ pour les productions hispaniques.

La question reste bien évidemment celle de l'origine du contenu de ces amphores. Si la nature du contenu ne peut être mise en doute (les nombreuses inscriptions indiquent bien qu'il s'agit de saumures ou de conserves), pouvons-rious concevoir raisonnablement une telle production à Lyon? A moins de supposer l'existence des saumures préparées à partir de poissons d'eau douce, comme le silure qui fut 


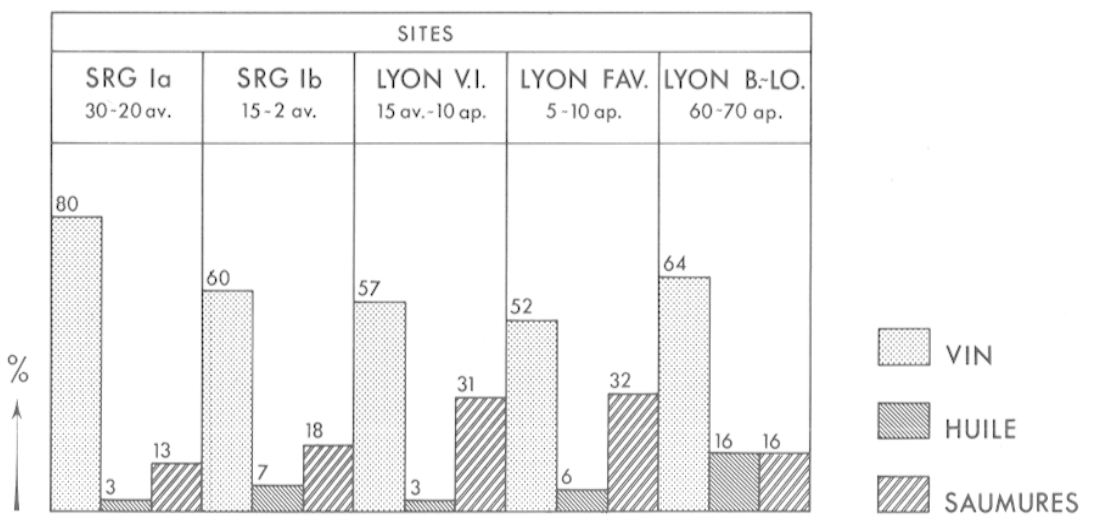

Fig. 23 - Evolution des produits sur les sites de Lyon et de Vienne (Saint-Romain-en-Gal).

SRG : Saint-Romain-en-Gal, Maison des dieux-océans, états Ia et Ib

V.I. : Verbe Incarné

FAV. : I,a Favorite (chiffres d'après Desbat, Martin-Kilcher, 1986)

B.LO. : Bas-de-Loyasse

utilisé dans certaines conserves (André, 1981, p. 111), il faut de nouveau envisager le problème de produits arrivés dans d'autres conteneurs, puis transvasés. Comme pour les amphores vinaires régionales, la question doit rester posée dans l'attente d'éléments nouveaux.

Typologiquement enfin, on remarquera pour les amphores hispaniques, la prédominance du type Beltran IIa, avec $38,6 \%$ des amphores à saumures.

Malgré les réserves posées quant à l'origine des contenus de certaines amphores, il est possible de dresser un bilan des courants commerciaux à partir des éléments de réflexion apportés par le dépôt du Bas-de-Loyasse dans ce troisième quart du $\mathrm{I}^{\mathrm{rr}} \mathrm{s}$.

Nous constatons, pour l'Italie une diminution très nette des importations. Son vin ne représente plus que $2 \%$ (fig. 24) et l'huile de Brindes est devenue inexistante. Le vin d'Espagne qui, pendant la période augustéenne devance celui d'Italie, est supplanté à son tour par le vin provenant de Gaule. Celle-ci lui retire peut-être une part du marché des sauces de poisson. En revanche, la péninsule ibérique devient la grande pourvoyeuse d'huile: la grande mais aussi la seule. L'huile de Brindes, encore présente à la Favorite, a totalement disparu et l'huile africaine, si elle atteint déjà le marché romain du début du siècle (Hesnard, 1980) ne semble pas avoir encore pénétré le couloir rhodanien.

A notre connaissance, l'Orient est représenté uniquement par des amphores vinaires. D'Auguste à la fin $\mathrm{du} \mathrm{I}^{\mathrm{rr}} \mathrm{s}$., leur présence est relativement constante: elle se maintient entre 10 et $15 \%$ (fig. 25). Ce chiffre est considérable comparé aux

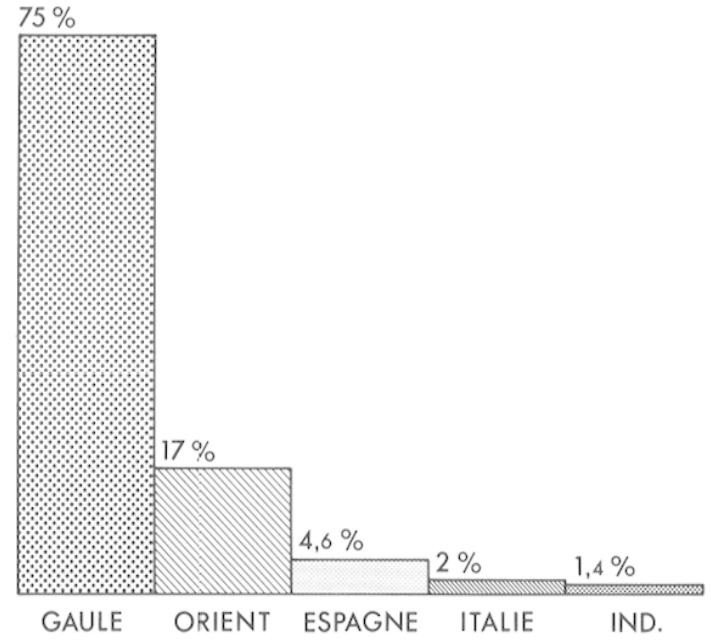

Fig. 24 - Répartition des amphores vinaires du Bas-deLoyasse par origine.

données d'Ostie: les amphores égéennes ne comptent que $3,3 \%$ à La Longarina et $1 \%$ seulement sous les Flaviens (Tchernia, 1986, p. 238). Nous remarquons cependant un changement du conteneur : l'amphore de type rhodien prend le pas sur la Dressel 2/4 (voir supra, fig. 22 et 24) et jusqu'au début du II" s. (Paunier, 1981, p. 235), le vin de provenance orientale est contenu dans ce type d'amphore et dans de petites amphores souvent mal individualisées.

La Gaule occupe maintenant une position dominante. Certes, le commerce de l'huile provient de la seule Bétique, mais la Gaule accroît de manière fort sensible, sa production d'amphores destinées à recevoir des sauces ou des conserves de poisson et 

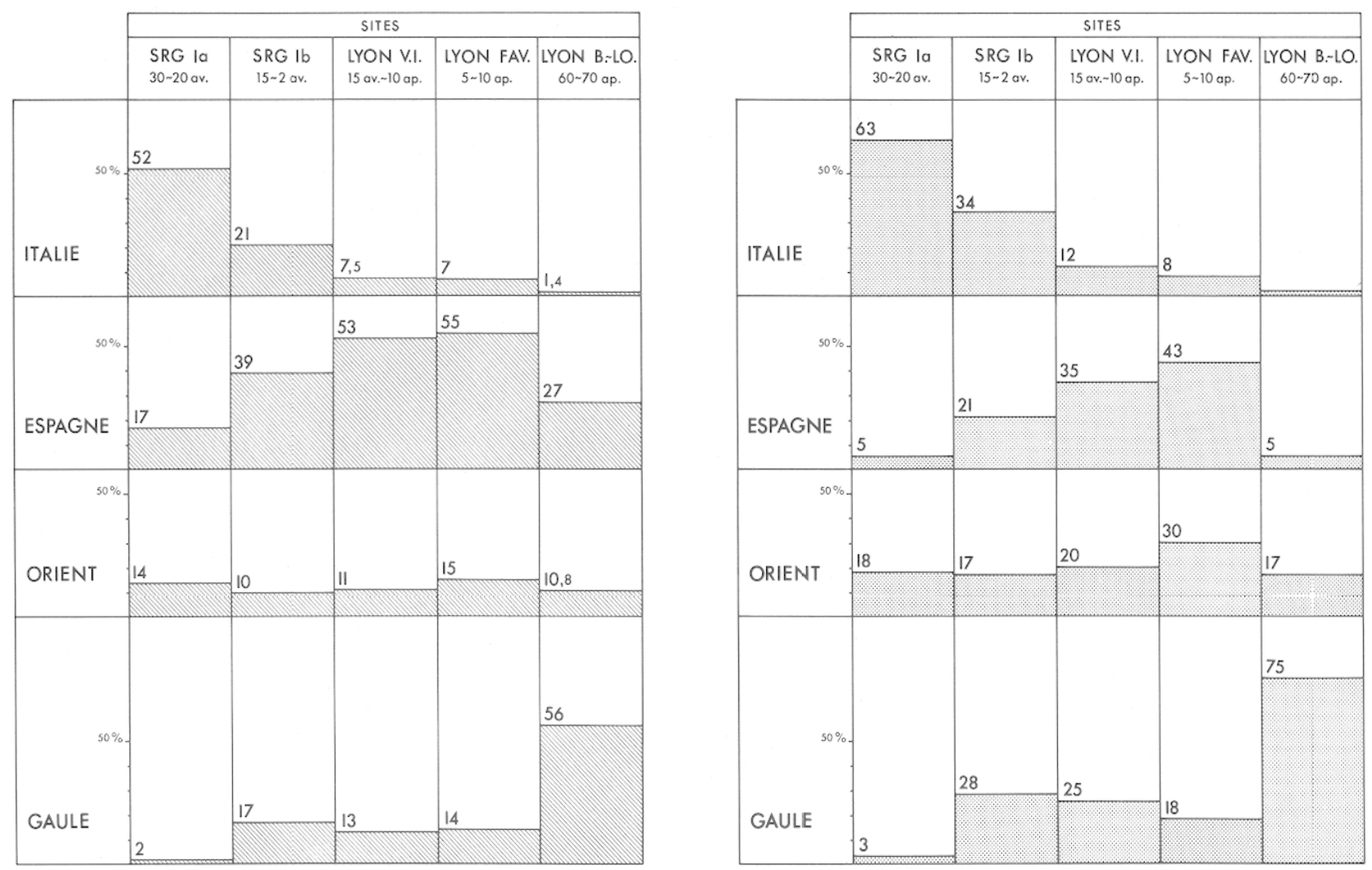

$\Lambda$ gauche. Fig. 25 - Origine des amphores sur les sites de Lyon et de Vienne.

$A$ droile. Fig. 26 - Origine des amphores vinaires sur les sites de Lyon et de Vienne.

SRG : Saint-Romain-en-Gal, Maison des dieux-océans, états Ia et Ib

V.I. : Verbe Incarné

FAV. : La Favorite (chiffres d'après Desbat, Martin-Kilcher, 1986)

B.LO. : Bas-de-Loyasse

surtout du vin. Pour ces dernières, les Dressel $2 / 4$ produites en Gaule tendent à disparaître $(8,5 \% \mathrm{du}$ lot des amphores vinaires à la Favorite, $4 \%$ au Basde-Loyasse) au profit des séries dites "gauloises à fond plat» et surtout de la Gauloise 4 qui représente à elle seule près de la moitié du lot des amphores vinaires.

A cet égard, pour la région, l'ensemble des Dressel 2/4 disparaît du marché, qu'elles soient italiques, hispaniques, orientales ou gauloises. En revanche, à Ostie, elles représentent encore $29,4 \%$ des amphores vinaires, à la même époque.

\section{$\stackrel{* *}{* *}$}

L'étude du dépotoir du Bas-de-Loyasse confirme la régression des importations italiques en même temps qu'elle souligne que le remplacement de cellesci par les amphores hispaniques, dès l'époque augustéenne, fut de courte durée : sous les Flaviens, les productions gauloises dominent largement.
Il apparaît, cependant, que les amphores gauloises présentes au Bas-de-Loyasse ne proviennent pas, dans leur majorité, des centres de productions connus en Narbonnaise. En fait, la perception des amphores gauloises est différente selon les pôles considérés : les ateliers de productions et les centres de consommation. La plupart des ateliers actuellement connus paraissent être, en effet, de petits ateliers dont la diffusion pourrait bien n'avoir été que locale. Il est important de faire la part entre les ateliers de diffusion restreinte et ceux qui alimentent les principaux courants d'exportation. Une telle distinction ne peut être faite que par l'étude des grands sites de consommation et de redistribution. Seule la Gauloise 1 semble avoir connu une diffusion plus large vers le Nord. Toutefois celle-ci reste faible, comparée à celle des G4 ou même des G5 dont les grands centres de production, certains étant probablement situés dans la vallée du Rhône, restent à découvrir.

Le problème majeur reste celui de la correspon- 
dance des amphores gauloises avec un contenu d'origine gauloise. Une question à ne pas écarter : le faible nombre d'amphores de Tarraconaise peut être mis en relation avec un autre mode de transport comme les dolia dont plusieurs épaves du $\mathrm{I}^{\text {er }} \mathrm{s}$. prouvent l'utilisation. N'oublions pas non plus les G4 avec inscription "Massicum». Cette question est rendue pertinente par la multiplication des productions régionales et locales, Dr 2j4, Haltern 70, G3 et G4, Dr 28 (sans compter d'autres types encore, absents du Bas-de-Loyasse mais reconnus dans d'autres contextes).

La réponse apportée montrera soit la diversité des produits transvasés, soit la variété des productions alimentaires locales, certaines, comme les saumures, pour le moins inattendues.

N.B. - Depuis la rédaction de cet article et les premières corrections d'épreuves, plusieurs éléments nous ont amenés à situer la date de constitution de ce dépôt plutôt vers 80 ap. J.-C. Il s'agit en premier lieu de l'étude récente de B. Prerdenirt (Die römische Okkupation Germaniens und Rätiens von der Zeit des Tiberius bis zum Tode Trajans, Jahrbuch des Römische-Germanische Zentralmuseums, 33, 1986, p. 221-320) qui démontre que la diffusion de la forme
Le bilan dépasse donc de loin le seul dénombrement des amphores. Si celui-ci a permis de placer le dépotoir du Bas-de-Loyasse dans la perspective d'une évolution des échanges commerciaux, d'autres questions sont désormais posées quant à l'origine des produits contenus dans les amphores dites "similis" et quant au rôle de la région lyonnaise voire de la ville même, dans cette production. Au terme de cette étude, il apparaît du moins certain que l'équation commode, une forme $=$ un produit $=$ une origine, n'est plus aussi fiable que l'on se plaisait à l'espérer.

\section{Bernard Dangréaux et Armand Desbat}

Drag. 37 ne commence pas avant 68 et ne devient vraiment conséquente qu'à partir de 80 ap. J.-C. Par ailleurs, l'étude en cours du matériel recueilli en stratigraphie dans les fouilles de Saint-Romain-en-Gal, tend à démontrer que la forme G4 apparaîtrait à la mème époque, les niveaux Claude-.Véron ne livrant que des G3. Cette précision importante sur la date d'apparition des $\mathrm{G} 4$ tend également à descendre la date du dépôt du Bas-de-Loyasse.

\section{BIBLIOGRAPHIE}

Allmer (A.) et Dissard (P.), 1887 - Trion, antiquités découvertes en 1885, 1886 el anlérieurement, au quartier de Lyon dit le Trion, Lyon.

- 1892-Musée de Lyon; inscriptions antiques, IV, Lyon.

Amar (G.) et Liou (B.), 1984 - Les estampilles sur amphores du golfe de Fos, Archaeonaulica, 4, p. 145-211.

ANDré (J.), 1981 - L'alimentation et la cuisine à Rome, Paris, Les Belles Lettres.

Aulas (C.), 1981 - Marques et inscriptions sur amphores trouvées à Roanne, Cahiers Archéologiques de la Loire, 1 , 1980-1981, p. 61-91.

Becker (C.), Constantin (C.), Desbat (A.), Jacquin (L.), Lascoux (J.-P.), 1986. - Le dépôt d'amphores augustéen de la rue de la Favorite à Lyon, Figlina, 7 (sous presse).

Beitran Lloris (M.), 1970 - Las anforas romanas en España, Saragosse.

- 1977 - Problemas de la morfologia y del concepto historico-geografico que recubbe la noción tipo, Méthodes classiques el méthodes formelles dans l'étude des amphores, École Française de Rome, p. 97-131.

Bfrtucchi (G.), 1983 - Fouilles d'urgence et ateliers de potiers sur la butte des Carmes à Marseille. Les amphores, Revue Archéologique de Narbonnaise (R.A.N.), XV, 1982, C.N.R.S. 1983, p. 135-160.

Boнn (O.), 1926 - Pinselschriften auf Amphoren aus Augst und Windisch, Anzeiger für Schweizerische Altertumskunde, XXVIII, p. 197-212.

Brentchaloff (D.), 1980 - L'atelier du Pauvadou, R.A.N., XIII, p. 73-114.
Ciallender (11.), 1965 - Roman Amphorae with Index of Stamps, Londres.

Castle (S.A.), 1978 - Amphorae from Brockley Hill, Britannia, 9, p. 383-392.

Colls (D.), Étienne (R.), Lequément (R.), Liou (B.), Mayet (F.), 1977 - L'épave Port-Vendres II et le commerce de la Bétique à l'époque de Claude, Archaeonautica, 1.

Comas I Sol.A (M.), 1985 - Baetulo. Les amfores, Monographies Badalonines, 8.

Corsi-Scialiano (M.) et Liou (B.), 1985 - Les épaves de Tarraconaise à chargement d'amphores Dressel 2-4, Archaeonautica, 5.

Cuni.iffe (B.), 1971 - Excavations at Fishbourne. Vol. II, The Finds. Reports of the Research Committee of the Sociely of Antiquaries of London.

Desbat (A.), 1985 - Les importations d'amphores vinaires à Lyon et Vienne au début de l'Empire, El vi a l'Antiguital, economia, producció $i$ commers al Medilerrani occidental, 1987, p. 407-416.

Desbat (A.), Martin-Kilcher (S.), 1986 - Les amphores sur l'axe Rhône-Rhin à l'époque d'Auguste. Colloque de Sienne, Anfore romane e sloria economica : un decennio di ricerche (à paraître).

Desbat (A.) et Picon (M.), 1986 - Les importations d'amphores de Méditerranée Orientale à Lyon (fin du Ier s. av. J.-C. - Ier s. ap. J.-C.), Recherches sur les amphores grecques, Bulletin de Correspondance Hellénique (B.C.H.), Suppl. XIII, p. 637-648.

Desbat (A.) et Picon (M.), 1987 - Les productions d'ampho- 
res à Lyon et à Vienne au début de l'Empire, Figlina, 8 (à paraître).

I)esbat (A.), Lequément (R.), Liou (B.), 1987 - Inseriptions peintes sur amphores; Lyon et Saint-Romain-en-Gal, Archaeonautica, 7 (à paraître).

Emprereur (J.-Y.) et Picon (M.), 1986 - A la recherche de fours d'amphores, Recherches sur les amphores grecques, B.C.II., Suppl. XIII, p. 103-126.

Ettuinger (E.), 1977 - Aspects of amphora typology seen from the North, Methodes classiques el méthodes formelles dans l'élude des amphores, Rome 1977, p. 9-16.

Ett.inger (E.) et Simonett (C.), 1952 - Römische Keramik aus dem Schutthügel von Vindonissa, Veröffentlichungen der Gesellschaft Pro Vindonissa, Band III, 1952.

Filtzınger (P.), 1972 - Die Römische Keramik aus dem Militarbereich von Novaesium, Novaesium V, Limes forschungen 11 .

Frère (S.), 1972-Verulamium Excavations, I, Reports of the Research Committee of the Society of Antiquaries of London.

Granier (A.), 1934 - Manuel d'archéologie gallo-romaine, II.

IIrSNARD (A.), 1980 - Un dépôt augustéen d'amphores à La Longarina, Ostie, Roman Seaborne Commerce, Memoirs of the American Academy of Rome, XXXVI, p. 141-156, Pl. I-VII.

Jonrs (D. M.), 1980 - Excavalions al Billingsgate Buildings "Triangle", Lower Thames Street 1974. Special Paper $\mathrm{n}^{\circ}$ 4, London and Middlesex Archaeological Society.

LaMoUr (C.) et MaYeT ( $\mathbf{F}$.), 1981 - Glanes amphoriques : 11. Régions de Montpellier, Sète, Ensérune, Le Cayla, (Mailhac), Éludes sur Pézenas el l'Hérault, XII, 3, p. 318.

Laubenheimer (F.), 1977 - Amphores gauloises de la région de Nîmes, Caesarodunum, 12, p. 197-226.

- 1985 - La production des amphores en Gaule Narbonnaise sous le Haut-Empire, Annales littéraires de l'Universilé de Besançon, vol. 66.

LaUbenheimer (F.) et WidemanN (F.), 1977 - L'atelier d'amphores de Corneilhan (Hérault), typologie et analyse, Revue d'Archéométrie, p. 59-82.

Lequément (R.), Massy (J.-L.), 1980 - Importation à Soisson (02) d'olives au defrutum en provenance de Bétique, Cahiers Archéologiques de Picardie, 7, p. 263266.

Liou (B.), 1982 - Informations archéologiques, Gallia, 40, p. $437-454$.

Liou (B.) et Marichal. (R.), 1978 - Les inscriptions peintes de l'anse Saint-Gervais à lios-sur-Mer, Archaeonautica, 2 , p. $145-159$.

Lofschске (S.), 1942 - Die Römische und die Belgische Keramik aus Oberaden, in C. A в.впсснт, Das Römerlager in Oberaden, Ileft 2.

MARTin-Kin.cher (S.), 1983 - Les amphores romaines à huile de Bétique d'Augst et Kaiseraugst, un rapport préliminaire, Producción y comercio del aceite en la antiguëdad, II Congresso, Madrid, p. 337-347.

Pandida (C.), 1970 - Anfore, Ostia II, Studi Miscellanei 16, Rome, p. 102-156.

- 1973 - Anfore, Ostia III, Studi Miscellanei 21, Rome.

- 1986 - Oriente ed Occidente : considerazioni su alcune anfore "Egee» di età imperiale a Ostia, Recherches sur les amphores grecques, B.C.II., Suppl. XIII, p. 609-636.
Parker (A. J.) et Price (J.), 1981 - The Significance of the Port-Vendres 2 Wreck reconsidered, International Journal of Nautical Archaeology, 10, p. 221-228.

Pascual Guash (R.), 1977 - Las anforas de la Layetania, Méthodes classiques el méthodes formelles dans l'étude des amphores, Rome, p. 47-96.

Paunier (I).), 1981 - La céramique Gallo-Romaine de Genève, Genève, Droz.

Peacock (D. P. S.), 1977 - Roman Amphorae, Typology, Fabric and Origins, Méthodes classiques et méthodes formelles dans l'élude des amphores, Rome, p. 261-278.

Peacock (D. P. S.) et Williams (D. F.), 1986 - Amphorae and the Roman Economy, an introduction guide, Longman Archaeology Series.

Pŕlichet (E.), 1946 - A propos des amphores romaines trouvées à Nyon, Zeitschrift für Schweizerische Archäologie und Kunstgeschichle, 8, p. 189-202.

Raynaun (C.), 1984 - Le quartier sud de l'agglomération antique de Lunel-Viel (IIérault), Locuments d'Archéologie Méridionale, 7, p. 121-147.

- 1986 - Céramiques du III siècle à Ambrussum, Figlina, 7 (sous presse).

Remesal Rodriguez (J.), 1978 - La economía oleicola bética : nuevas formas de análisis, Archivo Español de Arqueologia, 50-51, 1977-1978, p. 87-142.

Rотн-Ruвi (K.), 1975 - Die Gebrauchskeramik von der Fundstelle Solothurne Kreditanstadt, Grabrung 1964, Jahrbuch für Solothurnische Geschichte, 48, p. 241-351.

Rougier (J.), 1976 - Les amphores rondes du Musée d'Aoste (Isère) et le commerce de l'huile d'olive à l'époque romaine, Actes du $96^{\circ}$ Congrès National des Sociétés Savantes (Toulouse 1971), Paris, p. 359-364.

Rouguntre (D.), 1970 - Marques sur les amphores à huile du département de l'Hérault, Revue d'Études Ligures, XXXVI, IV, p. 319-330.

- 1980 - Nouvelles marques sur amphores à huile de l'Hérault, Archéologie en Languedoc, 3, p. 151-160.

Schupbach (S.), $1983-\Lambda$ venches : contribution à la connaissance de la chronologie des estampilles sur les amphores à huile de Bétique, Producción y comercio del aceite en la anliguëdad, II Congresso, Madrid, p. 349-361.

Seatey (Paul R.), 1985 - Amphorae from the 1970 Excavations at Colchester Sheepen, BAR British Series, 142.

Schweitz. (D. C.) et Toucier (B.), Fiamilere (A.), Fehrnbach (X.), Branc (P.-M.), 1986 - L'atelier de potier de Mougon (Crouzilles, Indre-et-Loire), Revue Archéologique du Centre, 25, 1, p. 37-73.

Tchernia (A.), 1967 - Les amphores romaines et l'histoire èconomique, Journal des Savants, p. 216-234.

- 1971 - Les amphores vinaires de Tarraconaise et leur exportation au début de l'Émpire, Archivo Español de Arqueología, 44, p. 38-85.

- 1976 - L'atelier d'amphores de Tivissa et la marque "Sex Iomiti", Mélanges J. Heurgon. Italie préromaine et la Rome Républicaine, Coll. École Française de Rome, 27, p. 973-979.

- $1980-$ Quelques remarques sur le commerce du vin et les amphores, Roman Seaborne Commerce, Memoirs of the American Academy in Rome, XXXVI, p. 305-311.

- 1986 - Le vin de l'Italie romaine, essai d'histoire 
économique d'après les amphores, École Française de Rome.

TChernia (A.) et Vili.a (J.-P.), 1977 - Note sur le matériel recueilli dans la fouille d'un atelier d'amphores à Velaux (Bouches-du-Rhône), Méthodes classiques et méthodes formelles dans l'étude des amphores, p. 231-239.

Tchernia (A.) et Zevi (F.), 1972 - Amphores vinaires de Campanie et de Tarraconaise à Ostie, Recherches sur les amphores romaines, Rome, p. 35-67.
Van der WerfF (J. H.), 1984 - Roman Amphoras at Nijmegen, a Preliminary Report, Berichten van de Rijksdienst voor het Oudheidkundig Bodemonderzoek, 34, p. $347-387$.

Wheeler (R. E. M.), 1930 - London in Roman Times, Londres.

Zevi (F.), 1966 - Appunti sulle anfore romane, I. La tavola tipologica del Dressel, Archeologica Classica, 18, p. 208247. 